Glauco Lini Perpétuo

\title{
ESTUDO TERMOANALÍTICO E CARACTERIZAÇÃO NO ESTADO SÓLIDO DA INTERAÇÃO QUÍMICA ENTRE CETOPROFENO E ALGUNS COMPOSTOS ORGÂNICOS
}

Tese apresentada ao Instituto de Química de São Carlos da Universidade de São Paulo, como parte dos requisitos para obtenção do título de Doutor em Ciências.

Área de concentração: Química Analítica

Orientador: Prof. Dr. Gilberto Orivaldo Chierice

SÃO CARLOS

2015 
Dedicado aos meus pais e a minha esposa Fernanda, por terem sempre me apoiado e respeitado as minhas escolhas, fossem elas boas ou não. 


\section{AGRADECIMENTOS}

A Deus e a todos os meus irmãos da espiritualidade, pela benção da oportunidade de recomeço. Desta vez, com bases mais sólidas.

Ao Prof. Dr. Gilberto Chierice, pela grandeza de espírito de ter perdoado as minhas faltas passadas e ter aceitado ser o meu orientador.

Aos amigos, Prof. Dr. Gilbert Bannach, Prof. Dr. Ricardo Castro e Prof ${ }^{a}$ Dr $^{a}$ Maria Ermelinda da Silva Eusébio, por todos os auxílios, sem os quais esse trabalho seria impossível.

Ao Prof. Dr. Éder Tadeu Gomes Cavalheiro por ter permitido o uso dos equipamentos de análise térmica.

Aos docentes e amigos dos departamentos de Química e de Engenharia Civil, pelo apoio e incentivo.

Ao amigos do laboratório de análise térmica, pela ajuda com os experimentos e análises térmica realizados.

Ao técnico e amigo Márcio Francisco da Silva, pala realização dos ensaios de Difração de Raios $\mathrm{X}$. 


\section{RESUMO}

Neste trabalho, foi realizado o estudo termoanalítico e a caracterização no estado sólido da interação química entre o cetoprofeno (CET) e alguns compostos orgânicos (benzamida (BA), picolinamida (PA), nicotinamida (NA), isonicotinamida (INA), pirazinamida (PZA), ácido salícílico (SA) e ácido benzoico (BA)), visando a obtenção de cocristais. A mecanoquímica foi utilizada como método de preparação dos compostos sólidos, e os mesmos foram analisados por calorimetria exploratória diferencial (DSC), espectroscopia de infravermelho com transformadas de Fourier (FTIR), e difração de raios X de pó (XRPD). A escolha dos compostostos orgânicos (co-formadores) foi baseada em suas estruturas moleculares, de modo que aqueles selecionados para esse trabalho possuíssem uma estrutura molecular capaz de possibilitar a formação de síntons moleculares adequados à formação dos cocristais desejados.

A análise dos resultados obtidos permitiu verificar que, nas condições experimentais utilizadas, todas as misturas estudadas formaram apenas compostos eutéticos. Entretanto, embora os diagramas de fases e os experimentos de DSC, raios X e FTIR tenham confirmado apenas a obtenção de compostos eutéticos entre o cetoprofeno e os co-formadores estudados, $\mathrm{o}$ método do contato de Kofler indicou a formação de um cocristal entre o cetoprofeno e nicotinamida.

Assim sendo, o trabalho realizado até agora abre portas para investigações futuras, nomeadamente, com relação aos estudos de termomicroscopia relativos aos demais sistemas estudados neste trabalho. 


\begin{abstract}
In this work, we performed the thermoanalytical study and characterization at the solid state on the chemical interaction between ketoprofen (CET) and some organic compounds (benzamide (BA), picolinamide (PA), nicotinamide (NA), isonicotinamide (INA), pyrazinamide (PZA), salicylic acid (SA) and benzoic acid (BA)), aimed at obtaining cocrystals. The mechanochemical method was used for the preparation of solid compounds, and they were analyzed by differential scanning calorimetry (DSC), infrared spectroscopy with Fourier transform (FTIR), and X-ray powder difraction (XRPD). The choice of the organic compounds (co-formers) was based on their molecular structures, so that those selected for this work possess a molecular structure able to allow the formation of molecular synthons suitable for cocrystals formation.

The analysis of the results has shown that under the experimental conditions used, all systems studied has formed only eutectic compounds. However, although the phase diagrams and DSC experiments, X-ray and FTIR have confirmed obtaining only eutectic compounds between ketoprofen and co-formers studied, the method of contact Kofler has indicated the discovery of a new co-crystal formed between ketoprofen and nicotinamide.

Therefore, the work done so far opens the door to future research in particular with regard to thermomicroscopy studies related to other systems studied in this work.
\end{abstract}




\section{LISTA DE FIGURAS}

Figura 1 - Formas de otimização das propriedades físico-químicas de um API 15

Figura 2 - Preparação da zona de mistura por fusão 17

Figura 3 - Relação entre o comportamento térmico observado na zona de mistura e os diagramas de fases obtidos 18

Figura 4 - Formação de um cocristal $X \cdot Y$ 20

Figura 5 - Processos que levam à formação de cocristal através da técnica de moagem 22

Figura 6 - Estruturas moleculares do API e co-formadores escolhidos 23

Figura 7 - Representação esquemática dos síntons supramoleculares que poderão ser estabelecidos entre o API e os co-formadores

Figura 8 - Equipamento utilizado em termomicroscopia, instalado no laboratório de investigação de termodinâmica, no departamento de Química da Universidade de Coimbra. 26

Figura 9 - - Representação esquemática de equipamento utilizado em termomicroscopia._ 27

Figura 10 - Curvas de DSC de amostras de cetoprofeno. Atmosfera de $\mathrm{N}_{2}$, razão de aquecimento $2{ }^{\circ} \mathrm{C} \mathrm{min}^{-1}$ e massas de $2 \mathrm{mg}$, aproximadamente.

Figura 11 - Difratogramas de raios $\mathrm{X}$ das amostras de cetoprofeno. 32

Figura 12 - CET $1^{\circ}$ aquecimento $\left(5^{\circ} \mathrm{C} / \mathrm{min}\right.$, atmosfera $\mathrm{N}_{2}$, aumento $\left.200 \mathrm{X}\right)$ 34

Figura 13 - CET $1^{\circ}$ resfriamento $\left(-5^{\circ} \mathrm{C} / \mathrm{min}\right.$, atmosfera $\mathrm{N}_{2}$, aumento $\left.200 \mathrm{X}\right)$ 35

Figura 14 - CET $2^{\circ}$ aquecimento $\left(5^{\circ} \mathrm{C} / \mathrm{min}\right.$, atmosfera $\mathrm{N}_{2}$, aumento $200 \mathrm{X}$ 35

Figura 15 - DSC cíclico do cetoprofeno (2,500 mg, $5{ }^{\circ} \mathrm{C} / \mathrm{min}$ (aq. e resf.), atmosfera $\mathrm{N}_{2}$, cadinho de alumínio selado) 36

Figura 16 - Diagrama de fases (Energia livre de Gibbs em função da temperatura) hipotético do cetoprofeno.

Figura 17 - Curva TG-DTA da benzamida pura: $\mathrm{m}_{\mathrm{i}}=5,8 \mathrm{mg}$, atmosfera de ar, razão de aquecimento $10^{\circ} \mathrm{C} \cdot \mathrm{min}^{-1}$.

Figura 18 - Curva DSC da benzamida pura: $\mathrm{m}=2,2 \mathrm{mg}$, atmosfera de $\mathrm{N}_{2}$, razão de aquecimento $10^{\circ} \mathrm{C} \cdot \mathrm{min}^{-1}$.

Figura 19 - Espectros de FTIR: (a) Benzamida pura e (b) composto coletado após a fusão e evaporação da

Figura 20 - Difratogramas de pó da benzamida pura (BA), benzamida pós-moagem (pm), e das simulações das suas formas polimórficas I e VI. 
Figura 21 - Curvas DSC dos componentes puros cetoprofeno, benzamida e da sua mistura (1:1) obtida por processo de moagem: $\mathrm{m} \sim 2 \mathrm{mg}$, atmosfera de $\mathrm{N}_{2}$, razão de aquecimento $10^{\circ} \mathrm{C} \cdot \mathrm{min}^{-1}$.

Figura 22 - Difratogramas de pó da mistura CET : BA (1:1), obtida por moagem, do cetoprofeno puro e da benzamida pós-moagem (pm).

Figura 23 - Espectros de FTIR da mistura CET : BA (1:1), obtida por moagem, do cetoprofeno e da benzamida 44

Figura 24 - Difratogramas de pó do ácido benzoico pós-moagem (pm), e do ácido benzoico puro.

Figura 25 - Curvas DSC dos componentes puros cetoprofeno, ácido benzoico e da sua mistura (1:1) obtida por

Figura 26 - Difratogramas de pó da mistura CET : BZ (1:1), obtida por moagem, e do cetoprofeno e do ácido 48

Figura 27 - Espectros de FTIR da mistura CET : BZ (1:1), obtida por moagem, do cetoprofeno e do ácido benzoico puros e o espectro soma $(\mathrm{CET}+\mathrm{BZ})$ dos compostos puros.

Figura 28 - Curvas DSC dos componentes puros cetoprofeno, ácido salicílico e da sua mistura (1:1) obtida por processo de moagem: $\mathrm{m} \sim 2 \mathrm{mg}$, atmosfera de $\mathrm{N}_{2}$, razão de aquecimento $10^{\circ} \mathrm{C} \cdot \mathrm{min}^{-1}$ 50

Figura 29 - Difratogramas de pó da mistura CET : SA (1:1), obtida por moagem, e do cetoprofeno e do ácido salicílico puros.

Figura 30 - Espectros de FTIR da mistura CET : SA (1:1), obtida por moagem, do cetoprofeno e do ácido salicílico puros e o espectro soma $(\mathrm{CET}+\mathrm{SA})$ dos compostos puros

Figura 31 - Difratogramas de pó da picolinamida pura, picolinamida pós-moagem (pm), e das simulações das suas formas polimórficas I e II. 53

Figura 32 - Curvas DSC dos componentes puros cetoprofeno, picolinamida e da sua mistura (1:1) obtida por processo de moagem: $\mathrm{m} \sim 2 \mathrm{mg}$, atmosfera de $\mathrm{N}_{2}$, razão de aquecimento $10^{\circ} \mathrm{C} \cdot \mathrm{min}^{-1}$.

Figura 33 - Difratogramas de pó da mistura CET : PA (1:1), obtida por moagem, e do cetoprofeno e da picolinamida (pós-moagem) puros. 
Figura 34 - Espectros de FTIR da mistura CET : PA (1:1), obtida por moagem, do cetoprofeno e da picolinamida puros e o espectro soma $(\mathrm{CET}+\mathrm{PA}) \mathrm{dos}$ compostos puros.

Figura 35 - Difratogramas de pó da isonicotinamida pós-moagem (pm), e da isonicotinamida pura. 57

Figura 36 - Curvas DSC dos componentes puros cetoprofeno, isonicotinamida e da sua mistura (1:1) obtida por processo de moagem: $\mathrm{m} \sim 2 \mathrm{mg}$, atmosfera de $\mathrm{N}_{2}$, razão de aquecimento $10^{\circ} \mathrm{C} \cdot \mathrm{min}^{-1}$.

Figura 37 - Difratogramas de pó da mistura CET : INA (1:1), obtida por moagem, e do cetoprofeno e da isonicotinamida puros.

Figura 38 - Espectros de FTIR da mistura CET : INA (1:1), obtida por moagem, do cetoprofeno e da isonicotinamida puros e o espectro soma (CET + INA) dos compostos puros. 60

Figura 39 - Difratogramas de pó da pirazinamida pura, pirazinamida pós-moagem (pm), e da simulações da forma polimórfica $\alpha$.

Figura 40 - Curvas DSC dos componentes puros cetoprofeno, pirazinamida e da sua mistura (1:1) obtida por processo de moagem: $\mathrm{m} \sim 2 \mathrm{mg}$, atmosfera de $\mathrm{N}_{2}$, razão de aquecimento $10^{\circ} \mathrm{C} \cdot \mathrm{min}^{-1}$. 62

Figura 41 - Difratogramas de pó da mistura CET : PZA (1:1), obtida por moagem, e do cetoprofeno e da pirazinamida puros. 63

Figura 42 - Espectros de FTIR da mistura CET : PZA (1:1), obtida por moagem, do cetoprofeno e da pirazinamida puros e o espectro soma (CET + PZA) dos compostos puros.

Figura 43 - Difratogramas de pó da nicotinamida pós-moagem (pm), e da nicotinamida pura. 65

Figura 44 - Curvas DSC dos componentes puros cetoprofeno, nicotinamida e da sua mistura (1:1) obtida por processo de moagem: $\mathrm{m} \sim 2 \mathrm{mg}$, atmosfera de $\mathrm{N}_{2}$, razão de aquecimento $10^{\circ} \mathrm{C} \cdot \mathrm{min}^{-1}$. 66

Figura 45 - Difratogramas de pó da mistura CET : NA (1:1), obtida por moagem, e do cetoprofeno e da nicotinamida puros.

Figura 46 - Espectros de FTIR da mistura CET : NA (1:1), obtida por moagem, do cetoprofeno e da nicotinamida puros e o espectro soma $(\mathrm{CET}+\mathrm{NA})$ dos compostos puros. 
Figura 47 - Curvas DSC dos componentes puros CET, INA, e suas proporções ( $2 \mathrm{mg}, 5$ ${ }^{\circ} \mathrm{C} / \mathrm{min}$, atmosfera $\mathrm{N}_{2}$ ). 69

Figura 48 - Cálculos para a construção das curvas do diagrama de fases experimental 70

Figura 49 - Cálculo das temperaturas de fusão teóricas para cada fração molar x. 71

Figura 50 - Diagrama de fases para o sistema CET-INA 72

Figura 51 - Diagrama de fases para o sistema CET-BA 73

Figura 52 - Diagrama de fases para o sistema CET-BZ. 74

Figura 53 - Diagrama de fases para o sistema CET-NA. 74

Figura 54 - Diagrama de fases para o sistema CET-PA. 75

Figura 55 - Diagrama de fases para o sistema CET-PZA. 75

Figura 56 - Diagrama de fases para o sistema CET-SA. 76

Figura 57 - Aquecimento do sistema CET-NA $\left(2{ }^{\circ} \mathrm{C} / \mathrm{min}\right.$, atmosfera $\mathrm{N}_{2}$, aumento 200X). $\mathrm{a}=$ $\mathrm{CET} ; \mathrm{b}=\mathrm{NA} ; \mathrm{c}=$ cocristal formado. 77

Figura 58 - Aquecimento do cocristal formado $\left(5^{\circ} \mathrm{C} / \mathrm{min}\right.$, atmosfera $\mathrm{N}_{2}$, aumento $\left.50 \mathrm{X}\right)$ 78

Figura 59 - DSC cíclico do cocristal CET:NA. 79

Figura 60 - FTIR do composto CET:NA (1:1) e do cocristal formado. 80 


\section{LISTA DE TABELAS}

Tabela 1 - Definições de cocristal 19

Tabela 2 - Temperaturas de fusão de amostras de cetoprofeno puro. 29

Tabela 3 - Condições de moagem de amostras de cetoprofeno puro 31

Tabela 4 - Parâmetros termodinâmicos das curvas DSC do primeiro aquecimento de CET, BA e CET:BA 42

Tabela 5 - Parâmetros termodinâmicos das curvas DSC do primeiro aquecimento de CET, BZ e CET:BZ

Tabela 6 - Parâmetros termodinâmicos das curvas DSC do primeiro aquecimento de CET, SA e CET:SA 50

Tabela 7 - Parâmetros termodinâmicos das curvas DSC do primeiro aquecimento de CET, PA e CET:PA 54

Tabela 8 - Parâmetros termodinâmicos das curvas DSC do primeiro aquecimento de CET, INA e CET:INA 57

Tabela 9 - Parâmetros termodinâmicos das curvas DSC do primeiro aquecimento de CET, PZA e CET:PZA 62

Tabela 10 - Parâmetros termodinâmicos das curvas DSC do primeiro aquecimento de CET, NA e CET:NA 66

Tabela 11 - Composições teórica e experimental dos compostos eutéticos. 76 


\section{LISTA DE ABREVIATURAS E SIGLAS}

API do Inglês "Active Pharmaceutical Ingredient"

ATR do Inglês "Attenuated Total Reflection"

BA sigla para o composto benzamida

BZ sigla para o composto ácido benzoico

CET sigla para o composto cetoprofeno

DSC do Inglês "Differential Sacnning Calorimetry"

DTA do Inglês "Differential Thermal Analysis"

FTIR do Inglês "Fourier Transform Infra Red"

INA sigla para o composto isonicotinamida

NA sigla para o composto nicotinamida

PA sigla para o composto picolinamida

PLTM do Inglês "Polarized Light Thermal Microscopy"

PZA sigla para o composto pirazinamida

SA sigla para o composto ácido salicílico

TG do Inglês "Thermogravimetry"

XRPD do Inglês "X-ray Powder Diffraction” 


\section{SUMÁRIO}

1. INTRODUÇÃO

1.1. Polimorfismo

1.2. Termomicroscopia com Luz Plano Polarizada (PLTM) _ 16

1.3. Método de Kofler _ 17

1.4. Cocristais _ 18

1.5. Técnicas de obtenção de cocristais __ 21

1.6. Cetoprofeno e co-formadores __ 22

1.7. Objetivos__ 24

2. REAGENTES, TÉCNICAS E EQUIPAMENTOS UTILIZADOS _ 25

2.1. Reagentes _ 25

2.2. Calorimetria Exploratória Diferencial (DSC) 25

2.3. Termogravimetria - Análise Térmica Diferencial (TG-DTA) _ 25

2.4. Termomicroscopia de luz plano polarizada (PLTM) _ 25

2.5. Espectroscopia de absorção na região infravermelho com transformada de Fourier (FTIR) 27

2.6. Difração de raios X pelo método do pó __ 27

2.7. Moagem (mecanoquímica) _ 28

2.8. Método do contato de Kofler _ 28

3. RESULTADOS E DISCUSSÕES _ 29

3.1. Caracterização do cetoprofeno

3.1.1. Determinação da temperatura de fusão __ 29

3.1.2. Difratometria de raios $X$ pelo método do pó ___ 31

3.1.3. Estudo do comportamento térmico do cetoprofeno por PLTM.__ 33

3.2. Caracterização dos sistemas estudados _ 37

3.2.1. Sistema cetoprofeno (CET) : Benzamida $(B A) \_37$

3.2.2. Sistema cetoprofeno (CET) : ácido benzóico $(\mathrm{BZ}) \_45$

3.2.3. Sistema cetoprofeno (CET) : ácido salicílico $(\mathrm{SA}) \_49$

3.2.4. Sistema cetoprofeno (CET) : picolinamida (PA)

3.2.5. Sistema cetoprofeno (CET) : isonicotinamida (INA)_ 56

3.2.6. Sistema cetoprofeno (CET) : pirazinamida (PZA) _ 60

3.2.7. Sistema cetoprofeno (CET) : nicotinamida (NA) _ 64

3.3. Diagramas de fases sólido-líquido__ 68

3.4. Método do contato de Kofler _ 77 
4. CONCLUSÕES

80

REFERÊNCIAS 


\section{INTRODUÇÃO}

O desenvolvimento de uma nova molécula farmacologicamente ativa (API, do Inglês “Active Pharmaceutical Ingredient”) é dividido em várias etapas que incluem: (1) descoberta/caracterização de um composto com atividade terapêutica; (2) estudos pré-clínicos e (3) estudos clínicos. Introduzir um novo fármaco na área terapêutica é um processo longo (cerca de doze anos, em média) e bastante oneroso, com probabilidade de sucesso pequena. De cada cem mil novos compostos descobertos, apenas duzentos e cinquenta são submetidos aos ensaios pré-clínicos e, apenas cinco entram em ensaios clínicos (testes em humanos). Ao final, estima-se que apenas uma molécula chegue ao mercado e, para isso, deve ser segura, eficaz e/ou capaz de melhorar a qualidade de vida dos pacientes (FERREIRA et al., 2009)

A maioria dos medicamentos comercializados é formulada em formas farmacêuticas sólidas e de uso oral. Tais formas farmacêuticas, apesar de serem de administração cômoda ao paciente, necessitam que o fármaco seja disponibilizado, em tempo razoável, em seu sítio de absorção no trato gastrintestinal (SHEKUNOV; YORK, 2000). Além disso, as empresas farmacêuticas pesquisam por APIs cujas formas cristalinas sejam estáveis durante as etapas de produção e armazenamento de um medicamento. Entretanto, essa estabilidade nem sempre é conseguida, já que os APIs podem apresentar variações polimórficas metaestáveis ou menos solúveis, sendo difícil prever o número de formas polimórficas que podem existir para um determinado API e as condições experimentais para a obtenção de cada uma delas (ARORA; ZAWOROTKO, 1999).

Mesmo depois da fase de comercialização, um API continua sendo alvo de pesquisas, cujo objetivo é a melhoria das suas propriedades físico-quimicas, principalmente, a sua solubilidade em água. Dentre as várias maneiras de se otimizar essas propriedades, destacamse a obtenção de sais, através de uma reação ácido-base entre o API e uma outra substância ácida ou básica. Uma outra forma é através da obtenção de solvatos, quando o solvente é retido e incorporado na estrutura cristalina durante o processo de cristalização. Pode-se, ainda, tentar a otimização dessas propriedades através da obtenção de cocristais (SCHULTHEISS; NEWMAN, 2009; SUN, 2013). Todos esses processos encontram-se ilustrados na Figura 1. 
Figura 1 - Formas de otimização das propriedades físico-químicas de um API

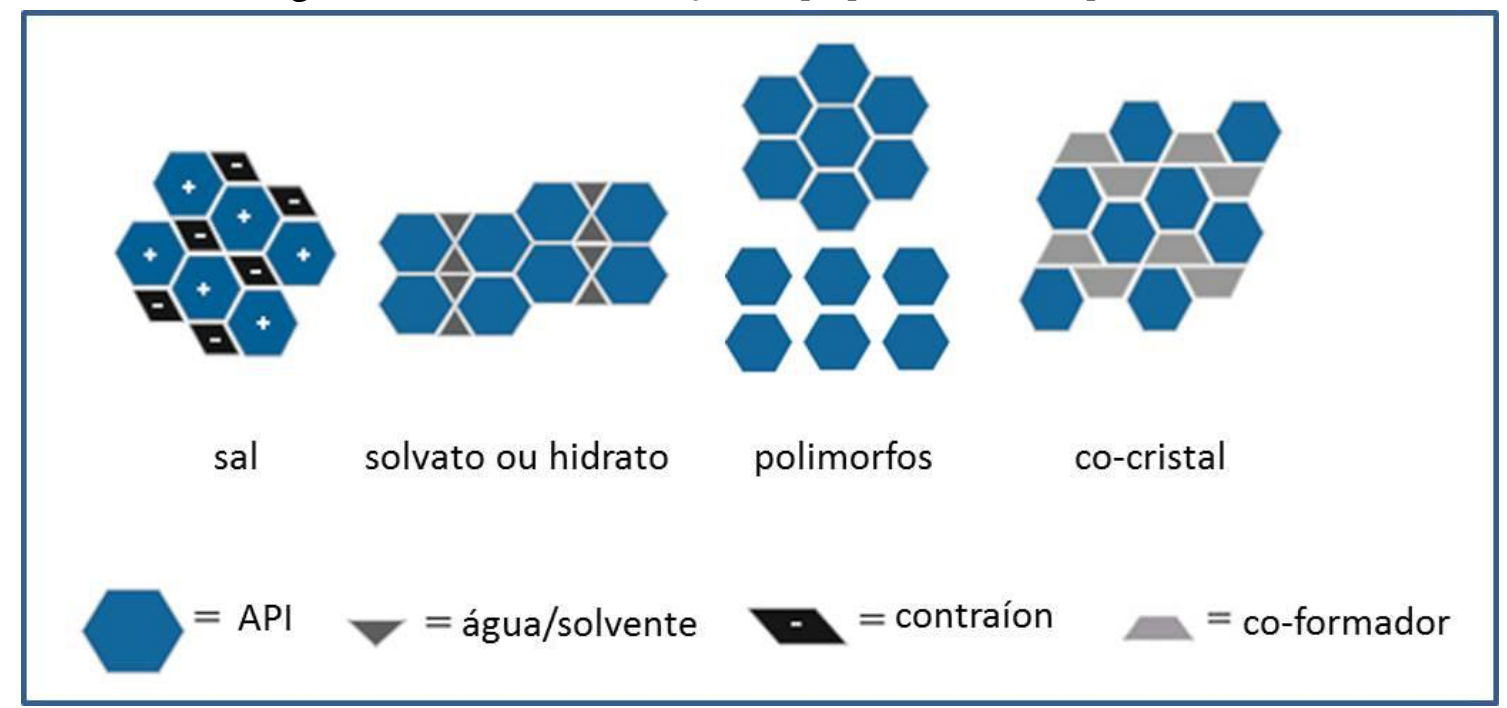

Fonte: (SCHULTHEISS; NEWMAN, 2009)

Embora possuam grande diversidade e representem cerca de $50 \%$ das formas farmacêuticas comerciáveis, os sais de um API apresentam algumas desvantagens, uma vez que algumas moléculas de APIs podem não apresentar grupos ionizáveis capazes de proporcionar a formação de sal, enquanto que outras podem ser quimicamente instáveis em valores extremos de pH (SHAN et al., 2014).

Diferentemente dos solvatos e polimorfos que apresentam termodinâmica de estado sólido e solubilidade semelhantes entre si, a formação de um cocristal proporciona aumento de solubilidade e melhorias no perfil de dissolução de um API (SHAN et al., 2014).

As técnicas termoanalíticas podem contribuir no controle de qualidade durante todo o processo de produção dos fármacos e das matérias primas utilizadas na sua fabricação. Os métodos termoanalíticos são utilizados para verificar a estabilidade térmica, indicar possíveis formas polimórficas/pseudo-polimórficas, reações no estado sólido, possíveis interações entre os princípios ativos e os excipientes, pureza dos princípios ativos e os excipientes, entre outras propriedades (GIRON, 2001, 2003; GIRON; MUTZ; GARNIER, 2004; MOHAMAD et al., 1997).

\subsection{Polimorfismo}

Polimorfismo é definido como a possibilidade de um sólido poder se cristalizar em diferentes formas cristalinas. Um polimorfo, portanto, é um material sólido com ao menos dois diferentes arranjos moleculares que resultam em espécies cristalinas distintas entre si (NANGIA, 2007). 
No estado sólido, os polimorfos cristalinos apresentam mesma composição química, mas possuem diferentes estruturas cristalinas. Por isso, possuem diferentes propriedades físicoquímicas (ponto de fusão, ponto de ebulição, cor, estabilidade, solubilidade, entalpia de fusão, etc.). Já que as diferentes estruturas cristalinas diferem entre si quanto ao empacotamento, observam-se diferenças de conformação molecular e entropia na rede cristalina. Estas diferenças desaparecem no estado líquido ou no vapor. Os outros polimorfos são metaestáveis, que se convertem na forma estável. Há, potencialmente, grandes diferenças nas suas propriedades físicas, de modo que se comportam como entidades químicas distintas. A análise térmica associada a outras técnicas podem contribuir ao entendimento destes quesitos, pois permitem determinar se há diferenças nos pontos de fusão e, também, permitem determinar as temperaturas e entalpias envolvidas nas transições cristalinas. Tais informações são fundamentais na formulação, processamento e armazenamento dos medicamentos em geral (CAIRA, 2008).

\subsection{Termomicroscopia com Luz Plano Polarizada (PLTM)}

A termomicroscopia é uma técnica termoanalítica que permite observar as alterações morfológicas e estruturais produzidas numa amostra em função da temperatura, através da observação microscópica com luz plano polarizada. Através dessa técnica, é possível obter grande número de informações relativas aos aspectos estruturais da amostra em estudo, tais como hábitos cristalinos, transformações de fases, estados físicos da matéria, etc. É considerada atualmente como uma das mais importantes técnicas de pesquisa na área de termoptometria, segundo a Confederação Internacional para Análise Térmica e Calorimetria (ICTAC, sigla em Inglês) (WIEDEMANN; FELDER-CASAGRANDE, 1998).

A técnica de PLTM baseia-se nas propriedades eletromagnéticas da luz. Quando no ar, as componentes da luz polarizada propagam-se, inicialmente, numa mesma velocidade. Entretanto, ao atingir um sólido cristalino, uma das componentes sofre uma diminuição de velocidade em relação à outra, devido às propriedades intrínsecas do sólido cristalino em estudo, nomeadamente, o índice de refração. Assim, devido a esse retardamento na velocidade de propagação, essas componentes sofrem interferência destrutiva ao emergirem do cristal, causando recombinações que dão origem às diversas cores observadas nas imagens obtidas (VITEZ; NEWMAN, 2007) 


\subsection{Método de Kofler}

O método de Kofler é realizado com o auxílio da PLTM. Inicialmente, adiciona-se o composto com maior ponto de fusão a uma lâmina e adiciona-se uma lamela, que encontra-se sustentada sobre a lâmina, através de pedaços de vidro, pequenos e delgados, que atuam como separadores, permitindo que haja espaço suficiente para que o composto adicionado possa se solidificar após a sua fusão e, também, permitir a adição de um segundo composto, cujo ponto de fusão é menor que o do primeiro composto adicionado. Dessa forma, primeiramente, fundese o composto com maior temperatuta de fusão e deixa-se resfriar até a sua completa solidificação (Figura 2-a). Em seguida, adiciona-se o composto com menor ponto de fusão e aquece-se o sistema até que o mesmo passe do estado sólido para o estado líquido e entre em contato com a fase cristalizada do composto X (Figura 2-b). O sistema é então armazenado num dessecador e mantido em tempartura ambiente até cristalizar-se por completo. Nessa etapa, podem ocorrer duas situações distintas na zona de mistura:

- Formação de um composto eutético de X e Y (Figura 2-c)

- Formação de um cocristal de X e Y, juntamente com a formação de dois compostos eutéticos (Figura 2-d)

Figura 2 - Preparação da zona de mistura por fusão

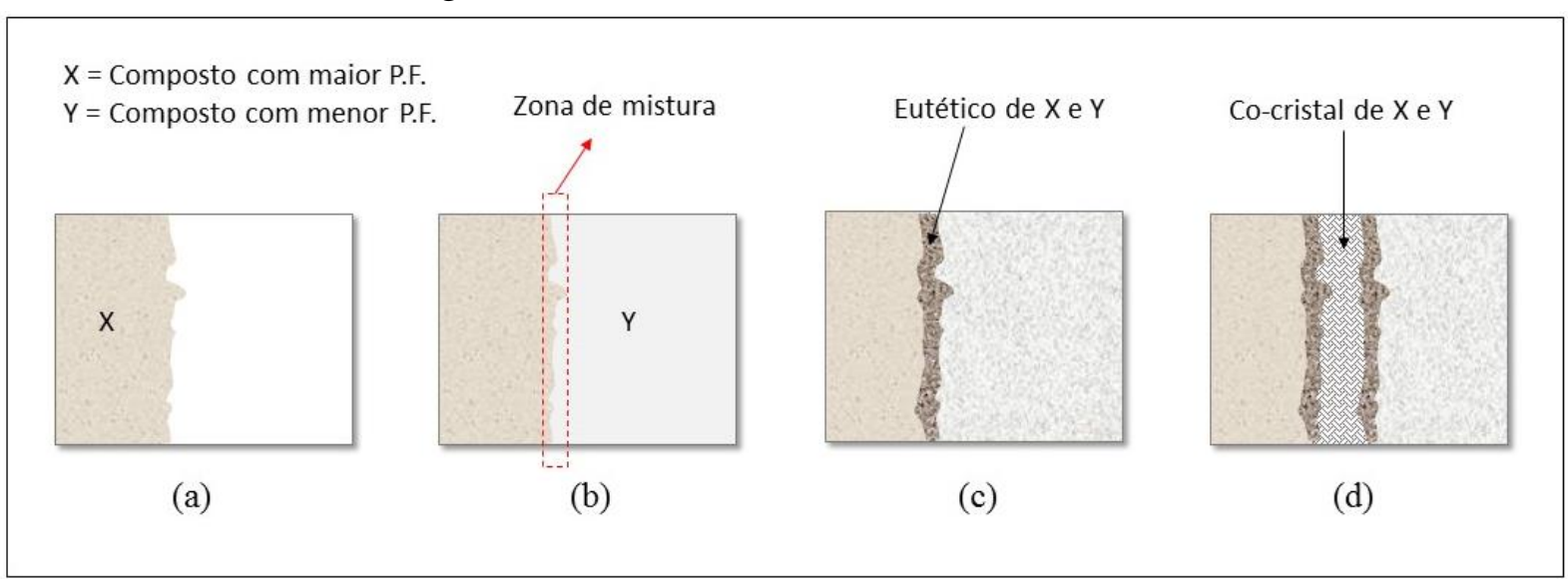

Fonte: (adaptada de STAHLY, 2009).

Quando o sistema é aquecido e observado com luz plano polarizada, as diferentes fases sólidas tornam-se visíveis, possibilitando, assim, a identificação do tipo de composto formado na zona de mistura entre os compostos X e Y, bem como a obtenção de um diagrama de fases binário através das informações qualitativas obtidas durante a realização desse experimento. Se durante o aquecimento o composto formado na zona de mistura fundir numa temperatura menor 
que os compostos $\mathrm{X}$ e $\mathrm{Y}$, indicará a formação de um composto eutético, com um diagrama de fases mostrado na Figura 3-a. Por outro lado, a Figura 3-b mostra que se os compostos X e Y interagirem entre si, haverá a formação de um cocristal entre dois compostos eutéticos, sendo que a ordem de fusão (em ordem crescente de temperatura) observada através da PLTM deverá ser a seguinte: eutético 1, composto Y puro, cocristal, eutético 2, composto X puro (STAHLY, 2009).

Figura 3 - Relação entre o comportamento térmico observado na zona de mistura e os diagramas de fases obtidos

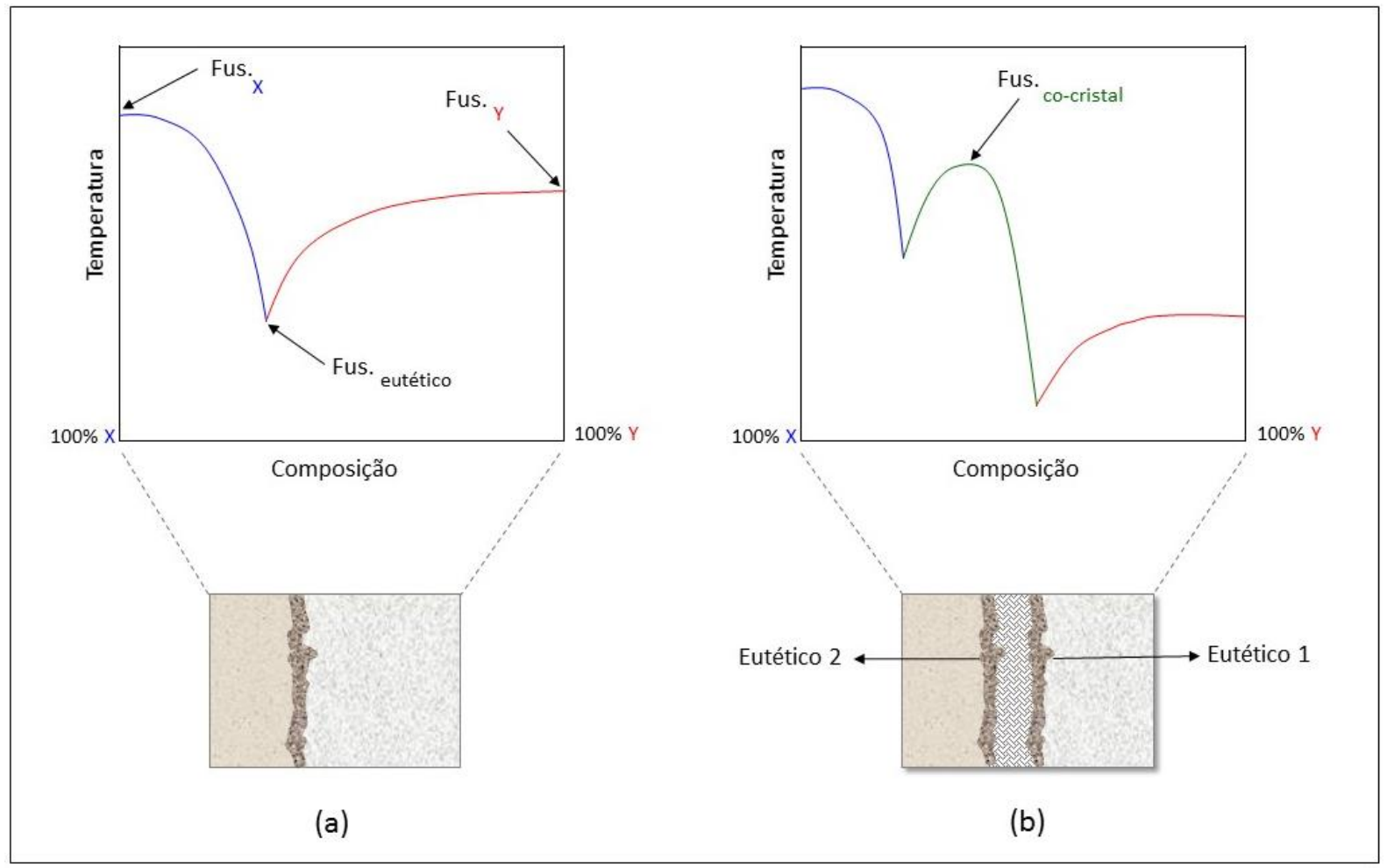

Fonte: (adaptada de STAHLY, 2009).

\subsection{Cocristais}

As definições de cocristal vêm evoluindo ao longo do tempo. A Tabela 1 apresenta algumas das definições mais citadas na literatura, desde as mais resumidas até as mais abrangentes. 
Tabela 1 - Definições de cocristal

\begin{tabular}{|c|c|c|c|}
\hline Autor & Definição de cocristal & Ano & Referência \\
\hline Aakeröy, C. B. & $\begin{array}{l}\text { "compounds constructed from discrete } \\
\text { neutral molecular species...all solids } \\
\text { containing ions, including complex } \\
\text { transition-metal ions, are excluded" "made } \\
\text { from reactants that are solids at ambient } \\
\text { conditions" "structurally homogeneous } \\
\text { crystalline material that contains two or } \\
\text { more neutral building blocks that are present } \\
\text { in definite stoichiometric amounts" }\end{array}$ & 2005 & $\begin{array}{c}\text { (AAKERÖY; SALMON, } \\
2005)\end{array}$ \\
\hline
\end{tabular}

"a crystalline complex of two or more neutral molecular constituents bound Jones, W. together in the crystal lattice through noncovalent interactions, often including (JONES, 2006) hydrogen bonding"

"are formed between a molecular or ionic

Vishweshwar, P. et al. API and a co-crystal former that is a solid under ambient conditions" components, usually in stoichiometric ratio, each component being an atom, ionic 2007) compound, or molecule"

Stahly, G. P. Stahly, G. P.

Bond, A. Nangia, A. "a molecular complex that contains two or more different molecules in the same crystal 2007 lattice"

Devido às suas características cristalinas, os cocristais apresentam maior estabilidade com relação à umidade e ao armazenamento. Além disso, possuem menor tendência de sofrerem transformações de fases e são estáveis durante os processos de granulação úmida, formação de comprimidos, compactação, etc. (JANGADEESH BABU; NANGIA, 2011).

O API 2-[4-(4-cloro-2-fluorofenoxi)fenil]pirimidina-4-carboxamida, pertencente à classe farmacológica dos bloqueadores dos canais de sódio, é utilizado para tratamento ou 
prevenção de dores, mas apresenta baixa solubilidade em água. Entretanto, os cocristais desse API com ácido glutárico (co-formador), melhoraram a biodisponibilidade oral desse API em estudos com cães (MCNAMARA et al., 2006).

$\mathrm{Na}$ literatura, são encontrados outros trabalhos que relatam melhorias das propriedades físico-químicas de alguns fármacos, quando na forma de cocristais. Para os pacientes, essas melhorias podem trazer benefícios que vão desde um melhor conforto durante a ingestão, devido a uma melhor solubilidade do API, até a diminuição de possíveis efeitos colaterais (ALMARSSON; ZAWOROTKO, 2004; CHIENG et al., 2009; GOOD; NAÍR, 2009; JUNG et al., 2010; SHIRAKI et al., 2008; YADAV, 2009).

Berry et. al. (BERRY et al., 2008) relatam a obtenção de cocristais de alguns antiinflamatórios, utilizando-se nicotinamida como co-formador. Apesar dos bons resultados obtidos, não houve formação de cocristais de cetoprofeno (através de métodos de cristalização em solução). Entretanto, nesse trabalho, não foram feitos estudos da obtenção de cocristais por métodos mecanoquímicos. Esses métodos são uma alternativa muito interessante para o estudo da obtenção de cocristais e serão descritos no item 1.5.

Em outro trabalho, Castro et. al. (CASTRO et al., 2011) relatam a obtenção de cocristais de naproxeno (API) com diferentes co-formadores, isômeros da piridina-carboxamida. Os resultados obtidos evidenciaram que os cocristais formados apresentaram menores temperaturas de fusão com relação ao naproxeno puro, indicando que a formação desses cocristais pode aumentar a solubilidade desse API em água.

A formação de um cocristal ocorre através da interação representada a seguir, na Figura 4, onde X representa um API e Y um co-formador. Dessa forma, um cocristal farmacêutico é resultante da interação entre um API e um co-formador, ambos no estado sólido, sem que ocorra transferência de prótons entre essas duas espécies.

Figura 4 - Formação de um cocristal $X \cdot Y$

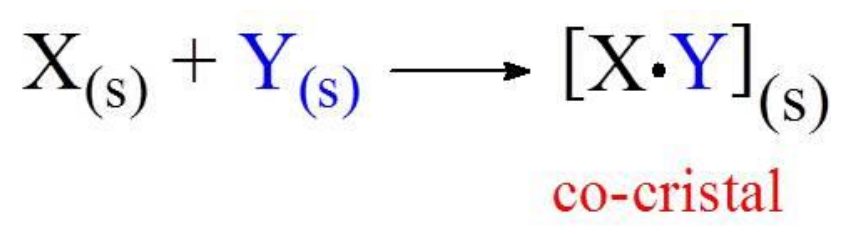

As interações moleculares que podem ser estabelecidas para a formação de um cocristal são do tipo ligações de hidrogênio, interações $\pi-\pi$ e interações de Van der Waals (LARAOCHOA; ESPINOSA-PÉREZ, 2007). 


\subsection{Técnicas de obtenção de cocristais}

Atualmente, a cristalização em solvente ou em misturas de solventes é o método mais utilizado para a obtenção de cocristais, principalmente para a obtenção de monocristais para a determinação de suas estruturas moleculares (CHIARELLA; DAVEY; PETERSON, 2007).

Entretanto, a obtenção desses cristais através de cristalização constitui uma etapa muito difícil de ser vencida, já que a formação de cocristais depende de uma série de fatores, tais como: temperatura, tempo de evaporação da solução, solubilidade dos componentes no solvente (ou na mistura de solventes) e da qualidade dos reagentes. Além disso, muitas vezes, os cristais obtidos não são puros, mas sim, misturas de cocristal com um dos co-formadores utilizados no processo de cristalização.

O tamanho dos cristais obtidos também é um fator essencial a ser considerado, pois estes podem não ter as dimensões adequadas para serem analisados por difração de raios $\mathrm{X}$ de monocristal.

Entretanto, apesar das dificuldades, a obtenção de monocristais e sua análise por difração de raios $\mathrm{X}$ de monocristal são de grande importância, visto que esta técnica propicia o conhecimento da estrutura do cocristal e a forma de como o API e o co-formador estabelecem a rede de ligações intermoleculares para formarem o cocristal.

Recentemente, foram reconhecidas diversas técnicas para obtenção de cocristais, particularmente, os métodos mecanoquímicos de moagem e moagem assistida por líquido, constituindo, assim, uma alternativa interessante aos métodos tradicionais de cristalização em solução (FRISCIC, 2009).

A primeira referência à mecanoquímica na literatura científica ocorreu em 1844, quando Wöhler preparou o cocristal quinona-hidroquinona 1:1 (WEYNA et al., 2009).

A moagem assistida por líquido consiste na adição de uma pequena quantidade de solvente (gotas) à mistura que será submetida ao processo de moagem. O solvente adicionado atuará como catalisador, auxiliando a formação dos cocristais (WEYNA et al., 2009).

Essa técnica foi inicialmente utilizada para aumentar as possibilidades de sucesso na obtenção de cocristais no estado sólido. Com o desenvolvimento dos estudos, verificou-se que a moagem assistida por líquido proporciona maiores vantagens em comparação com a moagem convencional, já que proporciona um aumento na produtividade e permite a obtenção de produto com maior grau de cristalinidade. Essas duas técnicas foram estabelecidas como métodos altamente eficientes de pesquisa de cocristais, sais e formas polimórficas de compostos 
farmacêuticos. A mecanoquímica permite o aumento da homogeneidade do tamanho da partícula e também fornece energia cinética que produz transformações estruturais e químicas, o que contribui para uma melhor interação molecular entre os reagentes (FRISCIC; JONES, 2009). A Figura 5 apresenta um possível mecanismo de reação quando os reagentes (API e coformador) são submetidos à moagem para formar um cocristal.

Figura 5 - Processos que levam à formação de cocristal através da técnica de moagem

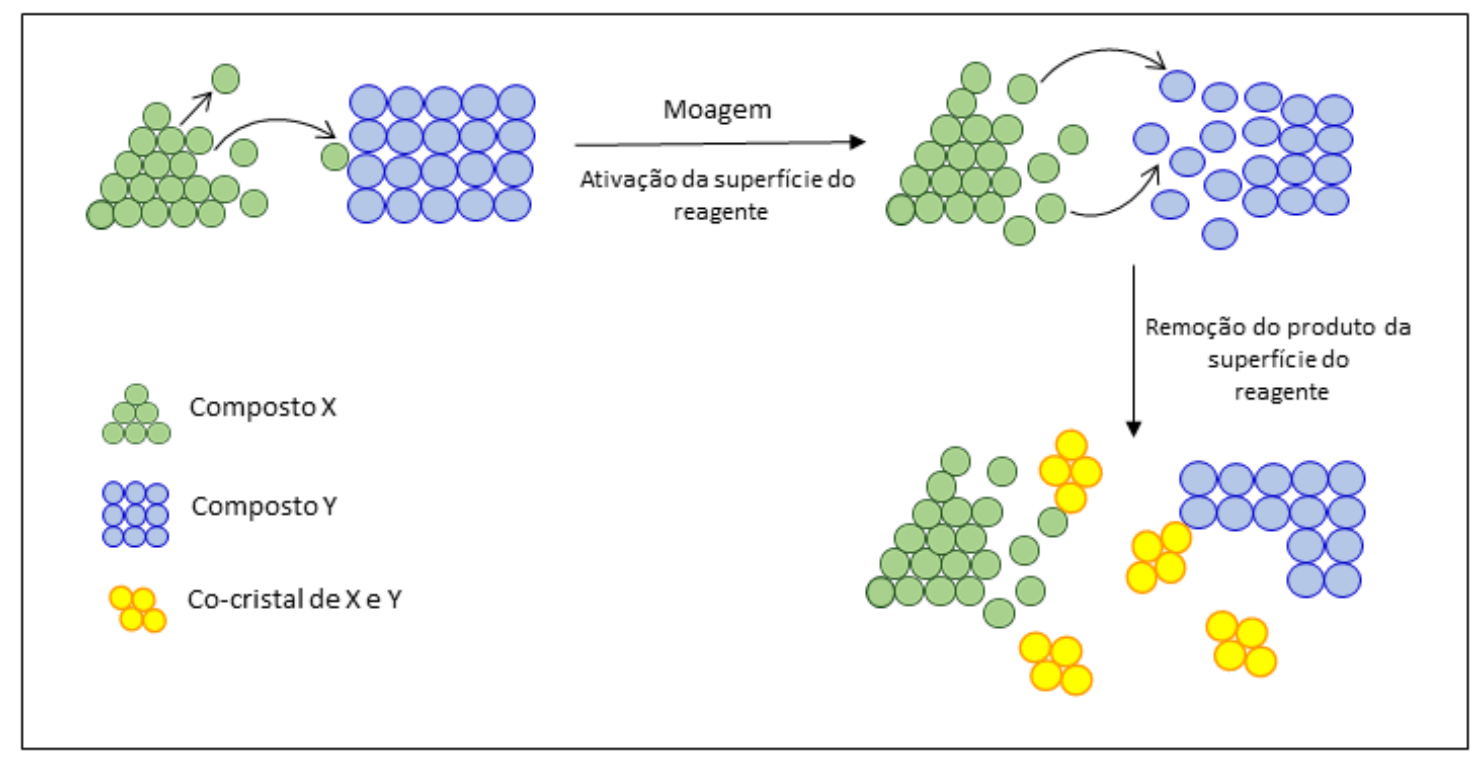

Observando a Figura acima, verifica-se que o processo de moagem aumenta a difusão na superfície dos reagentes, através da mistura dos mesmos, originando novas superfícies de reação e remoção de cocristais. O processo de moagem ativa a superfície de reação, provocando tensão e defeitos na superfície dos reagentes.

\subsection{Cetoprofeno e co-formadores}

O cetoprofeno, API escolhido para este trabalho, é um anti-inflamatório não esteroidal, derivado do ácido fenilpropiônico, e caracteriza-se farmacologicamente por sua ação antiinflamatória, antipirética e analgésica, sendo, por isso, bastante utilizado nas áreas da medicina humana e veterinária. Seu mecanismo de ação ocorre através da inibição da síntese de prostaglandina e leucotrieno, sendo que somente o seu enantiômero $S$ apresenta atividade farmacológica (MILES, 2008). Pertence à classe 2 do Sistema de Classificação Biofarmacêutica (BCS, em Inglês). Isso significa que esse API apresenta facilidade para 
atravessar biomembranas, mas é pouco solúvel em água (“Therapeutic Systems Research Laboratories," [s.d.]).

Quimicamente, caracteriza-se como um pó branco, com massa molar igual a 254,3 g $\mathrm{mol}^{-1}$ e ponto de fusão igual a $95^{\circ} \mathrm{C}$. É altamente solúvel em etanol, clorofórmio e éter etílico, benzeno e praticamente insolúvel em água (LIVERSIDGE, 1984; MILES, 2008).

As estruturas moleculares do API e co-formadores escolhidos para este trabalho estão representadas na Figura 6.

Figura 6 - Estruturas moleculares do API e co-formadores escolhidos

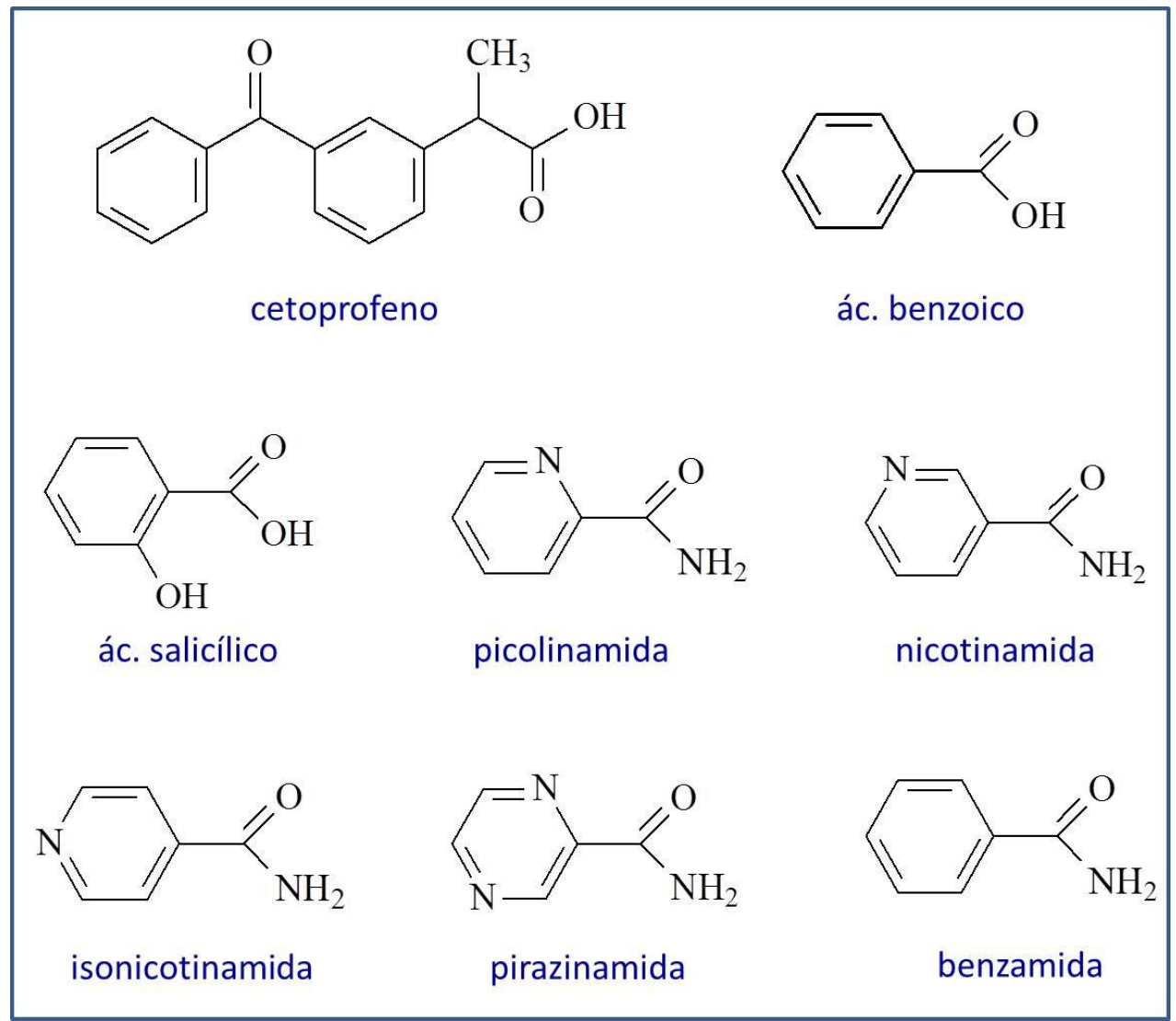

Nos cocristais, as moléculas do API e co-formador permanecem unidos entre si através de síntons supramoleculares (SHATTOCK et al., 2008; WEYNA et al., 2009), que são unidades estruturais dentro da supermolécula (cocristal) que podem ser formadas através de operações de sínteses conhecidas que envolvem interações intermoleculares, mais particularmente as ligações de hidrogênio (NANGIA, 2007). Os síntons que poderão ser estabelecidos entre o API e os co-formadores escolhidos para este trabalho estão mostrados na Figura 7. 
Figura 7 - Representação esquemática dos síntons supramoleculares que poderão ser estabelecidos entre o API e os co-formadores

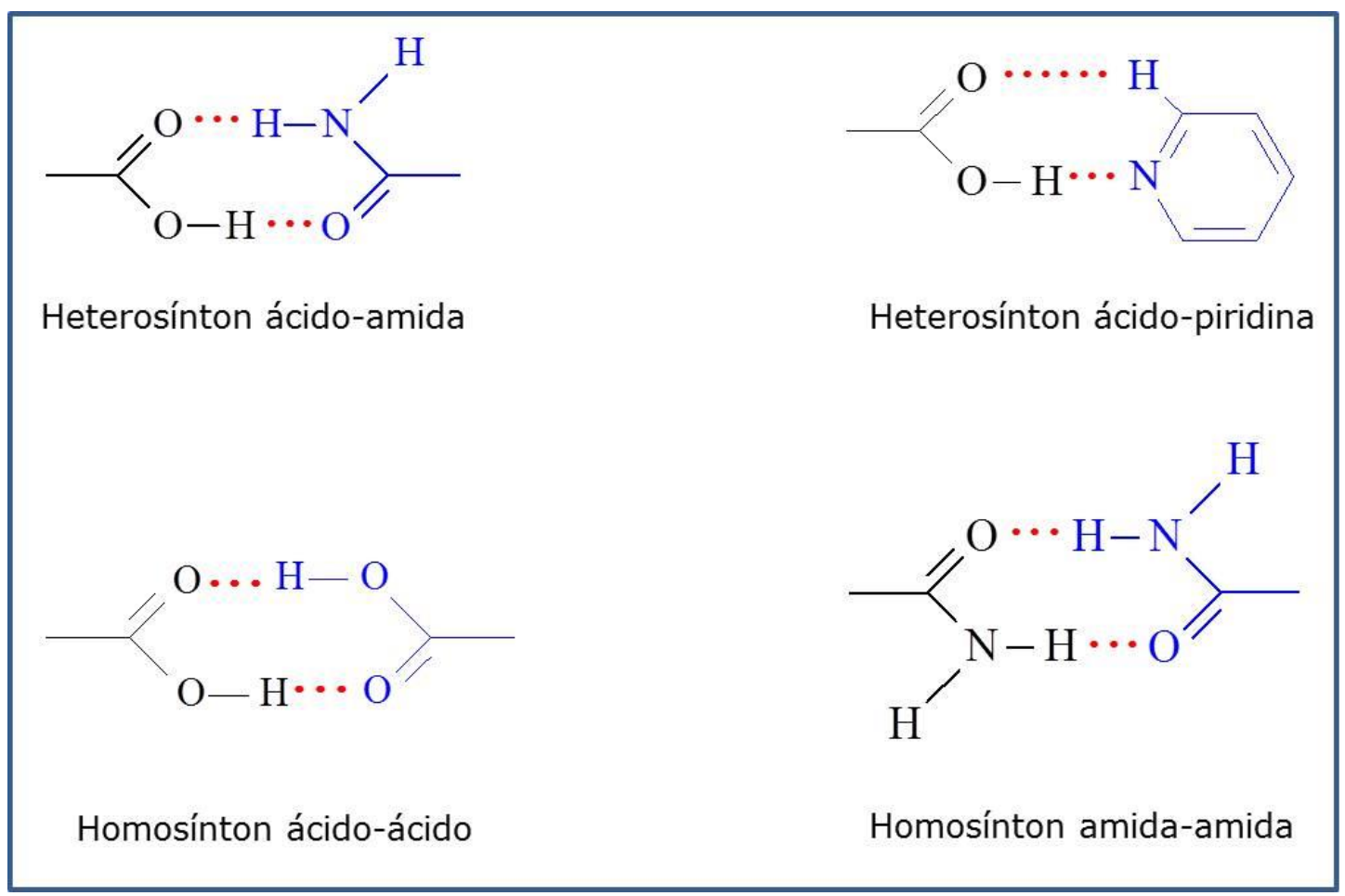

\subsection{Objetivo}

Este trabalho tem o seguinte objetivo:

- Estudo termoanalítico e caracterização no estado sólido dos compostos obtidos através da interação química entre o cetoprofeno e alguns compostos orgânicos. 


\section{REAGENTES, TÉCNICAS E EQUIPAMENTOS UTILIZADOS}

\subsection{Reagentes}

Todos os reagentes (incluindo o cetoprofeno) utilizados neste trabalho foram adquiridos da Sigma-Aldrich®, com grau de pureza mínimo de $98 \%$.

\subsection{Calorimetria Exploratória Diferencial (DSC)}

As curvas DSC foram obtidas através do equipamento DSC 1 Star ${ }^{\mathrm{e}}$ System da MettlerToledo. Utilizou-se como suporte de amostra, cadinho de alumínio com tampa prensada. Como referência, utilizou-se um cadinho similar, vazio. Em todas as análises foi utilizada atmosfera de nitrogênio com vazão de $50 \mathrm{~mL} \mathrm{~min}^{-1}$, com uma massa aproximada de amostra igual a $2 \mathrm{mg}$.

As curvas DSC realizadas em Portugal foram obtidas através do equipamento Pyris1, PerkinElmer, com compensação de potência. Um cadinho de alumínio de $30 \mu \mathrm{L}$, hermeticamente selado, foi usado como suporte para a amostra. Um cadinho vazio idêntico foi usado como referência. Todos os experimentos foram realizados em atmosfera de nitrogênio $\left(20 \mathrm{~mL} \mathrm{~min}^{-1}\right)$, com uma massa aproximada de amostra igual a $2 \mathrm{mg}$.

\subsection{Termogravimetria - Análise Térmica Diferencial (TG-DTA)}

As curvas TG-DTA foram obtidas pelo equipamento Netzsch modelo STA 449 F3, utilizando-se a massa de amostras próximas a $5 \mathrm{mg}$ e razão de aquecimento de $20^{\circ} \mathrm{min}^{-1} \mathrm{em}$ atmosfera de ar com vazão de $50 \mathrm{ml} \mathrm{min}{ }^{-1}$ e intervalo de temperatura de 30 a $800{ }^{\circ} \mathrm{C}$.

\subsection{Termomicroscopia de luz plano polarizada (PLTM)}

Os estudos de PLTM foram realizados num equipamento constituído por uma placa de aquecimento DSC600 da Linkam systems, por um bloco central constituído por uma unidade CI94 cuja função é controlar a temperatura nas etapas de aquecimento/resfriamento, uma unidade LNP94/2 que controla a refrigeração através de uma corrente de nitrogênio líquido que se encontra num Dewar ou corrente de ar, unidade VTO232 de interface gráfica e um 
computador que controla todo o sistema. A célula é aquecida com um microforno e a temperatura é controlada por sensores de Pt100.

Para a observação óptica, foi utilizado um microscópio Leica DMRB, uma câmara de vídeo Sony CCD-IRIS/RB modelo DXC-151 AP, e um monitor Sony HR Trinitron modelo PVM-2053MD e um DVDR 520H/00. Na análise das imagens, utilizou-se o software da Linkam systems com RTVMS. A Figura 8 mostra todo o equipamento a ser utilizado, que se encontra esquematizado na Figura 9.

Figura 8 - Equipamento utilizado em termomicroscopia, instalado no laboratório de investigação de termodinâmica, no departamento de Química da Universidade de Coimbra.

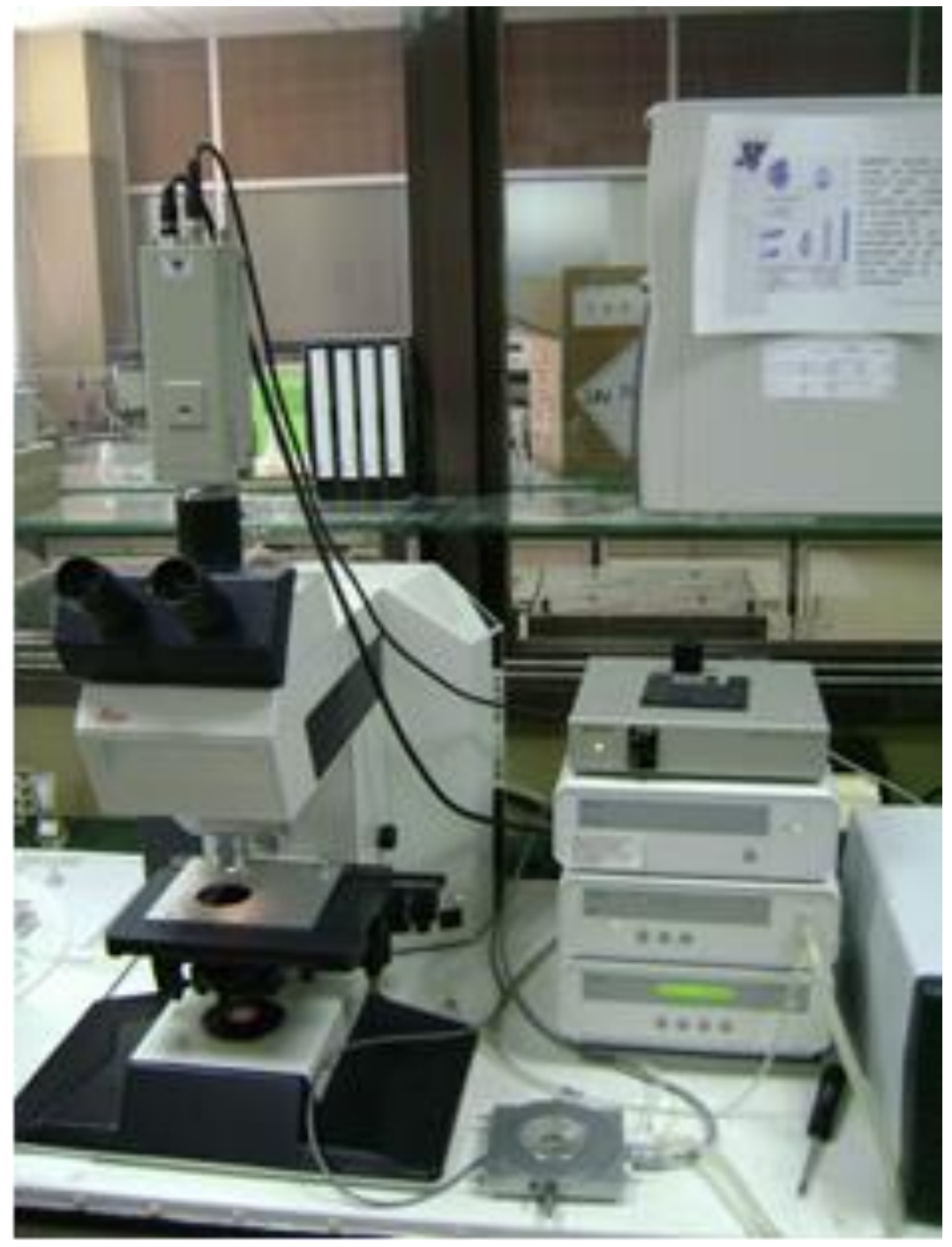


Figura 9 - - Representação esquemática de equipamento utilizado em termomicroscopia.

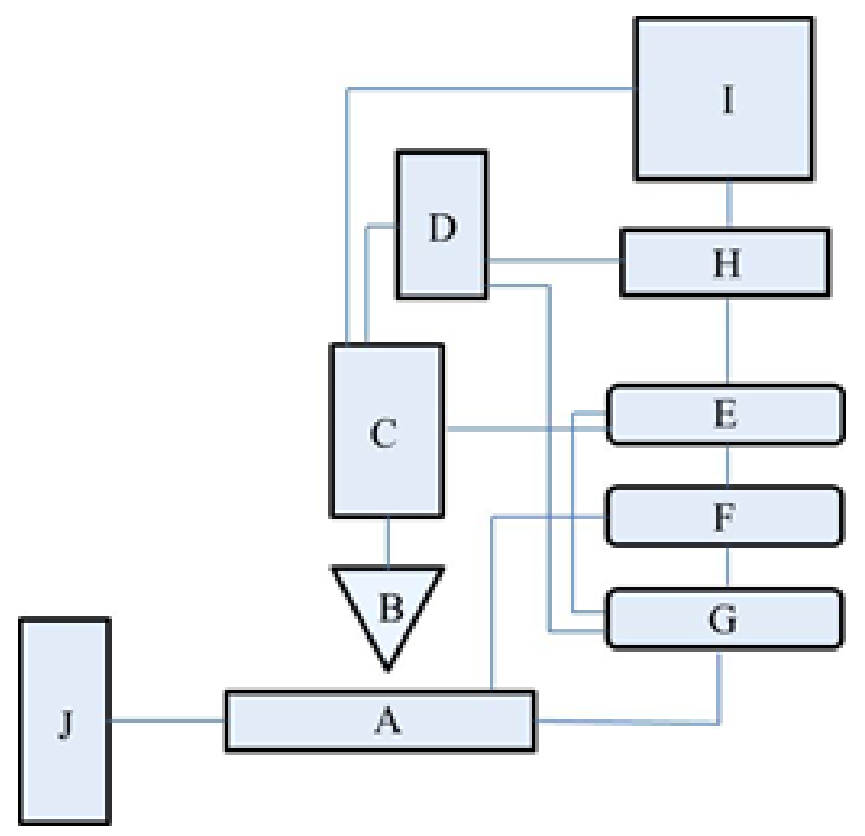

A- DSC600, B- microscópio, C- câmara de vídeo, D- computador, E- VTO, F- LNP, G- Unidade CI, HDVDR, I- monitor, J- Dewar

Os estudos de PLTM foram desenvolvidos em parceria com o departamento de Química, na Universidade de Coimbra, Portugal, com a colaboração do Prof. Dr. Ricardo António Esteves de Castro e da Prof ${ }^{a}$. Dr ${ }^{\mathrm{a}}$. Maria Ermelinda da Silva Eusébio.

\subsection{Espectroscopia de absorção na região infravermelho com transformada de Fourier (FTIR)}

Os espectros foram obtidos pelo espectrômetro Vertex 70, da Bruker. Os espectros foram obtidos através do método de refletância atenuada (ATR), com faixa de varredura entre $400 \mathrm{~cm}^{-1}$ e $4000 \mathrm{~cm}^{-1}$ (resolução de $4 \mathrm{~cm}^{-1}$ ) e um cristal de diamante como suporte.

\subsection{Difração de raios $X$ pelo método do pó}

Os difratogramas de raios $\mathrm{X}$ foram obtidos pelo Difratômetro RIGAKU DMAX ULTIMA+ utilizando-se tubo de cobre, submetido a $20 \mathrm{kV}$, corrente de $2 \mathrm{~mA}, \mathrm{Cu} \kappa \alpha, \lambda=$ 
$1,5406 \AA$. As amostras foram colocadas em suporte de vidro, e expostas à radiação $\left(3^{\circ} \leq 2 \theta \leq\right.$ $\left.50^{\circ}\right)$.

\subsection{Moagem (mecanoquímica)}

Um moinho de bolas, modelo MM400, Retsch, foi utilizado para a realização desses experimentos. Uma massa total (cetoprofeno + co-formador) de cerca de $50 \mathrm{mg}$ foi moída durante 30 minutos a uma frequência de $15 \mathrm{~Hz}$, num jarro de aço inoxidável, (volume total de $10 \mathrm{~mL}$ ) com duas esferas de aço inoxidável (7 mm de diâmetro cada) por jarro.

\subsection{Método do contato de Kofler}

Como não há nenhum equipamento para os estudos de PLTM nos laboratórios onde esse trabalho foi desenvolvido, o método de Kofler foi utilizado para complementar os demais métodos utilizados para caracterizar e avaliar os sistemas estudados, ao invés de ter sido utilizado como uma técnica preliminar de investigação.

Esse experimento foi realizado de acordo com Berry et al. e STAHLY (BERRY et al., 2008; STAHLY, 2009). Para isso, num sistema lâmina/lamela, fundiu-se a NA e deixou-se solidificar à temperatura ambiente. Em seguida, fundiu-se o CET, de modo que o mesmo, na fase líquida, entrasse em contato com a NA solidificada. Esse sistema foi mantido dentro de um dessecador à temperatura ambiente por cerca de 30 dias, tempo suficiente para que o CET cristalizasse. Após esse período, o comportamento térmico desse sistema foi analisado através de experimentos de PLTM. 


\section{RESULTADOS E DISCUSSÕES}

\subsection{Caracterização do cetoprofeno}

\subsubsection{Determinação da temperatura de fusão}

Cinco amostras de cetoprofeno puro foram analisadas pela técnica de DSC. A razão de aquecimento utilizada foi de $2{ }^{\circ} \mathrm{C} \mathrm{min}^{-1}$, com um intervalo de temperatura de $40-110{ }^{\circ} \mathrm{C}$.

As temperaturas de fusão ( $T_{\text {onset }}$ e $T_{p i c o}$ ), o valor médio, os desvios-padrão para cada amostra analisada e as curvas de DSC obtidas estão apresentadas na Tabela 2 e na Figura 10, respectivamente.

Tabela 2 - Temperaturas de fusão de amostras de cetoprofeno puro.

\begin{tabular}{cccc}
\hline Amostra & Massa $/ \mathrm{g}$ & $T_{\text {onset }} /{ }^{\circ} \mathrm{C}$ & $T_{\text {pico }} /{ }^{\circ} \mathrm{C}$ \\
\hline 1 & 0,0020 & 93,21 & 94,17 \\
2 & 0,0019 & 93,35 & 94,16 \\
3 & 0,0022 & 93,30 & 94,18 \\
4 & 0,0020 & 93,39 & 94,16 \\
5 & 0,0020 & 93,29 & 94,23 \\
Média & 0,0020 & 93,31 & 94,18 \\
Desvpad & $\pm 0,00$ & $\pm 0,06$ & $\pm 0,03$ \\
\hline
\end{tabular}


Figura 10 - Curvas de DSC de amostras de cetoprofeno. Atmosfera de $\mathrm{N}_{2}$, razão de aquecimento $2{ }^{\circ} \mathrm{C} \min ^{-1} \mathrm{e}$ massas de $2 \mathrm{mg}$, aproximadamente.

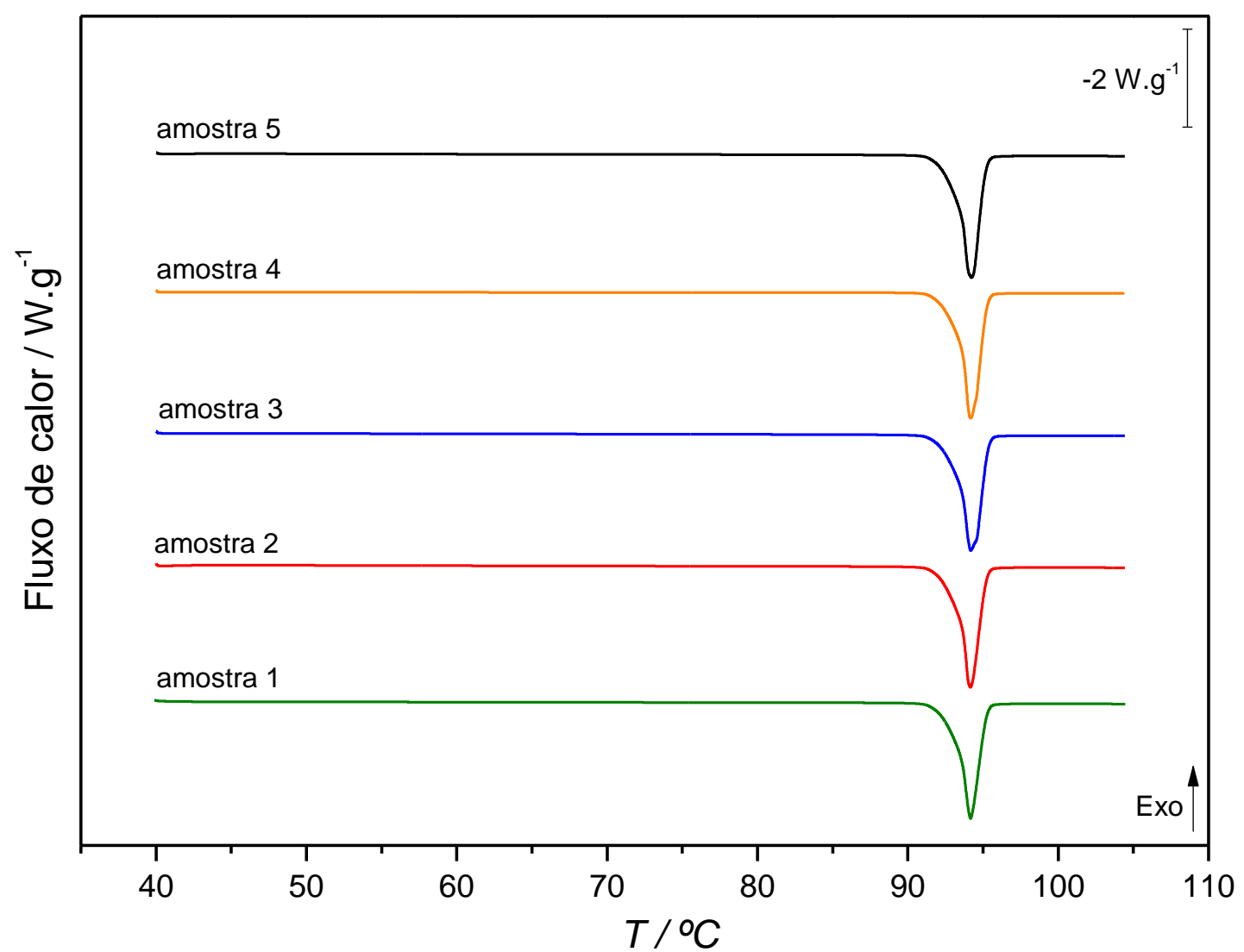

O valor do desvio-padrão para as temperaturas de pico $\left(T_{\text {pico }}\right)$ mostrados na Tabela 2 foi de $2,92 \%$. Dessa forma, pode-se adotar o valor médio de $94,18^{\circ} \mathrm{C}$ como sendo o valor correto para a temperatura de fusão do cetoprofeno puro. Esse valor está de acordo com o valor encontrado na literatura (LIVERSIDGE, 1984; MILES, 2008; The Merck Index: an encyclopedia of chemicals, drugs, and biologicals, 2001) e condiz com a posição dos picos de fusão mostrados na Figura 10.

Entretanto, devido ao fato de a temperatura de pico ser altamente dependente de fatores como cristalinidade da amostra, tamanho do cristal, razão de aquecimento, etc., faz com que esse parâmetro tenha uma confiança reduzida para efeito de comparações. Por outro lado, a temperatura onset ( $\left.T_{\text {onset }}\right)$, definida como uma intersecção entre a tangente do pico de fusão e a extrapolação da linha de base, permanece inalterada mesmo quando ocorram variações na temperatura de pico. Por essa razão, esse parâmetro apresenta maior confiabilidade e deve, portanto, ser utilizado para efeito de comparações (WENDLANDT, 1986).

Como o valor do desvio-padrão para as temperaturas onset $\left(T_{\text {onset }}\right)$ mostrados na Tabela 2 foi de $6,80 \%$. pode-se adotar o valor médio de $93,31^{\circ} \mathrm{C}$ como sendo o valor correto para a temperatura de fusão do cetoprofeno puro para efeito de comparações. 


\subsubsection{Difratometria de raios $X$ pelo método do pó}

A possibilidade de um fármaco ou co-formador apresentar polimorfismo permite um aumento na capacidade de formação de cocristais, devido a uma maior flexibilidade dos síntons moleculares presentes nas moléculas do fármaco ou co-formador (CASTRO et al., 2011).

Como o cetoprofeno pode se apresentar sob duas formas polimórficas distintas (LIVERSIDGE, 1984), torna-se necessário verificar se durante o processo de moagem ocorre alguma transição entre essas duas formas polimórficas. Essa verificação é importante porque polimorfos com estruturas cristalinas diferentes podem induzir a formação de cocristais com estruturas cristalinas distintas entre si (ÉVORA et al., 2011).

Assim sendo, quatro amostras de cetoprofeno puro foram moídas num moinho vibratório, modelo MM400 da Retsch. As condições de moagem encontram-se apresentadas na Tabela 3.

Tabela 3 - Condições de moagem de amostras de cetoprofeno puro

\begin{tabular}{ccccc}
\hline Amostra & Massa / g & $\begin{array}{c}\text { Tempo de moagem / } \\
\text { min. }\end{array}$ & Frequência / Hz & $\begin{array}{c}\text { Esferas } \\
\text { utilizadas }\end{array}$ \\
\hline 1 & 0,0500 & 30 & 30 & 1 \\
2 & 0,0502 & 30 & 15 & 2 \\
3 & 0,0506 & 45 & 30 & 2 \\
4 & 0,0500 & 60 & 30 & 2 \\
\hline
\end{tabular}

Após as moagens, cada amostra foi analisada por difração de raios $\mathrm{X}$ pelo método do pó. Os difratogramas obtidos estão representados na Figura 11. 
Figura 11 - Difratogramas de raios X das amostras de cetoprofeno.

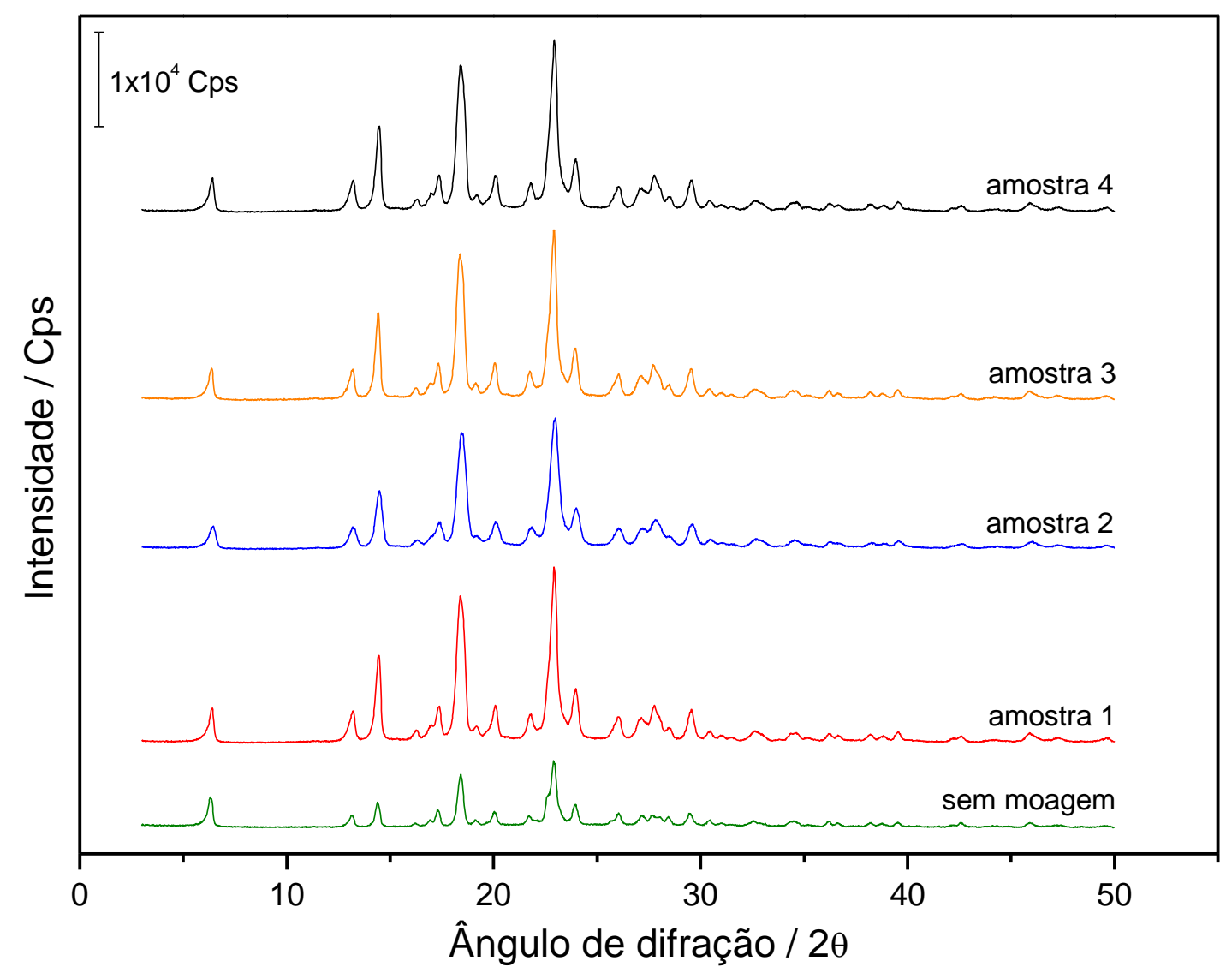

Através da comparação dos difratogramas da Figura 11 com os dados da Tabela 3, podese perceber que as variações de tempo de moagem e do número de esferas utilizadas não provocam alterações na estrutura cristalina dos compostos moídos em relação ao cetoprofeno puro (sem moagem), já que não existem deslocamentos nas posições dos picos de difração. Isso significa que cetoprofeno não sofre transição polimórfica durante o processo de moagem. Dessa forma, qualquer uma das condições de moagem apresentadas na Tabela 3 poderá ser adotada para a síntese de cocristais por processo mecanoquímico.

A literatura mostra que as condições de moagem são empíricas (ÉVORA et al., 2011; REHDER, 2011). Assim sendo, foi adotada a seguinte condição para todos os experimentos realizados:

- Jarro: Aço inox, capacidade máxima $10 \mathrm{~mL}$

- Frequência: $30 \mathrm{~Hz}$

- Tempo de moagem: 15 min.

- Número de esferas: 2 


\subsubsection{Estudo do comportamento térmico do cetoprofeno por PLTM.}

A Figura 12 mostra o comportamento térmico do cetoprofeno quando submetido ao aquecimento, através da técnica de PLTM. Nesse experimento, uma amostra de cetoprofeno puro foi aquecida de 25 a $100{ }^{\circ} \mathrm{C}$, a uma razão de $5{ }^{\circ} \mathrm{C} / \mathrm{min}$, em atmosfera de nitrogênio. É possível verificar que a sua fusão começa em $94,2{ }^{\circ} \mathrm{C}$, e termina entre 95,6 e $96,4{ }^{\circ} \mathrm{C}$. A ocorrência desse evento térmico também pode ser constatada através do pico endotérmico, mostrado no ciclo 1 da Figura 15. Numa segunda etapa, realizou-se o resfriamento dessa amostra, de 100 a $-110^{\circ} \mathrm{C}$, a uma razão de $-5^{\circ} \mathrm{C} / \mathrm{min}$, em atmosfera de nitrogênio (Figura 13). O segundo ciclo da Figura 15 mostra que o CET está no estado líquido a $25^{\circ} \mathrm{C}$, e que um pouco abaixo de $0^{\circ} \mathrm{C}$ sofre uma pequena transição vítrea, passando, assim, para o estado vítreo. Entretanto, não é possível fazer uma distinção clara entre esses dois estados, pois devido à elevada proximidade entre os valores dos índices de refração do líquido e do vidro, as imagens da Figura 13 são idênticas entre si para esses dois estados. Contudo, nessa Figura, pode-se verificar que em $-104,8^{\circ} \mathrm{C}$ ocorre o aparecimento de trincas, provando que o CET encontra-se no estado vítreo. O terceiro ciclo da Figura 15 e as imagens da Figura 14 mostram que o CET permanece no estado vítreo até $0^{\circ} \mathrm{C}$. Nessa temperatura, o mesmo sofre uma transição vítrea (passa novamente para o estado líquido) e, nas condições experimentais adotadas $\left(5^{\circ} \mathrm{C} / \mathrm{min}\right.$, atmosfera $\mathrm{N}_{2}$ ), não sofre cristalização durante o processo de aquecimento. 
Figura 12 - CET $1^{\circ}$ aquecimento $\left(5^{\circ} \mathrm{C} / \mathrm{min}\right.$, atmosfera $\mathrm{N}_{2}$, aumento 200X)

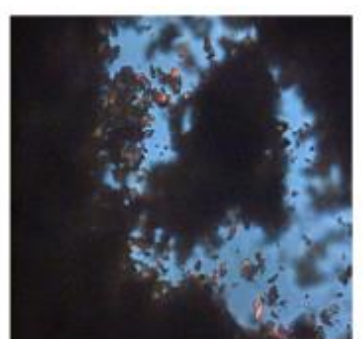

$25^{\circ} \mathrm{C}$

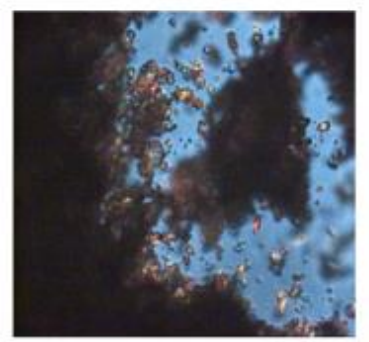

$94,2^{\circ} \mathrm{C}$

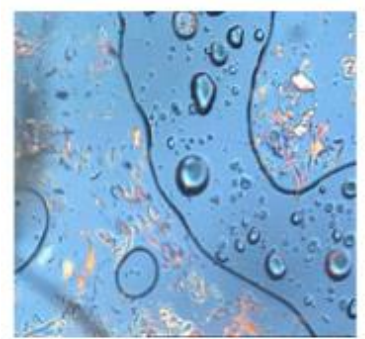

$95.6^{\circ} \mathrm{C}$

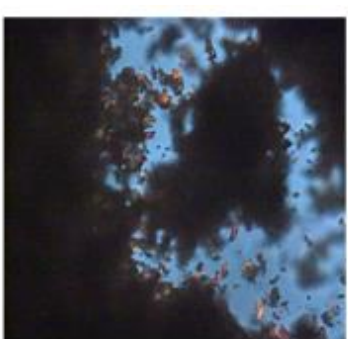

$50^{\circ} \mathrm{C}$

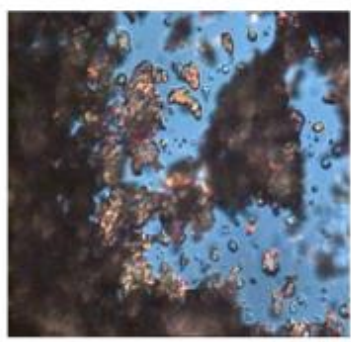

$94,5^{\circ} \mathrm{C}$

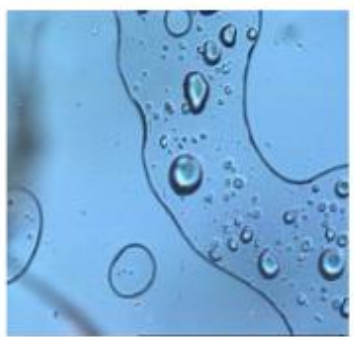

$96,4^{\circ} \mathrm{C}$

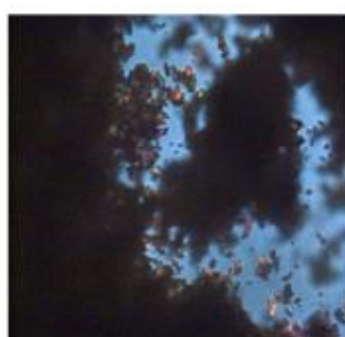

$75^{\circ} \mathrm{C}$

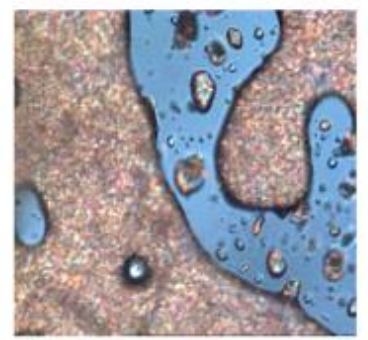

$94,9^{\circ} \mathrm{C}$

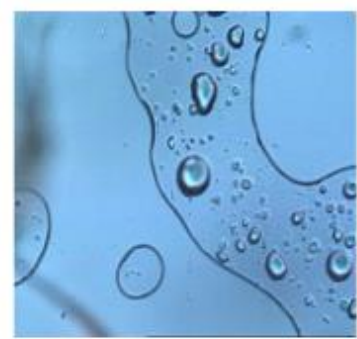

$96,8{ }^{\circ} \mathrm{C}$

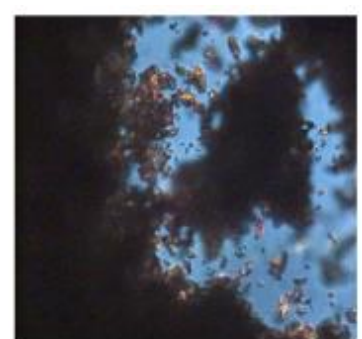

$93,9^{\circ} \mathrm{C}$

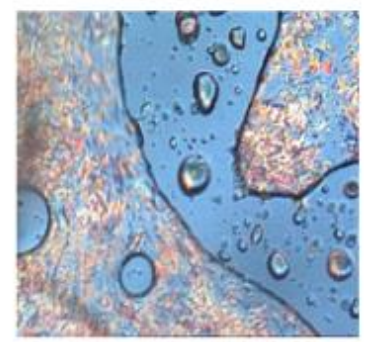

$95,2^{\circ} \mathrm{C}$

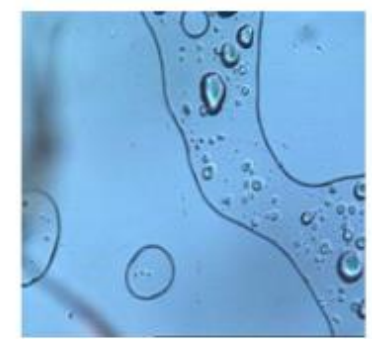

$100^{\circ} \mathrm{C}$ 
Figura 13 - CET $1^{\circ}$ resfriamento $\left(-5^{\circ} \mathrm{C} / \mathrm{min}\right.$, atmosfera $\mathrm{N}_{2}$, aumento $\left.200 \mathrm{X}\right)$

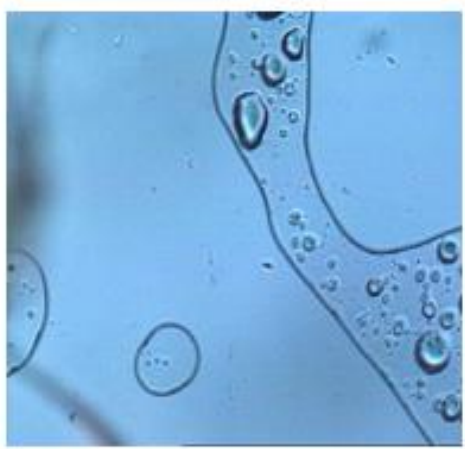

$75^{\circ} \mathrm{C}$

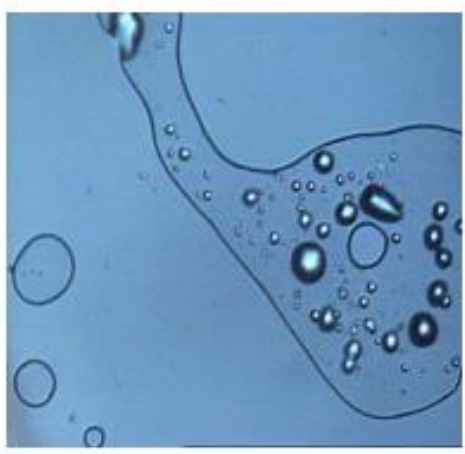

$-65^{\circ} \mathrm{C}$

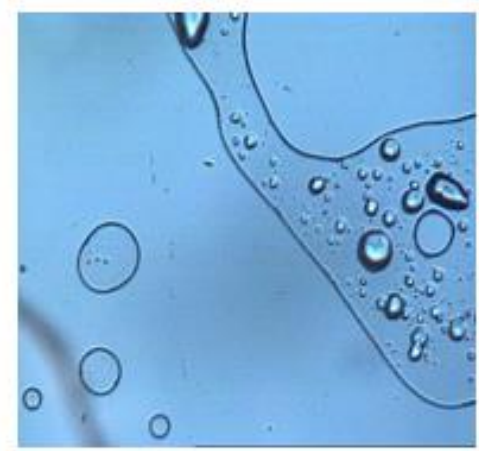

$25^{\circ} \mathrm{C}$

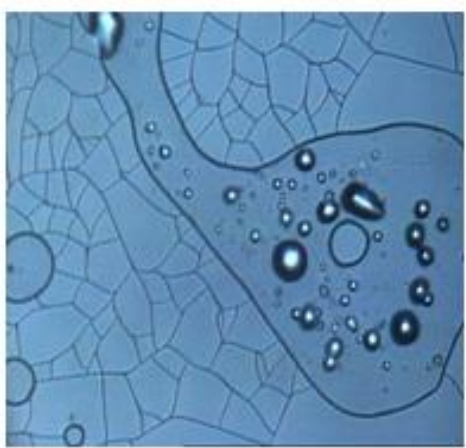

$-104,8{ }^{\circ} \mathrm{C}$

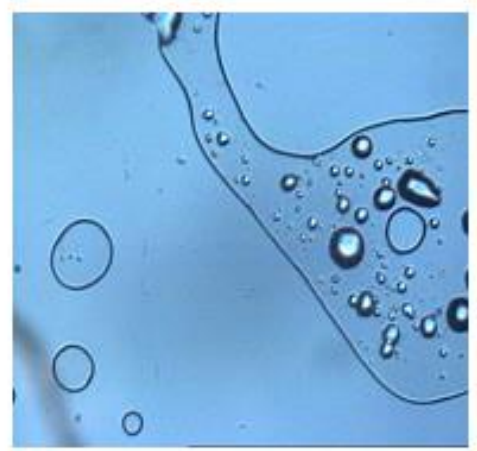

$0{ }^{\circ} \mathrm{C}$

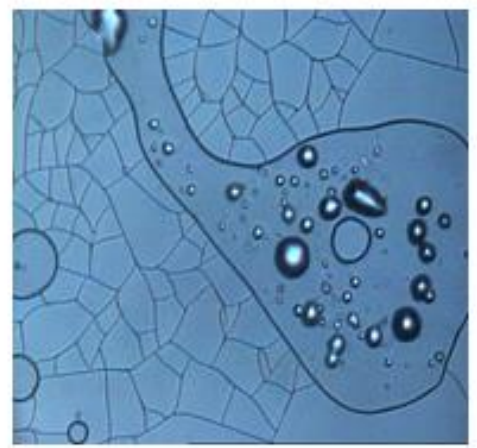

$-110^{\circ} \mathrm{C}$

Figura 14 - CET $2^{\circ}$ aquecimento $\left(5^{\circ} \mathrm{C} / \mathrm{min}\right.$, atmosfera $\mathrm{N}_{2}$, aumento $200 \mathrm{X}$

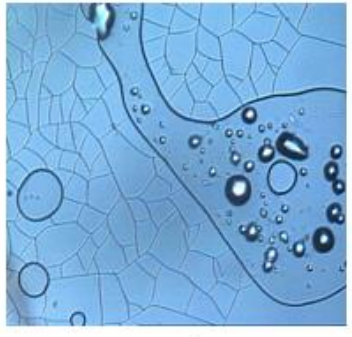

$-50{ }^{\circ} \mathrm{C}$

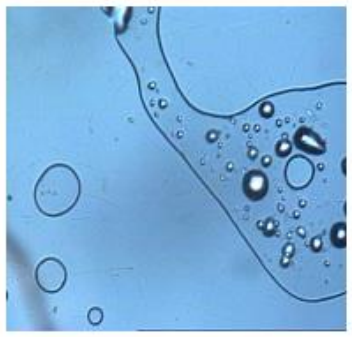

$4,1^{\circ} \mathrm{C}$

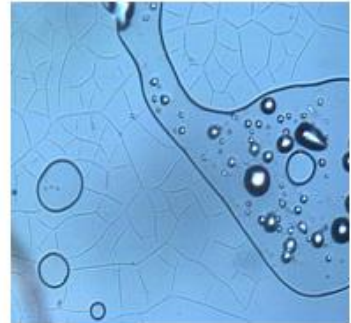

$-1{ }^{\circ} \mathrm{C}$

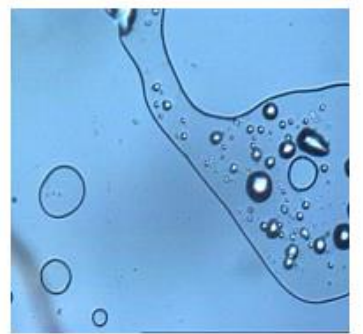

$5,8^{\circ} \mathrm{C}$

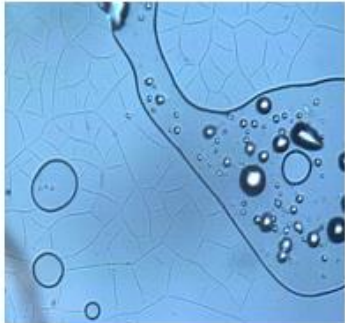

$0{ }^{\circ} \mathrm{C}$

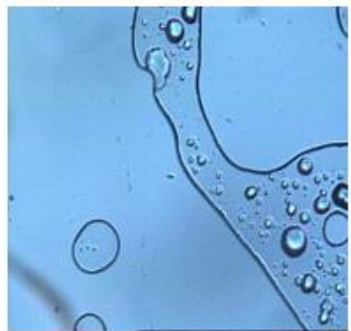

$25^{\circ} \mathrm{C}$

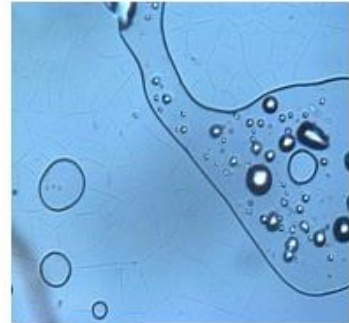

$3,2^{\circ} \mathrm{C}$

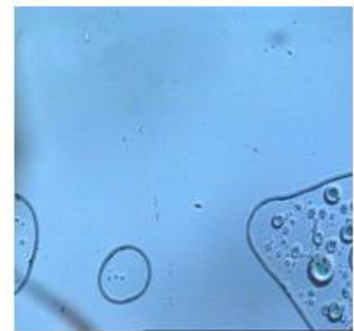

$75^{\circ} \mathrm{C}$ 
Figura 15 - DSC cíclico do cetoprofeno $\left(2,500 \mathrm{mg}, 5^{\circ} \mathrm{C} / \mathrm{min}\right.$ (aq. e resf.), atmosfera $\mathrm{N}_{2}$, cadinho de alumínio selado)

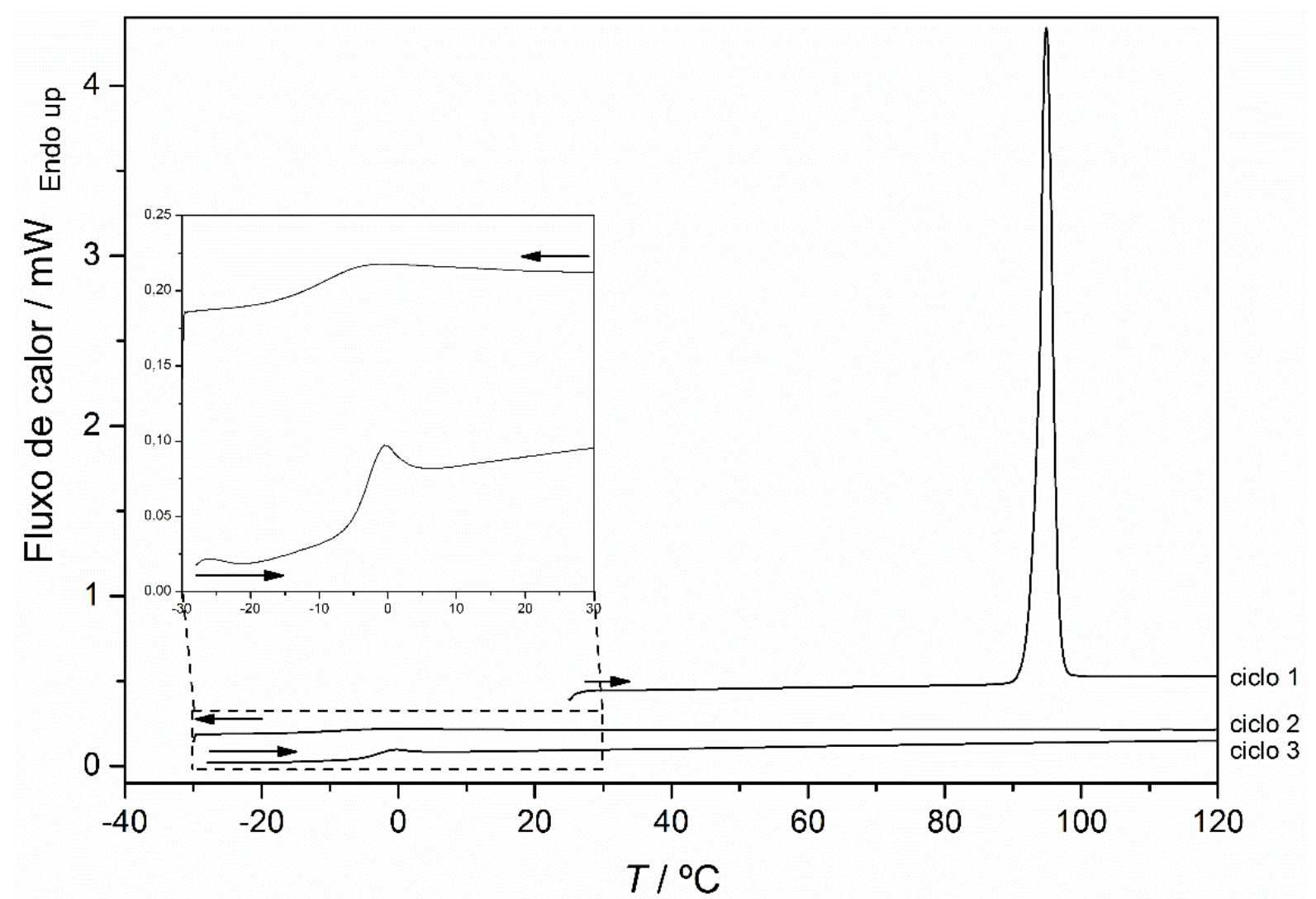

Dessa forma, a análise do comportamento térmico do cetoprofeno possibilita as seguintes observações: Abaixo de $0{ }^{\circ} \mathrm{C}$, o CET é um vidro (trinca a $-104,8^{\circ} \mathrm{C}$ ). À medida que a temperatura aumenta, o CET absorve energia térmica, passando para o estado líquido a $0{ }^{\circ} \mathrm{C}$. A partir desse ponto, com aumento da temperatura, o seu comportamento térmico segue pela linha do líquido, podendo, eventualmente, descer para a linha do sólido (ocorrência de cristalização com posterior fusão), ou permanecer no estado líquido até à temperatura de fusão do sólido. Essas observações estão ilustradas na Figura 16. 
Figura 16 - Diagrama de fases (Energia livre de Gibbs em função da temperatura) hipotético do cetoprofeno.

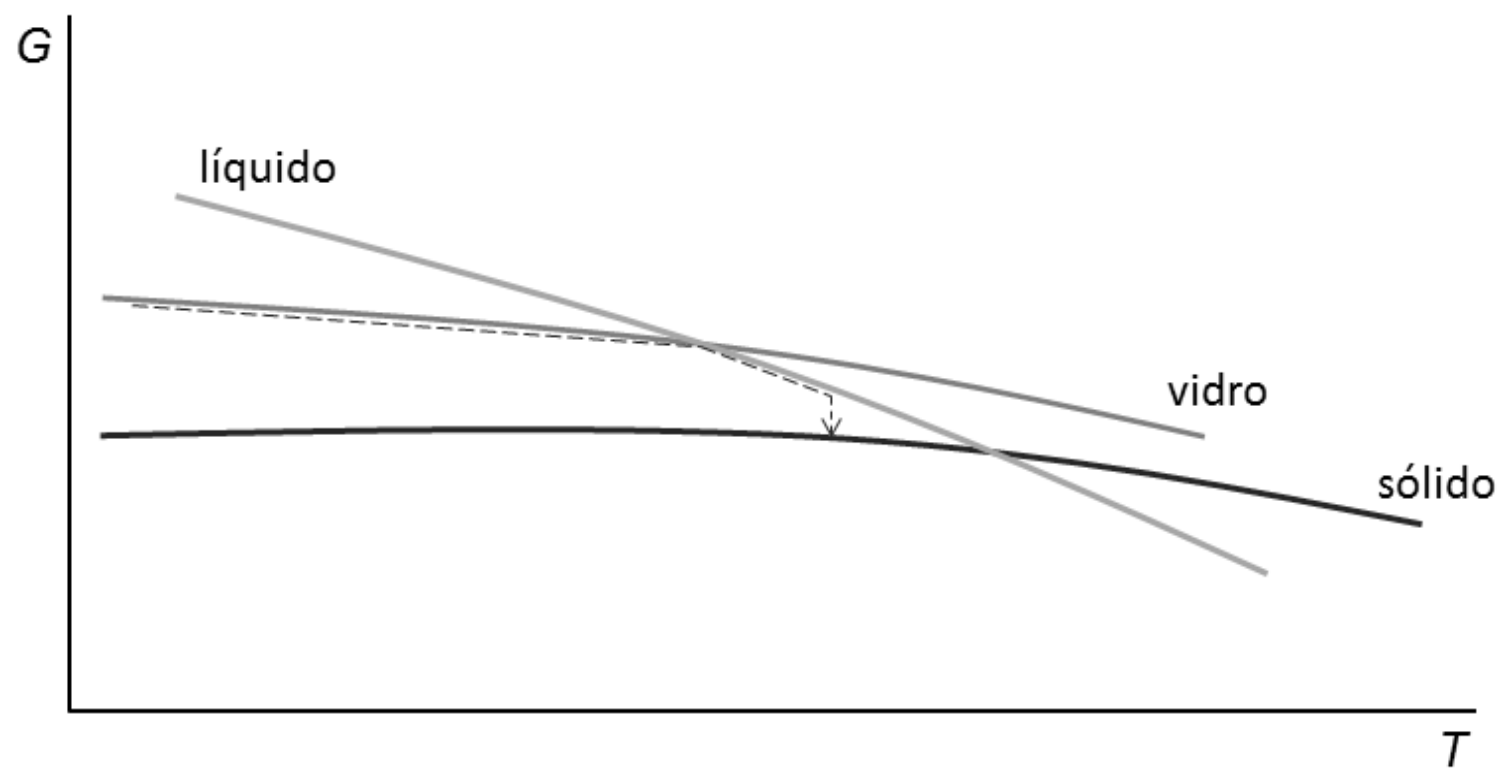

\subsection{Caracterização dos sistemas estudados}

\subsubsection{Sistema cetoprofeno (CET) : Benzamida (BA)}

A benzamida apresenta-se na forma sólida como um pó branco, possui variações polimórficas (BLAGDEN et al., 2005; DAVID et al., 2005; ECTORS; ZAHN, 2013) e pode ser usada para a síntese de cocristais (BRITTAIN, 2009; ELBAGERMA et al., 2010; SEATON; PARKIN, 2011).

As curvas TG e DTA da benzamida são mostradas na Figura 17. A curva TG mostra que a benzamida é estável até $100^{\circ} \mathrm{C}$, aproximadamente, quando se inicia o processo de fusão seguido de evaporação. Esses processos térmicos podem ser comprovados pelos dois picos endotérmicos que aparecem na curva DTA. Os picos em $124,19^{\circ} \mathrm{C}$ e $214,94{ }^{\circ} \mathrm{C}$ são atribuídos à fusão e à evaporação da benzamida, respectivamente. A curva DSC (Figura 18) mostra um pico endotérmico em $127,3{ }^{\circ} \mathrm{C}$ referente à fusão do composto, com $\Delta_{f u s} H=24,31 \mathrm{~kJ} \cdot \mathrm{mol}^{-1} \mathrm{e}$ pureza de $99,1 \%$ e um outro pico endotérmico em $258,4^{\circ} \mathrm{C}$ referente a evaporação do composto. Os picos observados na curva DSC estão de acordo com os da curva DTA. 
Figura 17 - Curva TG-DTA da benzamida pura: $\mathrm{m}_{\mathrm{i}}=5,8 \mathrm{mg}$, atmosfera de ar, razão de aquecimento 10

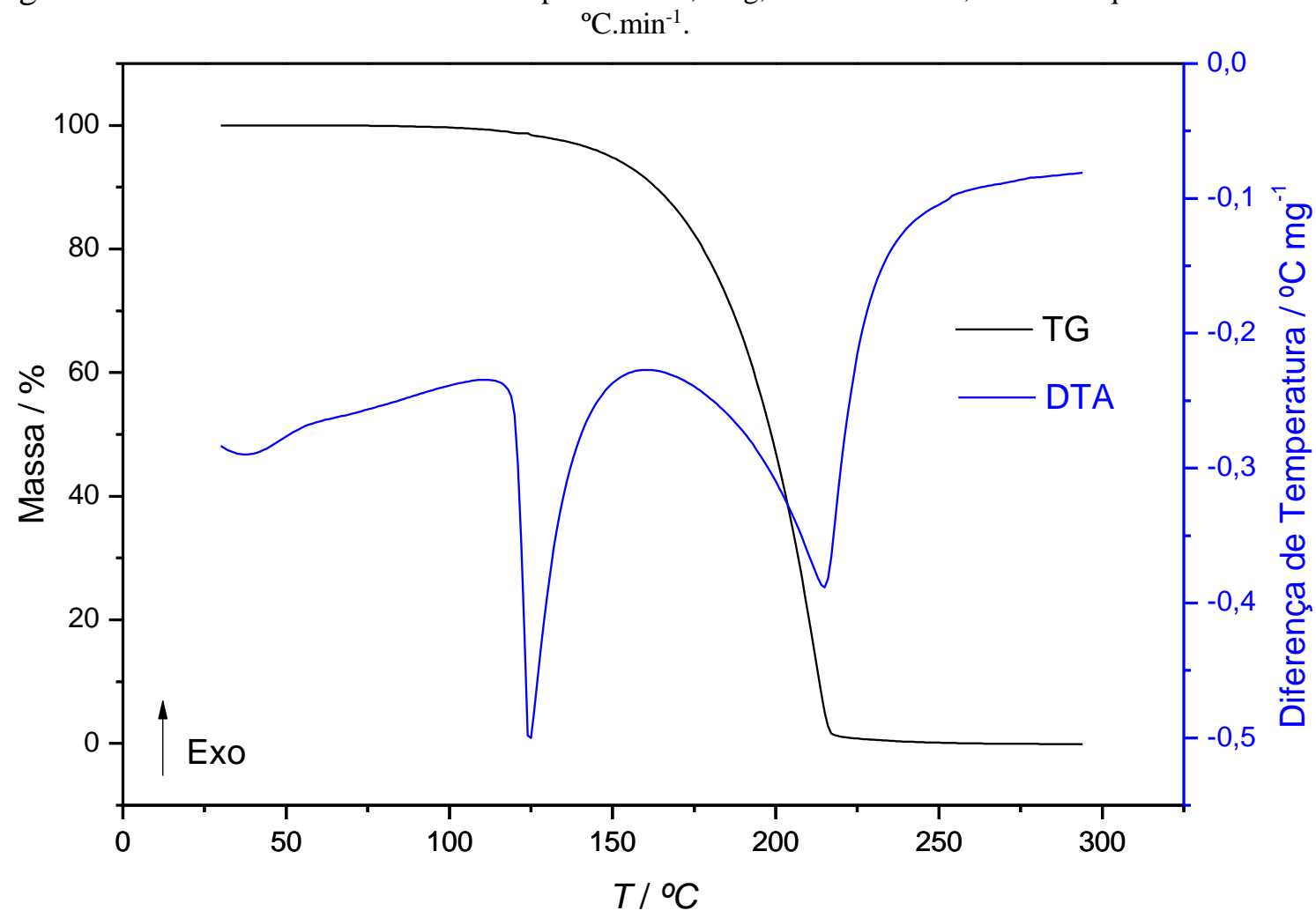


Figura 18 - Curva DSC da benzamida pura: $\mathrm{m}=2,2 \mathrm{mg}$, atmosfera de $\mathrm{N}_{2}$, razão de aquecimento $10^{\circ} \mathrm{C} \cdot \mathrm{min}^{-1}$.

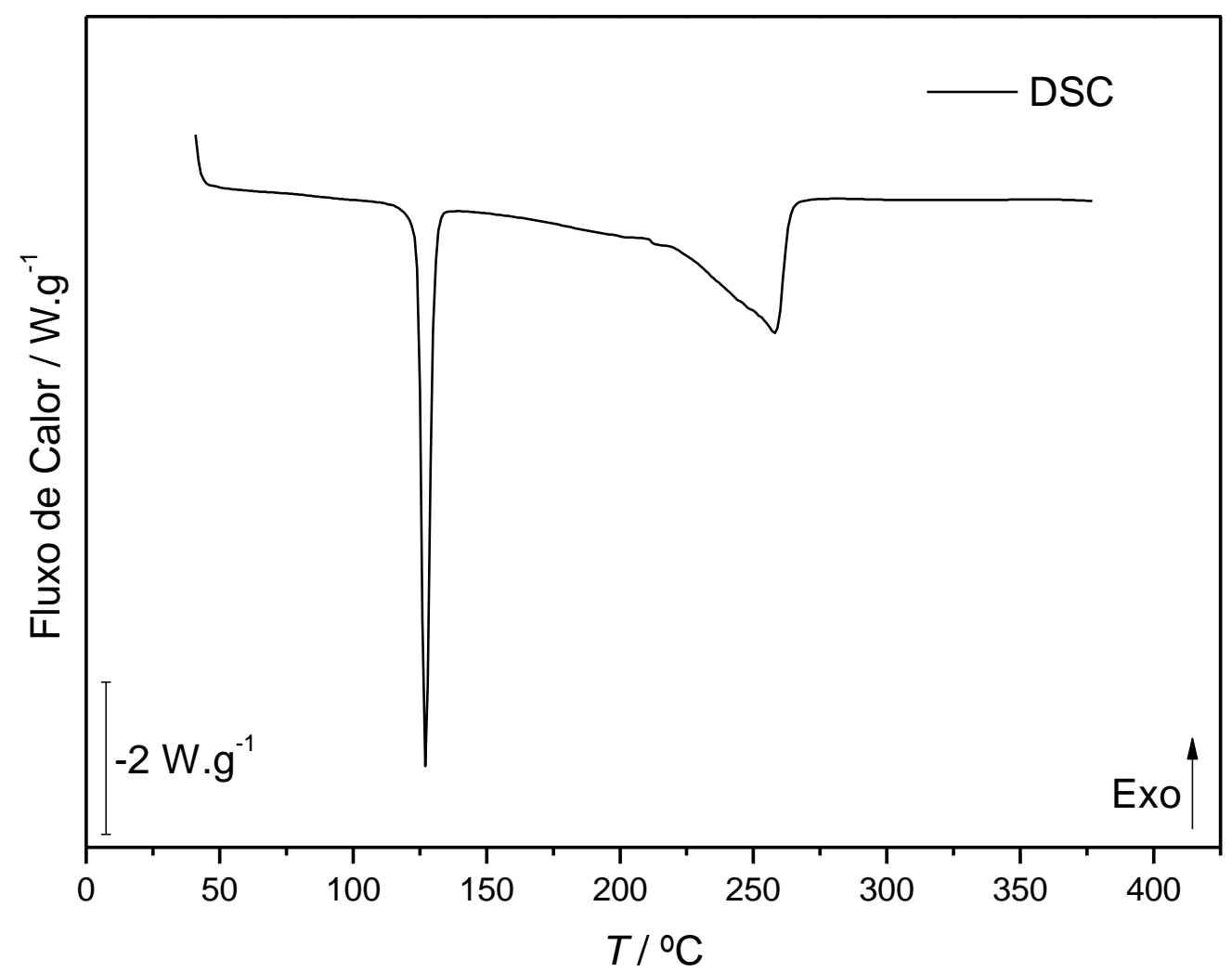

Apesar de a curva TG sugerir que a benzamida se decompõe em uma única etapa, comprovou-se, através de experimentos de FTIR, que, na verdade, ela evapora sem se decompor, conforme pode ser verificado através da análise da Figura 19, que mostra a comparação dos espectros de FTIR da benzamida pura e do sólido coletado após a fusão e evaporação da benzamida pura.

Esses resultados foram apresentados em congresso e também encontram-se publicados na forma de artigo (PERPÉTUO et al., 2014). 
Figura 19 - Espectros de FTIR: (a) Benzamida pura e (b) composto coletado após a fusão e evaporação da benzamida pura

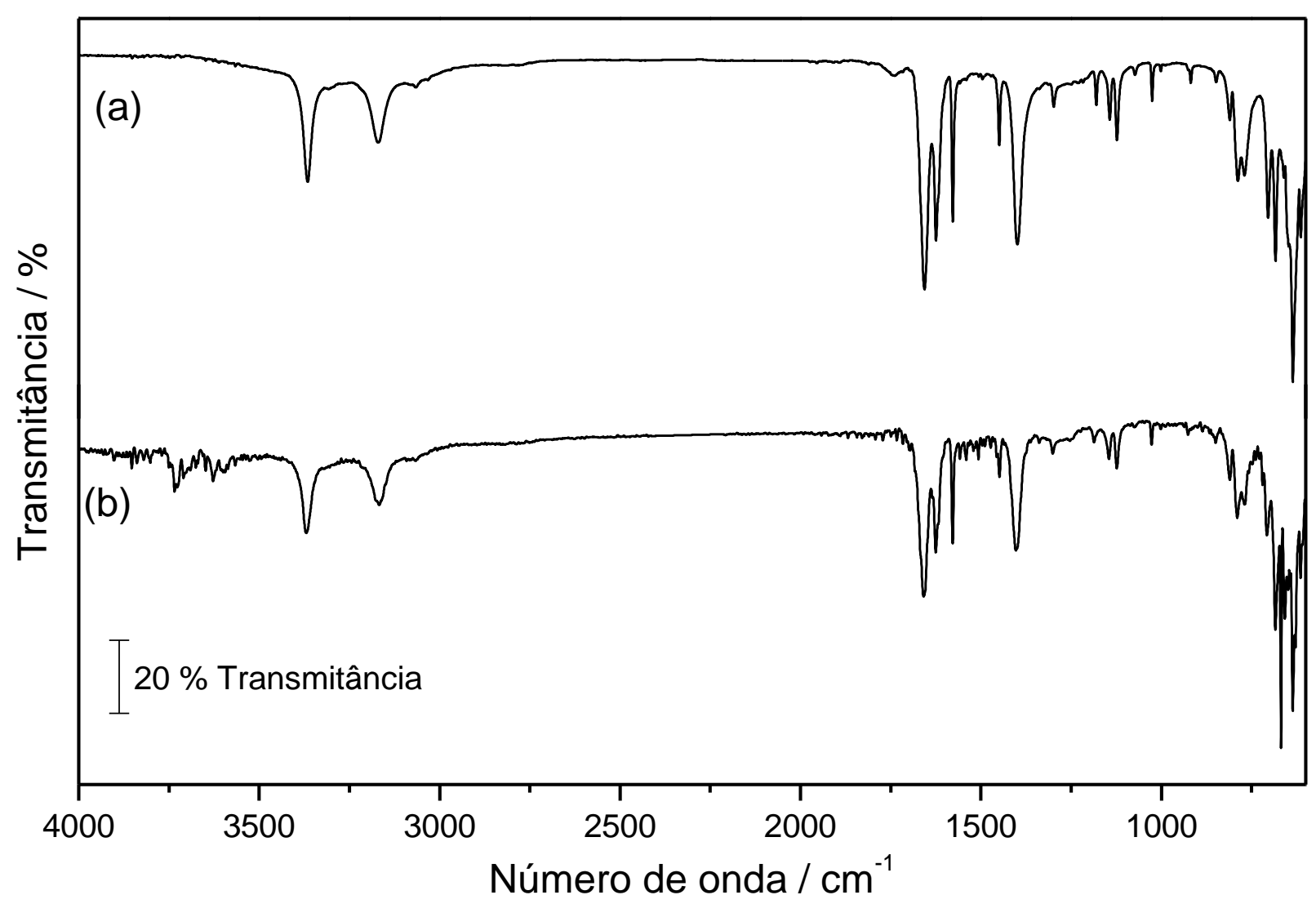

Devido ao fato da benzamida apresentar variações polimórficas, foi realizada uma investigação prévia para saber se o processo de moagem pode ocasionar alguma transição polimórfica. Para tanto, 0,5 g de benzamida pura foram moídas num moinho de bolas. Após a moagem, a amostra foi analisada por difração de raios X e o resultado obtido encontra-se apresentado na Figura 20. 
Figura 20 - Difratogramas de pó da benzamida pura (BA), benzamida pós-moagem (pm), e das simulações das suas formas polimórficas I e VI.

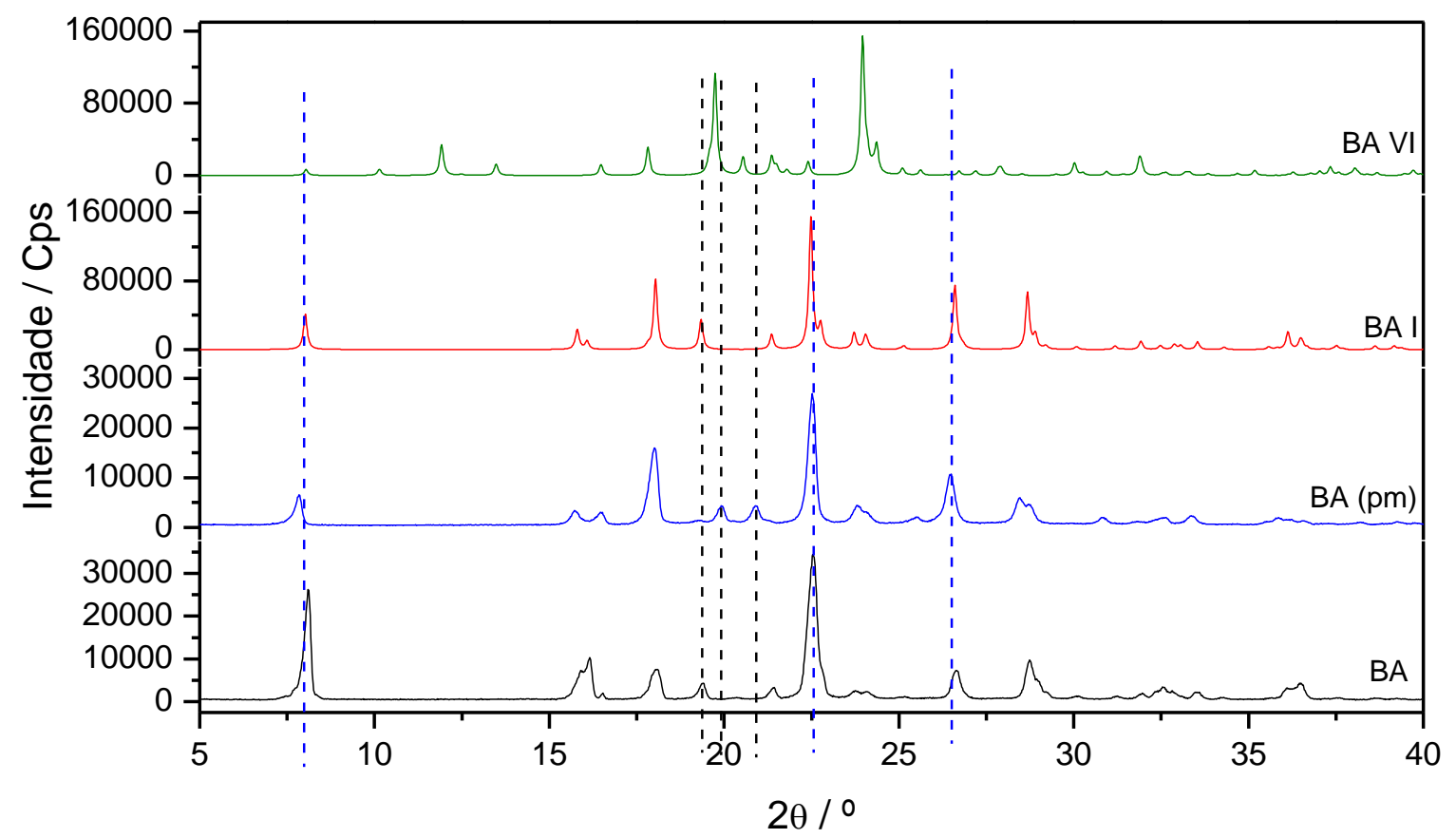

A análise da Figura 20 permite observar que as linhas pretas tracejadas indicam o surgimento de novos picos na BA (pm) e, também o desaparecimento de alguns picos que existiam antes da moagem. Entretanto, a comparação dos difratogramas da BA e da BA (pm) com aqueles simulados para as formas polimórficas I e VI, comprova que os principais picos dos difratogramas da $\mathrm{BA}$ e da $\mathrm{BA}(\mathrm{pm})$ pertencem à forma $\mathrm{I}$ da $\mathrm{BA}$, conforme pode ser verificado através das linhas tracejadas azuis.

Portanto, a condição de moagem adotada para a síntese de cocristais por processo mecanoquímico pode ser utilizada para esse co-formador, com a garantia de que não ocorrerá transição polimórfica durante o processo.

As curvas DSC do CET, da BA e da mistura CET : BA obtida através de moagem estão mostradas na Figura 21. Os parâmetros termodinâmicos encontram-se indicados na Tabela 4. 
Figura 21 - Curvas DSC dos componentes puros cetoprofeno, benzamida e da sua mistura (1:1) obtida por processo de moagem: $\mathrm{m} \sim 2 \mathrm{mg}$, atmosfera de $\mathrm{N}_{2}$, razão de aquecimento $10^{\circ} \mathrm{C} \cdot \mathrm{min}^{-1}$.

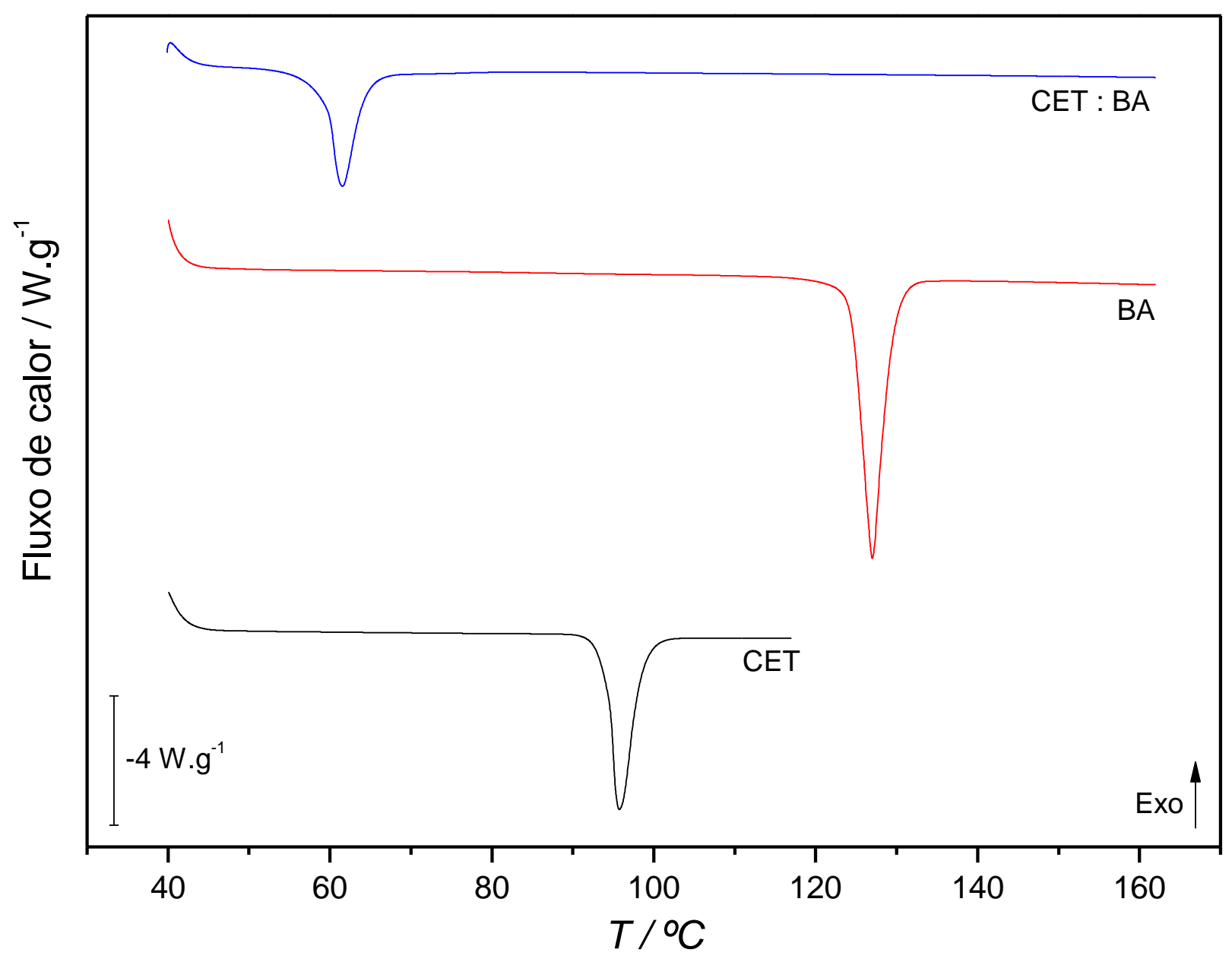

Tabela 4 - Parâmetros termodinâmicos das curvas DSC do primeiro aquecimento de CET, BA e CET:BA

\begin{tabular}{cccc}
\hline & $T_{\text {onset }} /{ }^{\circ} \mathrm{C}$ & $T_{\text {pico }} /{ }^{\circ} \mathrm{C}$ & $\Delta_{\text {fus }} H / \mathrm{kJ} \cdot \mathrm{mol}^{-1}$ \\
\hline CET & 94,22 & 95,73 & 30,54 \\
BA & 124,48 & 126,98 & 24,31 \\
CET : BA & 59,34 & 61,5 & 40,51 \\
\hline
\end{tabular}

A Figura 21 mostra que a mistura CET : BA funde a uma temperatura diferente daquela dos dois compostos isolados. Entretanto, o perfil da curva DSC indica que essa mistura pode ser um cocristal ou um composto eutético (GONSALVES; SERRA; EUSÉBIO, 2011). Dessa 
forma, as análises dos difratogramas de raios $\mathrm{X}$ e dos espectros de FTIR auxiliarão na identificação do tipo de composto que essa mistura constitui.

A Figura 22 mostra que o difratograma da mistura CET : BA corresponde à soma dos outros dois difratogramas, visto que as posições dos picos da mistura CET : BA coincidem com as posições dos picos do CET puro ou da BA pós-moagem. Pode-se, então, afirmar que nenhuma nova Figura de difração é formada e, dessa forma, é possível concluir que o composto em questão é um eutético.

Figura 22 - Difratogramas de pó da mistura CET : BA (1:1), obtida por moagem, do cetoprofeno puro e da benzamida pós-moagem $(\mathrm{pm})$.

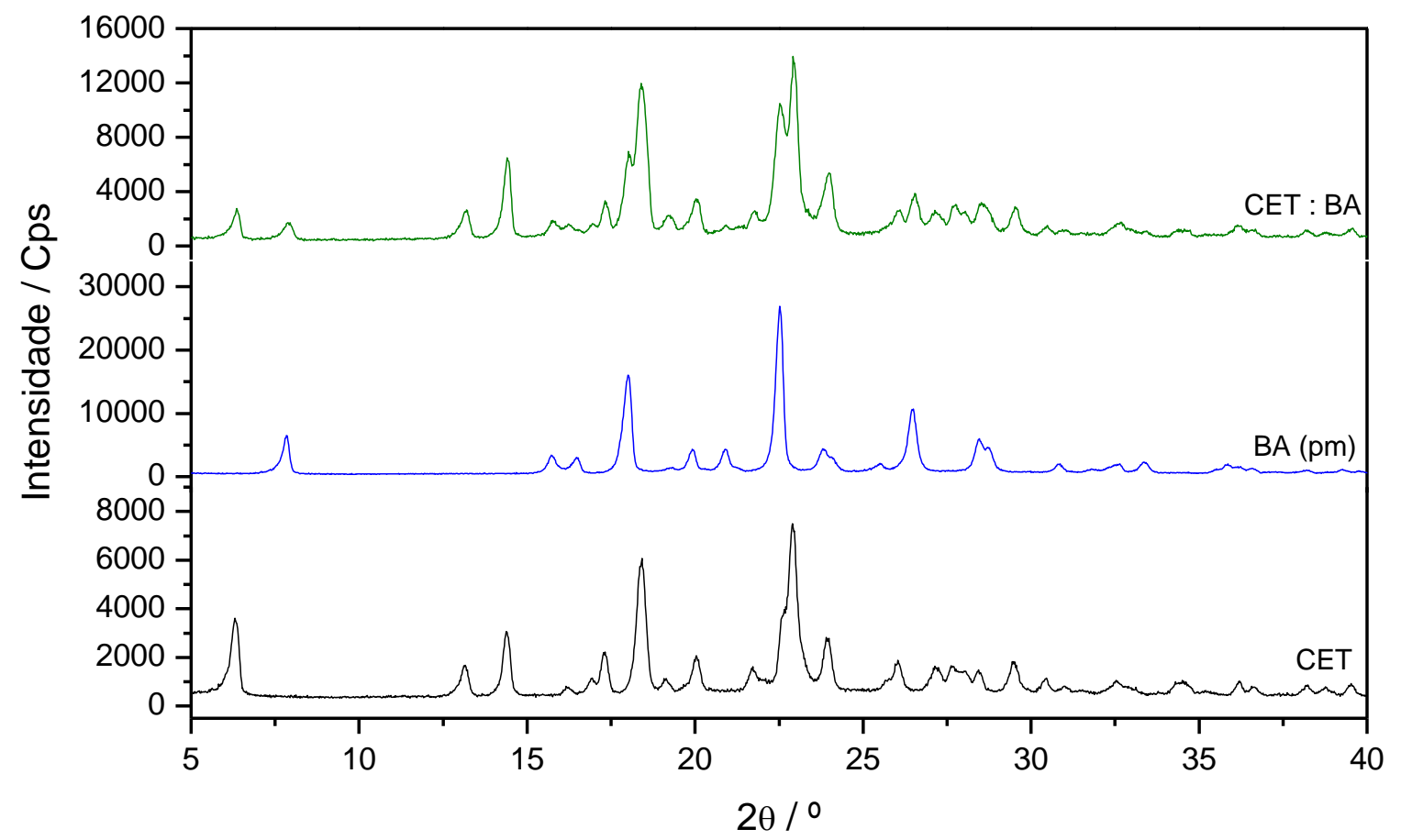

Experimentos de FTIR podem ser usados para identificar mudanças estruturais, especialmente aquelas que envolvem ligações de hidrogênio. Dessa forma, a técnica de FTIR torna-se uma ferramenta complementar bastante útil quando se deseja verificar se um sistema forma um cocristal ou um composto eutético.

Uma ligação de hidrogênio pode ocorrer em qualquer sistema que tenha um grupo doador de prótons $(\mathrm{X}-\mathrm{H})$ e um grupo aceptor de prótons $(\ddot{R})$, desde que o orbital $s$ do hidrogênio e orbitais $p$ ou $\pi$ do grupo aceptor interajam efetivamente entre si. Quando ocorre a formação de uma ligação hidrogênio, as bandas de deformação axial de $\mathrm{X}-\mathrm{H}$ deslocam-se para valores de menor frequência (maiores comprimentos de onda), sendo que esse deslocamento é 
proporcional à intensidade da interação entre os grupos doadores e aceptores de prótons (SILVERSTEIN; WEBSTER, 2000).

Quando ocorre a formação de um composto eutético, os compostos (API e co-formador) apenas se misturam fisicamente, sendo o ponto de fusão do eutético menor que o dos seus componentes isolados, como pode ser visto na Figura 21. Nesse caso, não se estabelecem ligações de hidrogênio entre os compostos, de modo que não ocorrem deslocamentos de bandas no espectro do composto obtido. No caso da formação de cocristal, ocorre o estabelecimento de ligações de hidrogênio entre o API e o co-formador, ocasionando deslocamentos de bandas no espectro do cocristal em relação aos espectros do API e co-formador (RIBEIRO, 2010).

Os espectros de FTIR da mistura CET : BA e dos compostos puros estão mostrados na Figura 23.

Figura 23 - Espectros de FTIR da mistura CET : BA (1:1), obtida por moagem, do cetoprofeno e da benzamida puros e o espectro soma (CET + BA) dos compostos puros

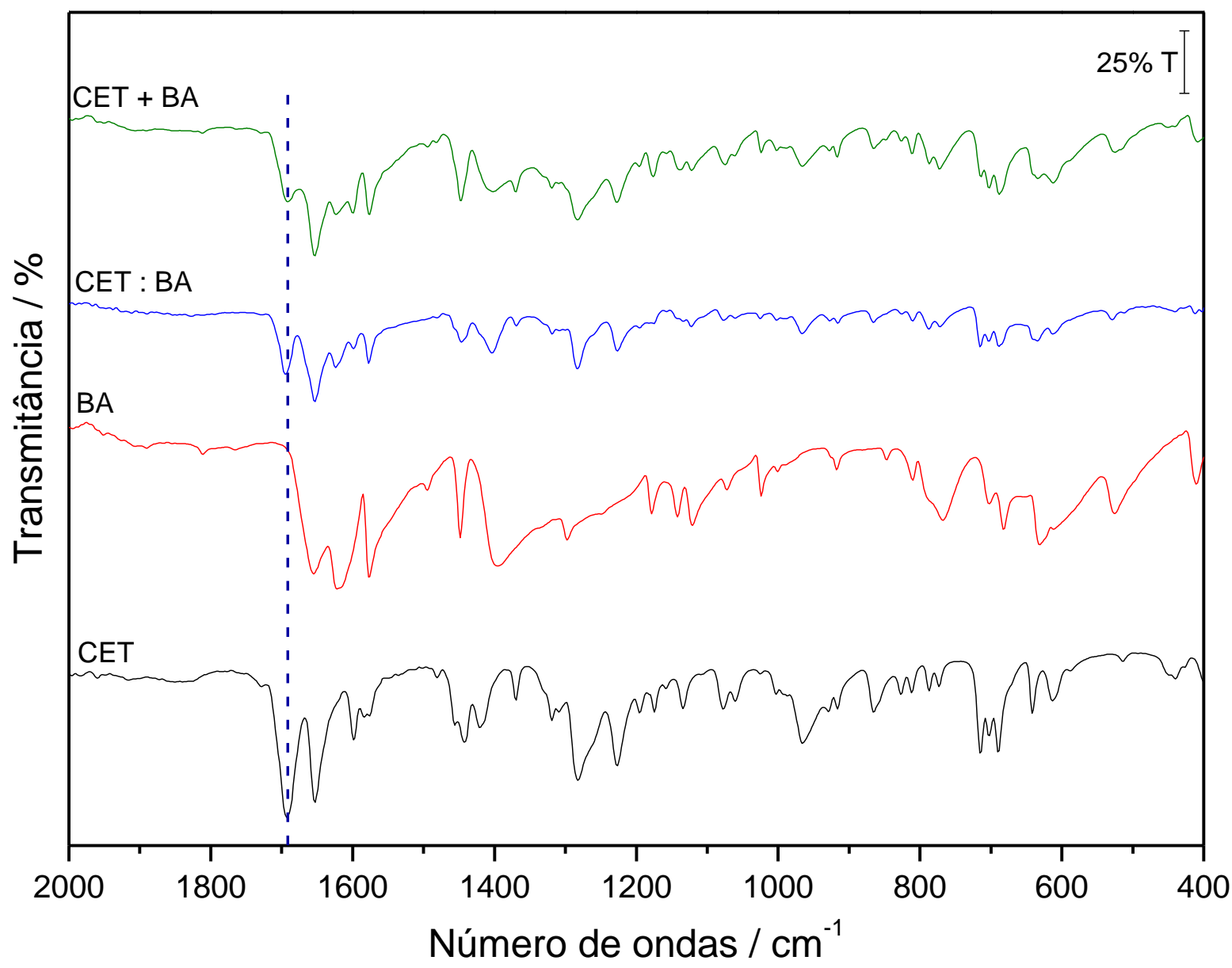


Através da análise da Figura 23 é possível verificar que na mistura CET : BA a banda $\mathrm{C}=\mathrm{O}$ do cetoprofeno não está deslocada em relação ao CET, visto que ambas se encontram a $1695,27 \mathrm{~cm}^{-1}$. Isso pode ver verificado pela observação através da linha pontilhada. Além disso, todas as demais bandas da mistura também não apresentaram deslocamentos com relação às bandas do CET e da BA, sendo que, nesse caso, o espectro de FTIR da mistura é idêntico à soma dos espectros do CET e da BA.

Assim sendo, como não ocorreram deslocamentos de bandas, fica evidenciado que houve apenas a formação do eutético, confirmando, assim, a informação obtida através das análises de raios $\mathrm{X}$.

\subsubsection{Sistema cetoprofeno (CET) : ácido benzóico (BZ)}

O ácido benzoico caracteriza-se como um pó branco, com massa molar igual a 122,12 g.mol ${ }^{-1}$ e ponto de fusão igual a $122,4{ }^{\circ} \mathrm{C}$. É altamente solúvel em acetona, benzeno, clorofórmio, etanol, éter etílico e metanol e praticamente insolúvel em água, apresentando variações polimórficas, de acordo com o solvente utilizado durante a cristalização (INDRAYANTO, 1999).

Como o ácido benzoico também pode apresentar variações polimórficas, 0,5 g desse composto puro foram moídas num moinho de bolas, com o objetivo de verificar se o processo de moagem pode ocasionar alguma transição polimórfica. Após a moagem, a amostra foi analisada por difração de raios $\mathrm{X}$ de pó e o resultado obtido encontra-se apresentado na Figura 24. 
Figura 24 - Difratogramas de pó do ácido benzoico pós-moagem (pm), e do ácido benzoico puro.

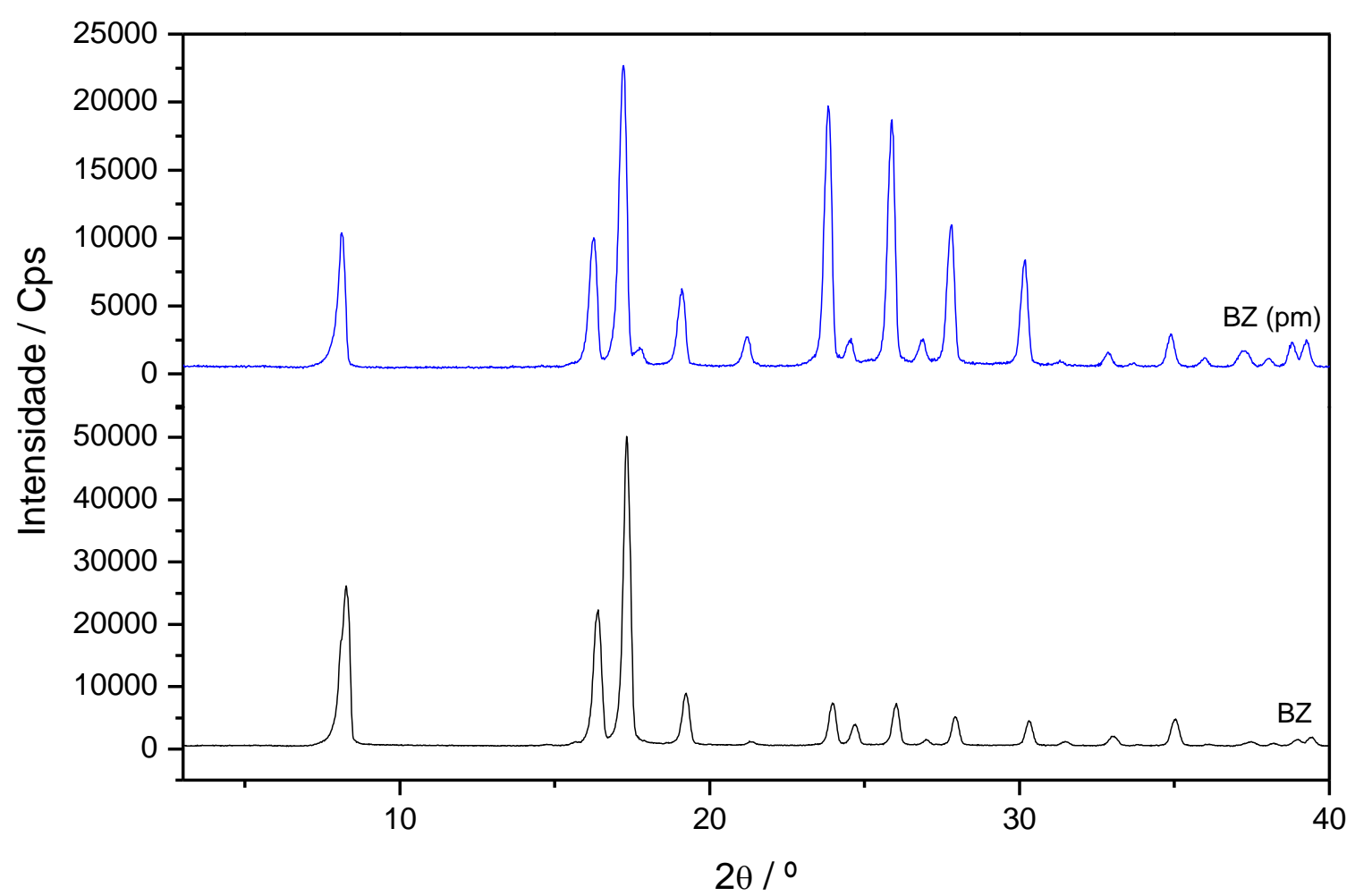

A Figura 24 mostra que o ácido benzoico não sofre transição polimórfica durante o processo de moagem, já que não existem deslocamentos nas posições dos picos de difração. Portanto, a condição de moagem adotada para a síntese de cocristais por processo mecanoquímico pode ser utilizada para esse co-formador, com a garantia de que não ocorrerá transição polimórfica durante o processo.

A Tabela 5 mostra os parâmetros termodinâmicos referentes às curvas DSC do CET, da BZ e da mistura CET : BZ (1:1), obtida através de moagem (Figura 25).

Tabela 5 - Parâmetros termodinâmicos das curvas DSC do primeiro aquecimento de CET, BZ e CET:BZ

\begin{tabular}{cccc}
\hline & $T_{\text {onset }} /{ }^{\circ} \mathrm{C}$ & $T_{\text {pico }} /{ }^{\circ} \mathrm{C}$ & $\Delta_{\text {fus }} H / \mathrm{kJ} \cdot \mathrm{mol}^{-1}$ \\
\hline CET & 94,22 & 95,73 & 30,54 \\
BZ & 121,89 & 123,89 & 22,21 \\
CET $:$ BZ & 69,23 & 71,13 & 44,23 \\
\hline
\end{tabular}


Figura 25 - Curvas DSC dos componentes puros cetoprofeno, ácido benzoico e da sua mistura (1:1) obtida por processo de moagem: $\mathrm{m} \sim 2 \mathrm{mg}$, atmosfera de $\mathrm{N}_{2}$, razão de aquecimento $10^{\circ} \mathrm{C} \cdot \mathrm{min}^{-1}$.

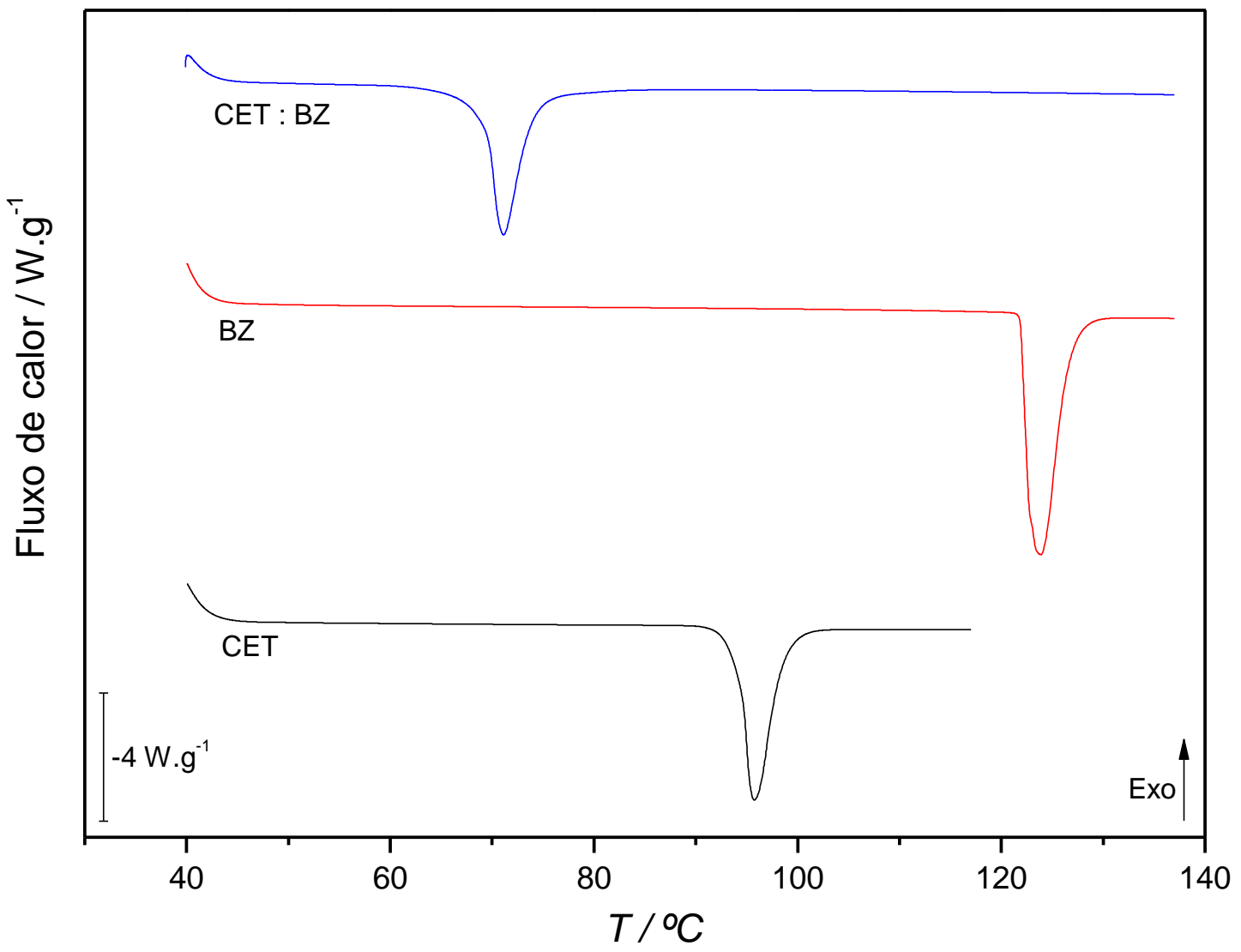

A Figura 25 mostra que a mistura CET : BA funde a uma temperatura diferente daquela dos dois compostos isolados. Entretanto, o perfil da curva DSC indica que essa mistura pode ser um cocristal ou um composto eutético (GONSALVES; SERRA; EUSÉBIO, 2011). Dessa forma, as análises dos difratogramas de raios $\mathrm{X}$ e dos espectros de FTIR auxiliarão na identificação do tipo de composto que essa mistura constitui.

A Figura 26 mostra que o difratograma da mistura CET : BZ corresponde à soma dos outros dois difratogramas, visto que as posições dos picos da mistura CET : BZ coincidem com as posições dos picos do CET ou da BZ puros. Pode-se, então, afirmar que nenhuma nova Figura de difração é formada e, dessa forma, é possível concluir que o composto em questão é um eutético. 
Figura 26 - Difratogramas de pó da mistura CET : BZ (1:1), obtida por moagem, e do cetoprofeno e do ácido benzoico puros.

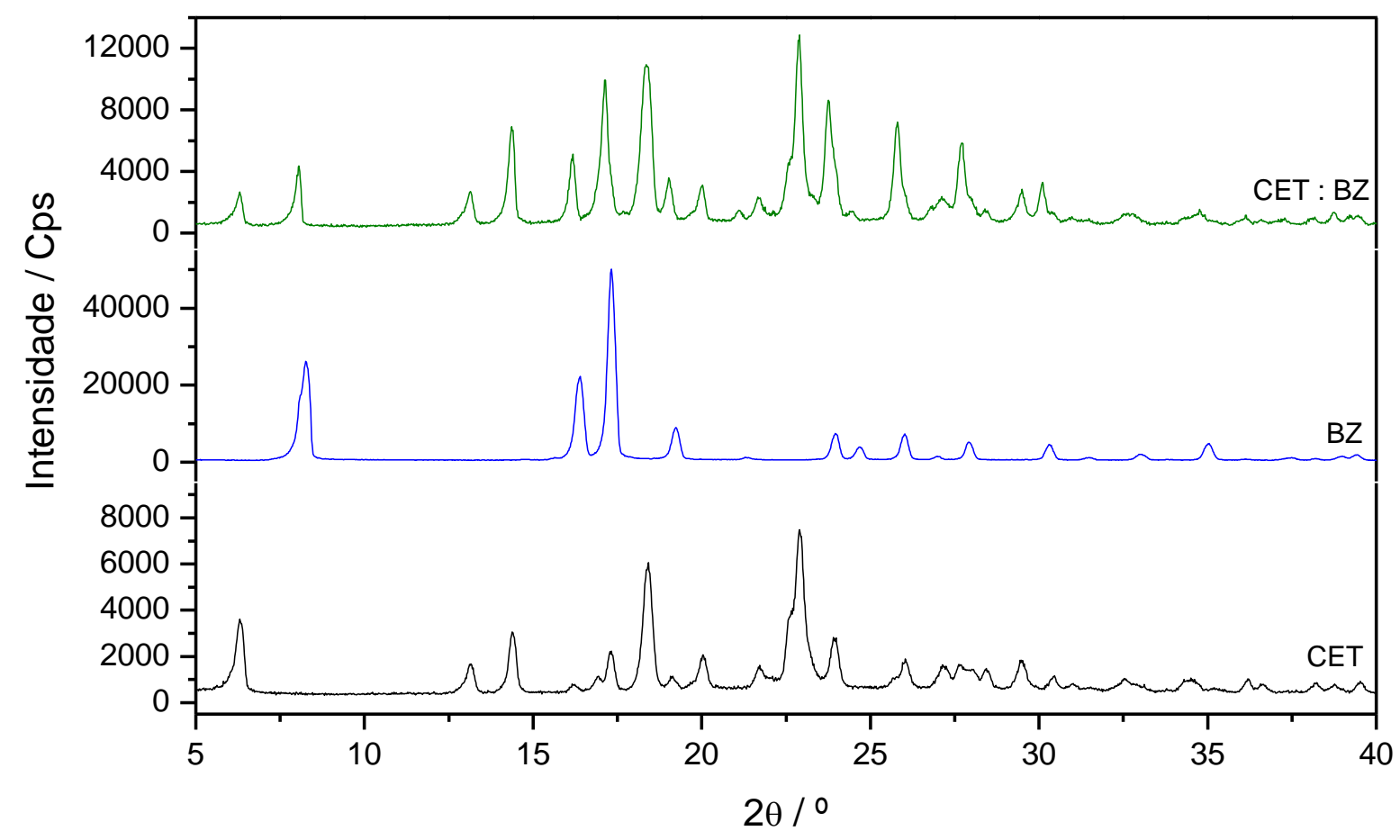

Figura 27 mostra os espectros de FTIR da mistura CET : BZ e dos compostos puros. 
Figura 27 - Espectros de FTIR da mistura CET : BZ (1:1), obtida por moagem, do cetoprofeno e do ácido benzoico puros e o espectro soma $(\mathrm{CET}+\mathrm{BZ})$ dos compostos puros.

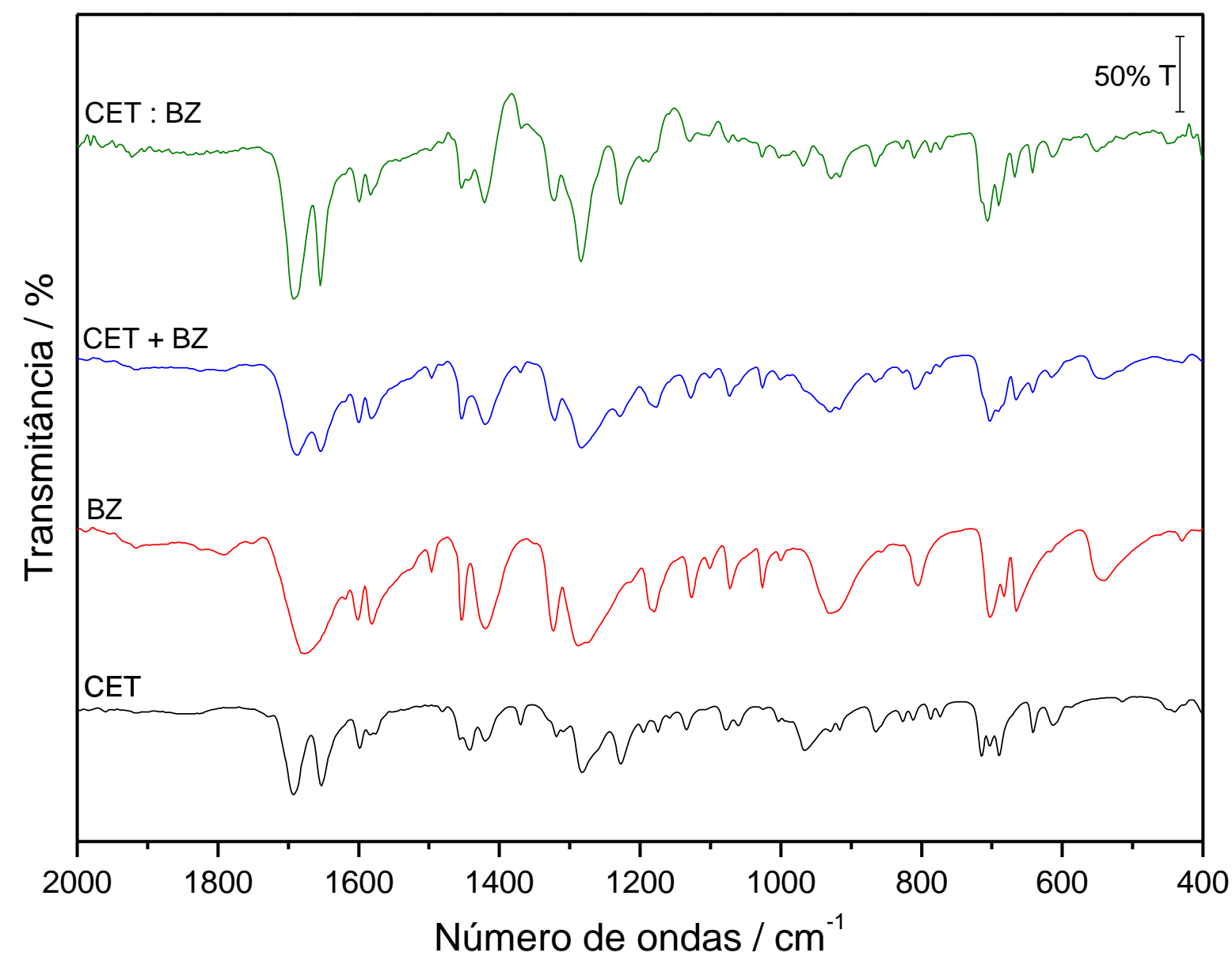

Através da análise da Figura 27 é possível verificar que na mistura CET : BZ a banda $\mathrm{C}=\mathrm{O}$ do cetoprofeno não está deslocada em relação ao CET, visto que ambas se encontram a $1691,41 \mathrm{~cm}^{-1}$. Além disso, todas as demais bandas da mistura também não apresentaram deslocamentos com relação às bandas do CET e BZ, sendo que, nesse caso, o espectro de FTIR da mistura é idêntico à soma dos espectros do CET e BZ.

Logo, como não ocorreram deslocamentos de bandas, fica evidenciado que houve somente a formação do eutético, confirmando, assim, a informação obtida através das análises de raios $X$.

\subsubsection{Sistema cetoprofeno (CET) : ácido salicílico (SA)}

O ácido salicílico caracteriza-se como um pó branco, com massa molar igual a 138,12 g.mol ${ }^{-1}$ e ponto de fusão igual a $157-159^{\circ} \mathrm{C}$, podendo apresentar-se, também, como cristais em 
forma de agulha, não apresentando indícios de polimorfismo. É altamente solúvel em acetona, clorofórmio, etanol, éter etílico e metanol e praticamente insolúvel em água (ABOUNASSIF, 1994).

Na Figura 28, encontram-se representados os resultados de DSC obtidos a partir do cetoprofeno e ácido salicílico puros (CET e SA) e da sua mistura CET : SA. Os parâmetros termodinâmicos referentes a essas curvas encontram-se apresentados na Tabela 6 .

Figura 28 - Curvas DSC dos componentes puros cetoprofeno, ácido salicílico e da sua mistura (1:1) obtida por processo de moagem: $\mathrm{m} \sim 2 \mathrm{mg}$, atmosfera de $\mathrm{N}_{2}$, razão de aquecimento $10^{\circ} \mathrm{C} \cdot \mathrm{min}^{-1}$

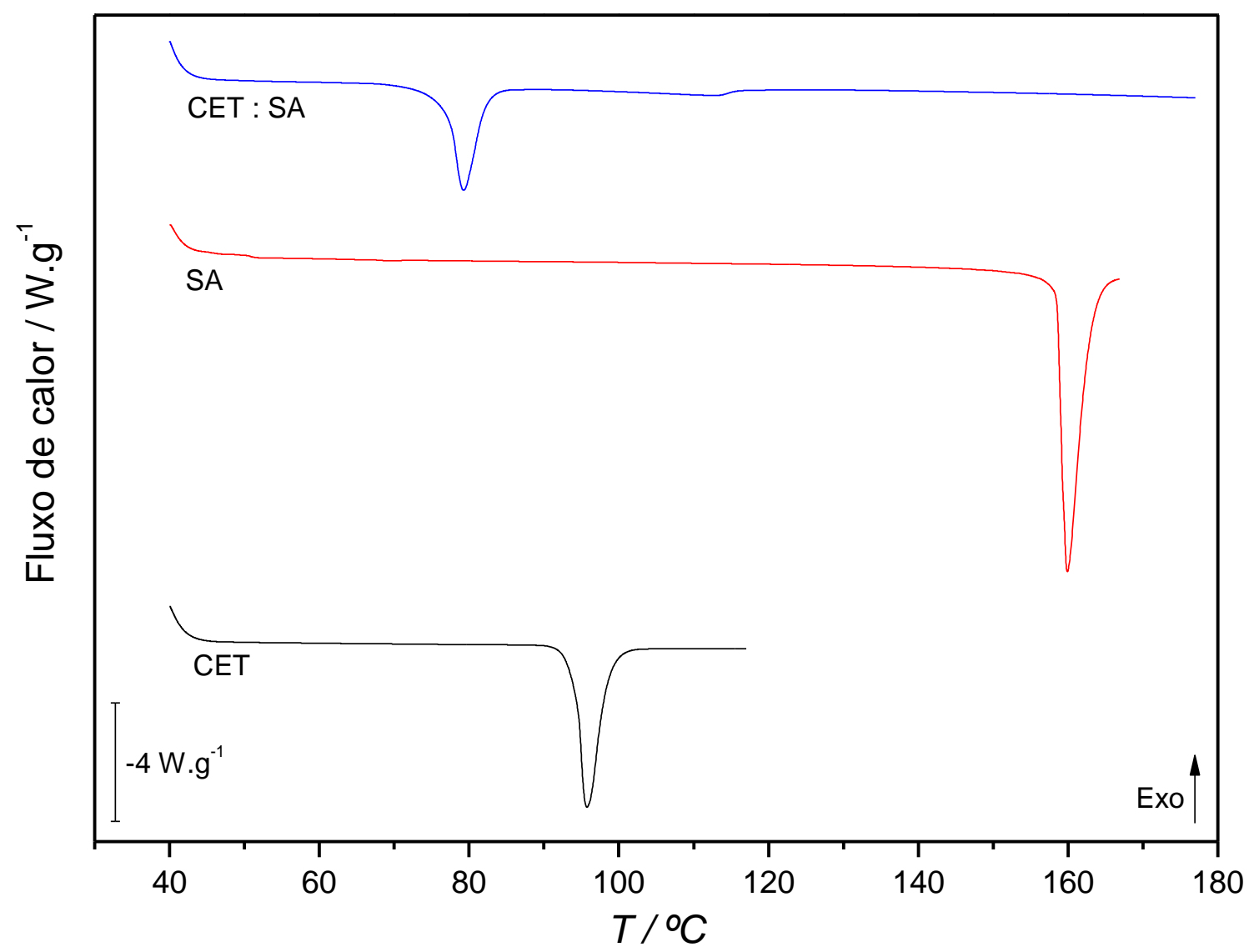

Tabela 6 - Parâmetros termodinâmicos das curvas DSC do primeiro aquecimento de CET, SA e CET:SA

\begin{tabular}{cccc}
\hline & $T_{\text {onset }} /{ }^{\circ} \mathrm{C}$ & $T_{\text {pico }} /{ }^{\circ} \mathrm{C}$ & $\Delta_{\text {fus }} H / \mathrm{kJ} \cdot \mathrm{mol}^{-1}$ \\
\hline CET & 94,22 & 95,73 & 30,54 \\
SA & 158,91 & 159,49 & 29,76 \\
CET $:$ SA & 77,02 & 79,26 & 36,09 \\
\hline
\end{tabular}


A Figura 28 mostra que a fusão do SA ocorre $64,69^{\circ} \mathrm{C}$ acima da fusão do CET, indicados pelos valores de $\Delta_{f u s} H$ na Tabela 6 , sendo que esses resultados estão de acordo com a curva DSC e com a Tabela 2, apresentados por Abounassif et. al. (ABOUNASSIF, 1994) e Nordström (NORDSTRÖM; RASMUSON, 2006), respectivamente. A curva DSC da mistura CET : SA, apresenta um pico de fusão com temperatura mais baixa que o CET e SA, sugerindo a ocorrência de formação de um cocristal, ou um composto eutético.

Comparando-se os difratogramas de raios X mostrados na Figura 29, verifica-se que o difratograma da mistura CET : SA corresponde à soma dos outros dois difratogramas, visto que as posições dos picos da mistura CET : SA coincidem com as posições dos picos do CET ou do SA puros. Essas informações sugerem a formação de um composto eutético, sem formação de cocristal.

Figura 29 - Difratogramas de pó da mistura CET : SA (1:1), obtida por moagem, e do cetoprofeno e do ácido salić́lico puros.

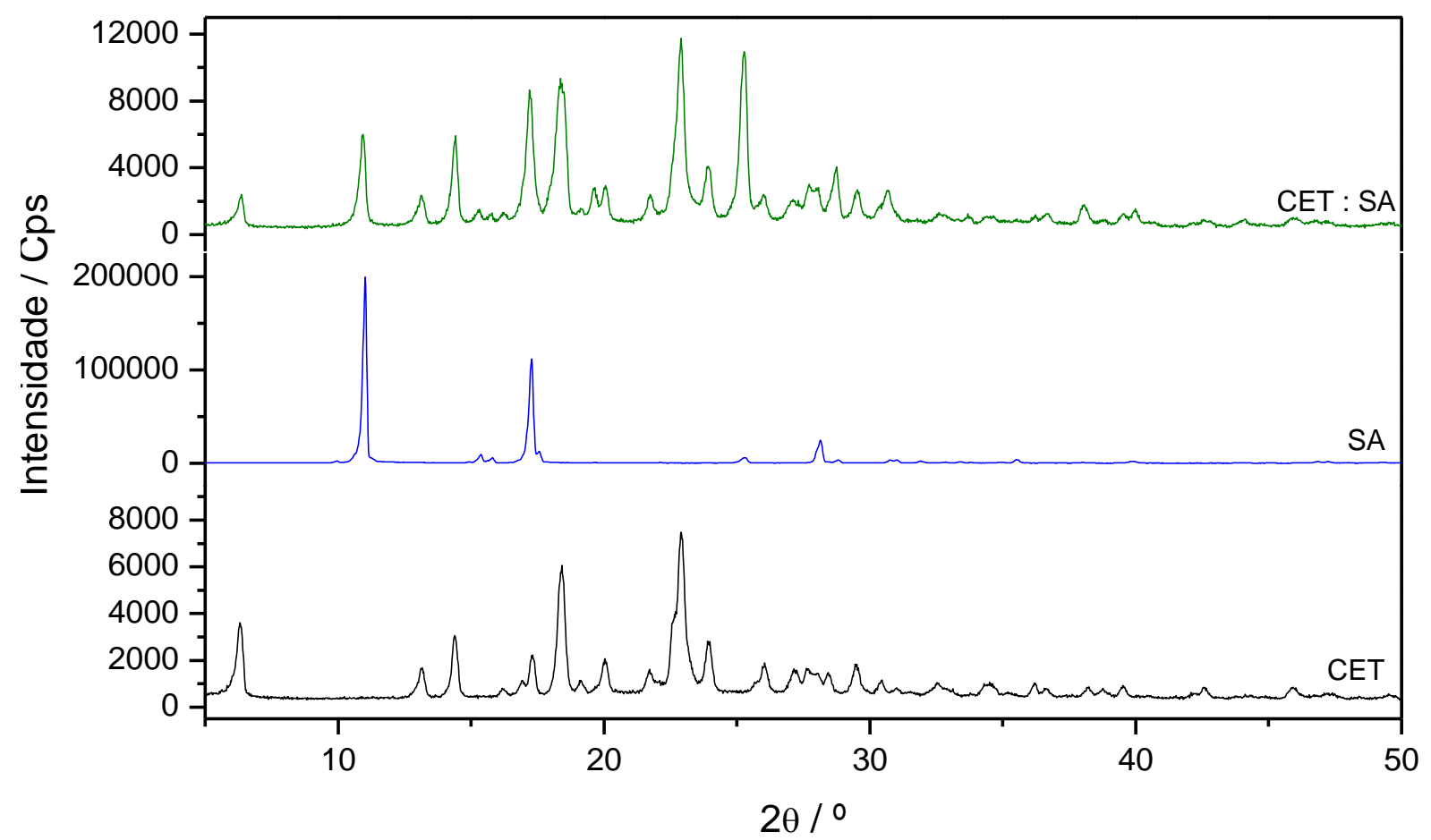

Na Figura 30 estão representados os espectros de FTIR do cetoprofeno, ácido salicílico, da mistura 1:1 destes compostos e o espectro soma simulado (CET + SA), resultante da soma dos espectros experimentais do CET e SA. Analisando a Figura, pode-se verificar que os 
espectros CET + SA e CET : SA são praticamente idênticos, como esperado para um composto eutético.

Dessa forma, fica evidenciado que houve apenas a formação do eutético, confirmando, assim, a informação obtida através das análises de raios $\mathrm{x}$.

Figura 30 - Espectros de FTIR da mistura CET : SA (1:1), obtida por moagem, do cetoprofeno e do ácido salicílico puros e o espectro soma $(\mathrm{CET}+\mathrm{SA})$ dos compostos puros

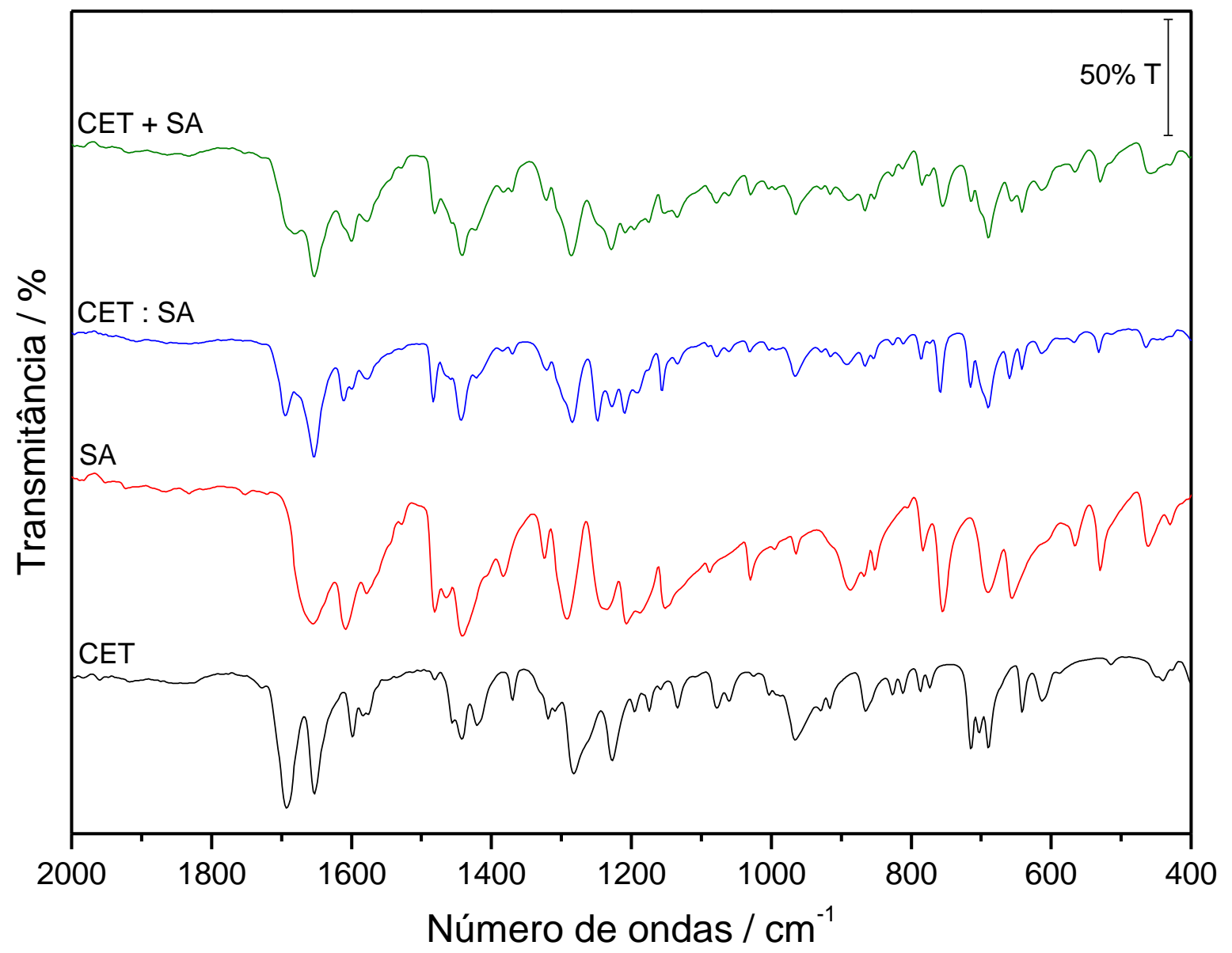

\subsubsection{Sistema cetoprofeno (CET) : picolinamida (PA)}

A picolinamida pode apresentar duas formas polimórficas distintas entre si, sendo que as estruturas cristalinas referentes a essas formas foram resolvidas e amplamente estudadas por Évora et. al. (ÉVORA, 2012).

Para verificar a ocorrência de possíveis transições polimórficas, $0,5 \mathrm{~g}$ desse composto puro foram moídas num moinho de bolas. Após a moagem, a amostra foi analisada por difração de raios X de pó e o resultado obtido encontra-se apresentado na Figura 31. 
Figura 31 - Difratogramas de pó da picolinamida pura, picolinamida pós-moagem (pm), e das simulações das suas formas polimórficas I e II.

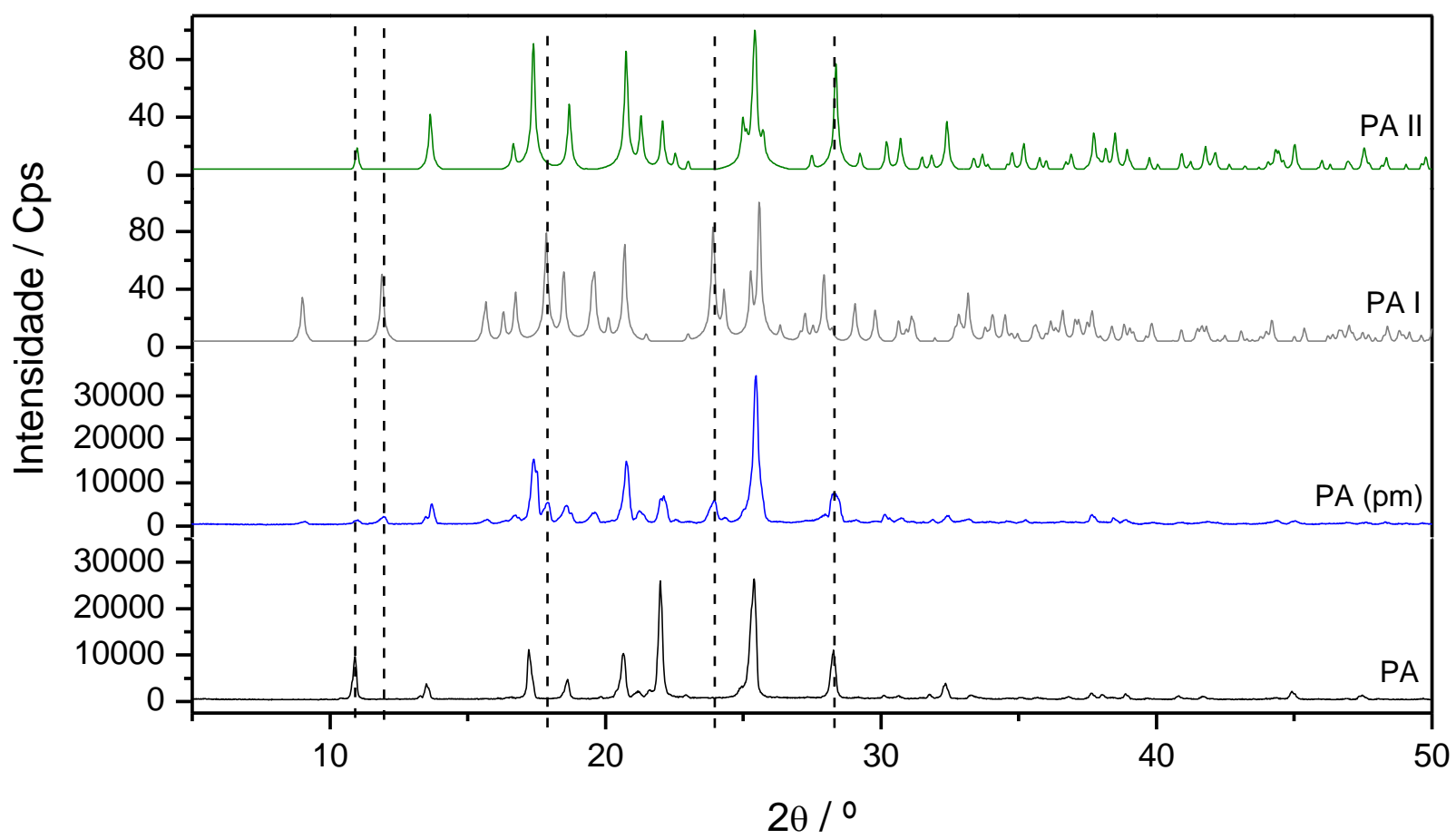

A Figura 31 mostra que na condição de moagem adotada neste trabalho, a picolinamida sofre uma transição polimórfica igual àquela relatada por Évora et.al., resultando numa mistura das formas I e II. As linhas tracejadas da Figura 31 mostram claramente que ocorre uma mudança na estrutura cristalina da picolinamida durante o processo de moagem, visto que, após a moagem, aparecem picos no difratograma que antes não apareciam. Além disso, esses dois difratogramas são idênticos aos apresentados por Évora et. al., confirmando, dessa forma, a ocorrência da transição polimórfica mencionada.

Nesse caso, a síntese de cocristais por processo mecanoquímico pode ser realizada na condição de moagem adotada neste trabalho. Entretanto, devido ao fato de após uma hora de moagem a picolinamida formar uma mistura de formas cristalinas, será preciso comparar os difratogramas das suas formas I e II com o difratograma do composto obtido para definir qual dessas duas formas estará presente, caso ocorra a formação do cocristal. Por outro lado, de acordo com Évora et. al., após um período de moagem de duas horas, a picolinamida passa completamente da forma II para a forma I, facilitando a comparação desses difratogramas. 
Na Figura 32, estão apresentados os resultados de DSC obtidos a partir do cetoprofeno e da picolinamida puros (CET e PA) e da sua mistura CET : PA. Os parâmetros termodinâmicos referentes a essas curvas encontram-se apresentados na Tabela 7.

Figura 32 - Curvas DSC dos componentes puros cetoprofeno, picolinamida e da sua mistura (1:1) obtida por processo de moagem: $\mathrm{m} \sim 2 \mathrm{mg}$, atmosfera de $\mathrm{N}_{2}$, razão de aquecimento $10^{\circ} \mathrm{C} \cdot \mathrm{min}^{-1}$.

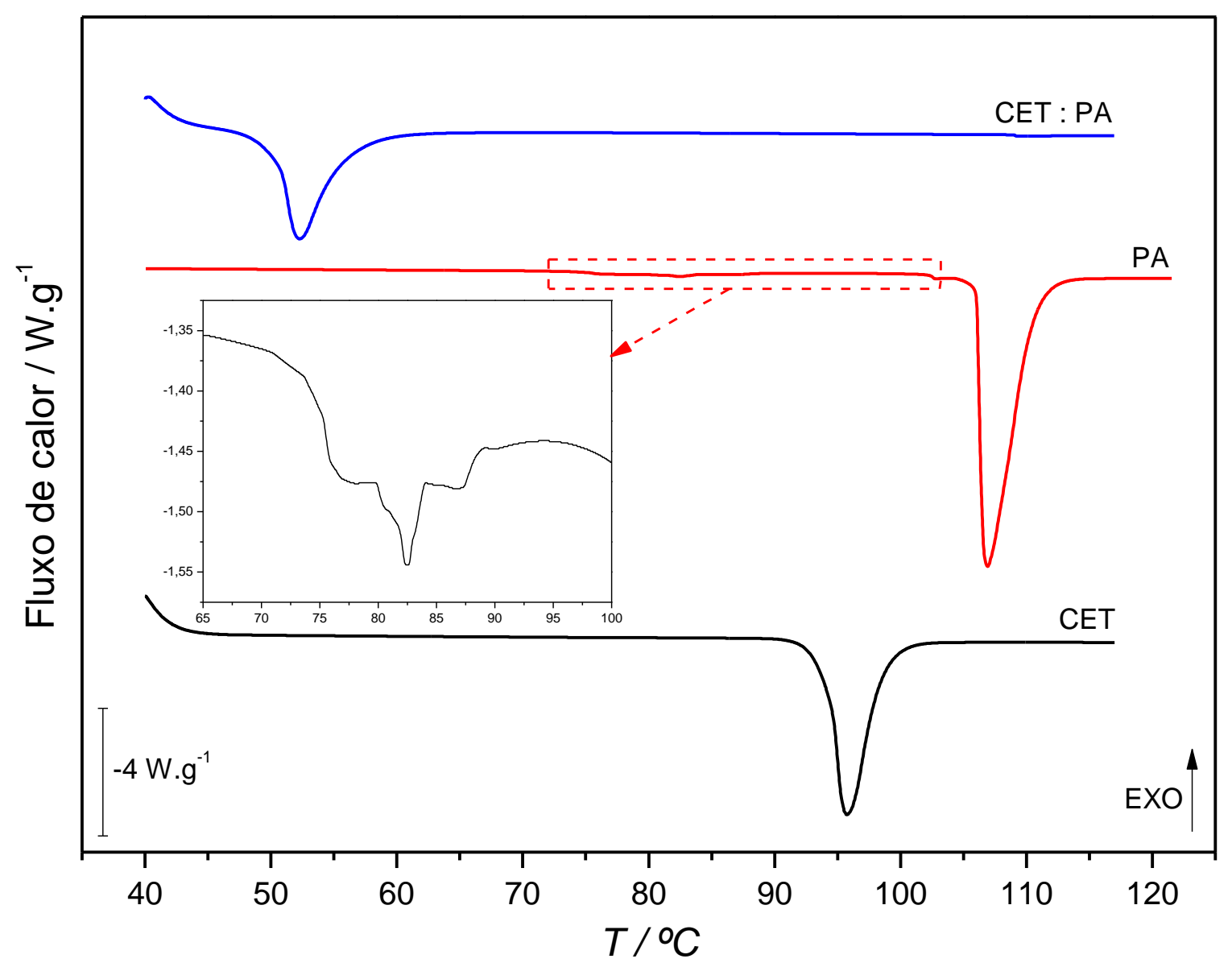

Tabela 7 - Parâmetros termodinâmicos das curvas DSC do primeiro aquecimento de CET, PA e CET:PA

\begin{tabular}{cccc}
\hline & $T_{\text {onset }} /{ }^{\circ} \mathrm{C}$ & $T_{\text {pico }} /{ }^{\circ} \mathrm{C}$ & $\Delta_{\text {fus }} H / \mathrm{kJ} \mathrm{mol}^{-1}$ \\
\hline CET & 94,22 & 95,73 & 30,54 \\
PA & 106,03 & 106,9 & 22,78 \\
CET : PA & 50,34 & 52,24 & 39,54 \\
\hline
\end{tabular}

A parte da curva destacada pelo tracejado vermelho na curva DSC da Figura 32 sugere que a PA sofre a mesma transição sólido-sólido da forma II para a forma I, sendo que o valor 
da temperatura de fusão ( $\left.T_{\text {onset }}\right)$ da forma I da PA, mostrado na Tabela 7, está de acordo com o valor encontrado para o DSC da Figura 2, mostrada no trabalho de Évora et. al. (ÉVORA, 2012).

A Figura 33 mostra os difratogramas de raios X de pó da mistura CET : PA e da PA (pós-moagem, pm) e do CET puros. Comparando-se esses difratogramas, é possível verificar que ao longo das linhas tracejadas vermelhas, aparecem picos referentes à PA, que não estão presentes no composto CET : PA. Essas informações sugerem a formação de um cocristal. Entretanto, as linhas tracejadas azuis mostram claramente que o difratograma CET : PA é uma soma dos outros dois difratogramas, já que os picos que aparecem no difratograma CET : PA são referentes à PA ou ao CET. Essas informações sugerem a formação de um composto eutético, sem formação de cocristal.

Figura 33 - Difratogramas de pó da mistura CET : PA (1:1), obtida por moagem, e do cetoprofeno e da picolinamida (pós-moagem) puros.

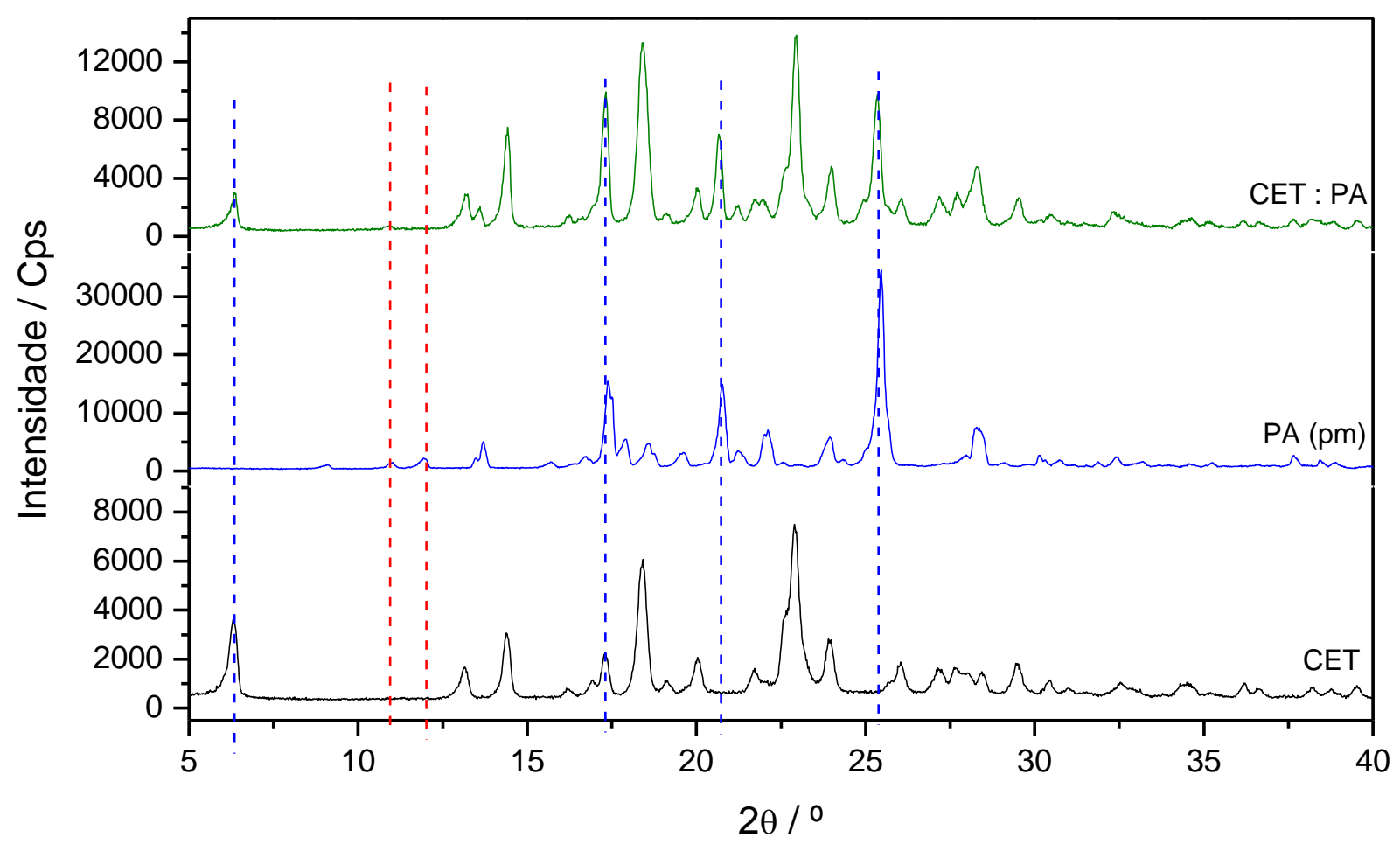

A Figura 34 mostra os espectros de FTIR do cetoprofeno, da picolinamida, da mistura 1:1 destes compostos e o espectro soma simulado (CET + PA), resultante da soma dos espectros experimentais do CET e da PA. A análise da figura permite verificar que os espectros CET + PA e CET : PA são praticamente idênticos, como esperado para um composto eutético. 
Figura 34 - Espectros de FTIR da mistura CET : PA (1:1), obtida por moagem, do cetoprofeno e da picolinamida puros e o espectro soma (CET + PA) dos compostos puros.

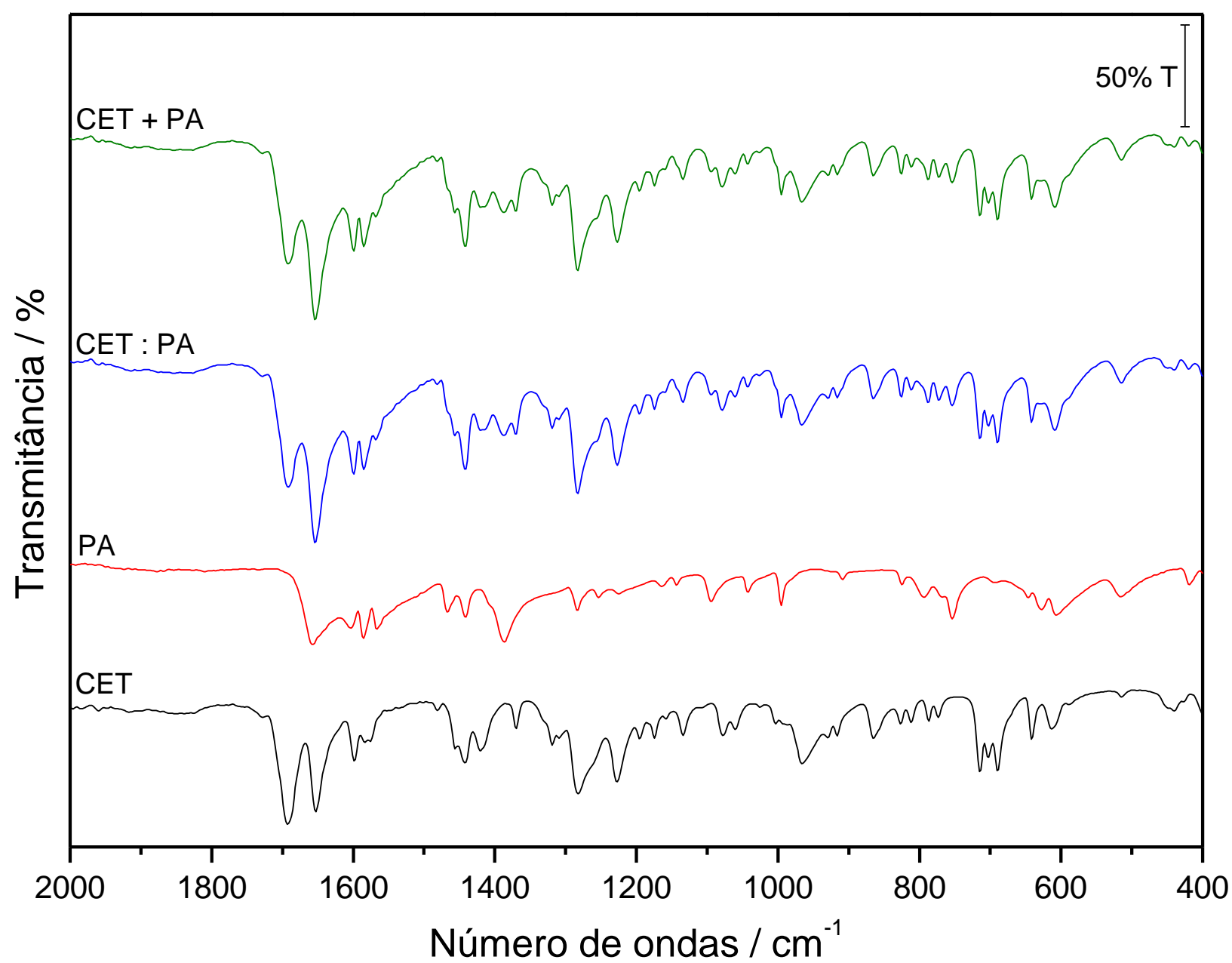

Dessa forma, fica evidenciado que houve apenas a formação do eutético, confirmando, assim, a informação obtida através das análises de raios $\mathrm{X}$.

\subsubsection{Sistema cetoprofeno (CET) : isonicotinamida (INA)}

A ocorrência de polimorfismo em isonicotinamida foi discutida pela primeira vez em 2001. Entretanto, somente em 2003 as estruturas cristalinas de duas formas polimórficas foram relatadas, sendo as únicas estruturas conhecidas até 2010, quando Jinjing Li e Caira descobriram e determinaram a estrutura de uma terceira forma cristalina (JINJING LI; CAIRA, 2011). 
Para verificar a ocorrência de possíveis transições polimórficas, $0,5 \mathrm{~g}$ desse composto puro foram moídas num moinho de bolas. Após a moagem, a amostra foi analisada por difração de raios $\mathrm{X}$ de pó e o resultado obtido encontra-se apresentado na Figura 35.

Figura 35 - Difratogramas de pó da isonicotinamida pós-moagem (pm), e da isonicotinamida pura.

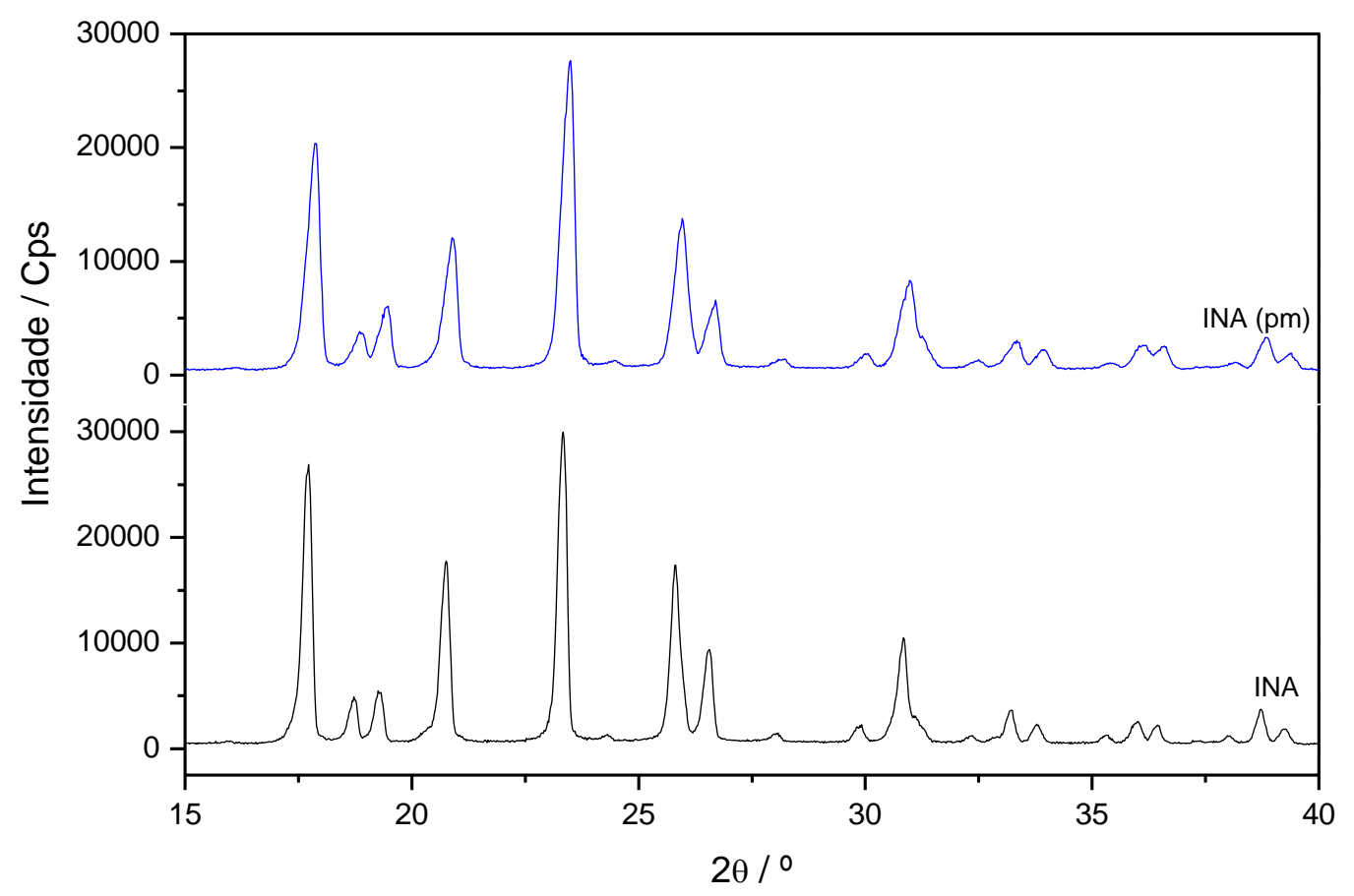

De acordo com a Figura 35, a isonicotinamida não sofre transição polimórfica durante o processo de moagem, já que não existem deslocamentos nas posições dos picos de difração. Dessa forma, a condição de moagem adotada para a síntese de cocristais por processo mecanoquímico pode ser utilizada para esse co-formador, com a garantia de que não ocorrerá transição polimórfica durante o processo.

A Tabela 8 mostra os parâmetros termodinâmicos referentes às curvas DSC do CET, da INA e da mistura CET : INA (1:1), obtida através de moagem (Figura 36).

Tabela 8 - Parâmetros termodinâmicos das curvas DSC do primeiro aquecimento de CET, INA e CET:INA

\begin{tabular}{cccc}
\hline & $T_{\text {onset }} /{ }^{\circ} \mathrm{C}$ & $T_{\text {pico }} /{ }^{\circ} \mathrm{C}$ & $\Delta_{\text {fus }} H / \mathrm{kJ} \cdot \mathrm{mol}^{-1}$ \\
\hline CET & 94,22 & 95,73 & 30,54 \\
INA & 155,70 & 156,66 & 28,22 \\
CET : INA & 58,26 & 61,68 & 30,25 \\
& & & \\
\hline
\end{tabular}


Figura 36 - Curvas DSC dos componentes puros cetoprofeno, isonicotinamida e da sua mistura (1:1) obtida por processo de moagem: $\mathrm{m} \sim 2 \mathrm{mg}$, atmosfera de $\mathrm{N}_{2}$, razão de aquecimento $10^{\circ} \mathrm{C} \cdot \mathrm{min}^{-1}$.

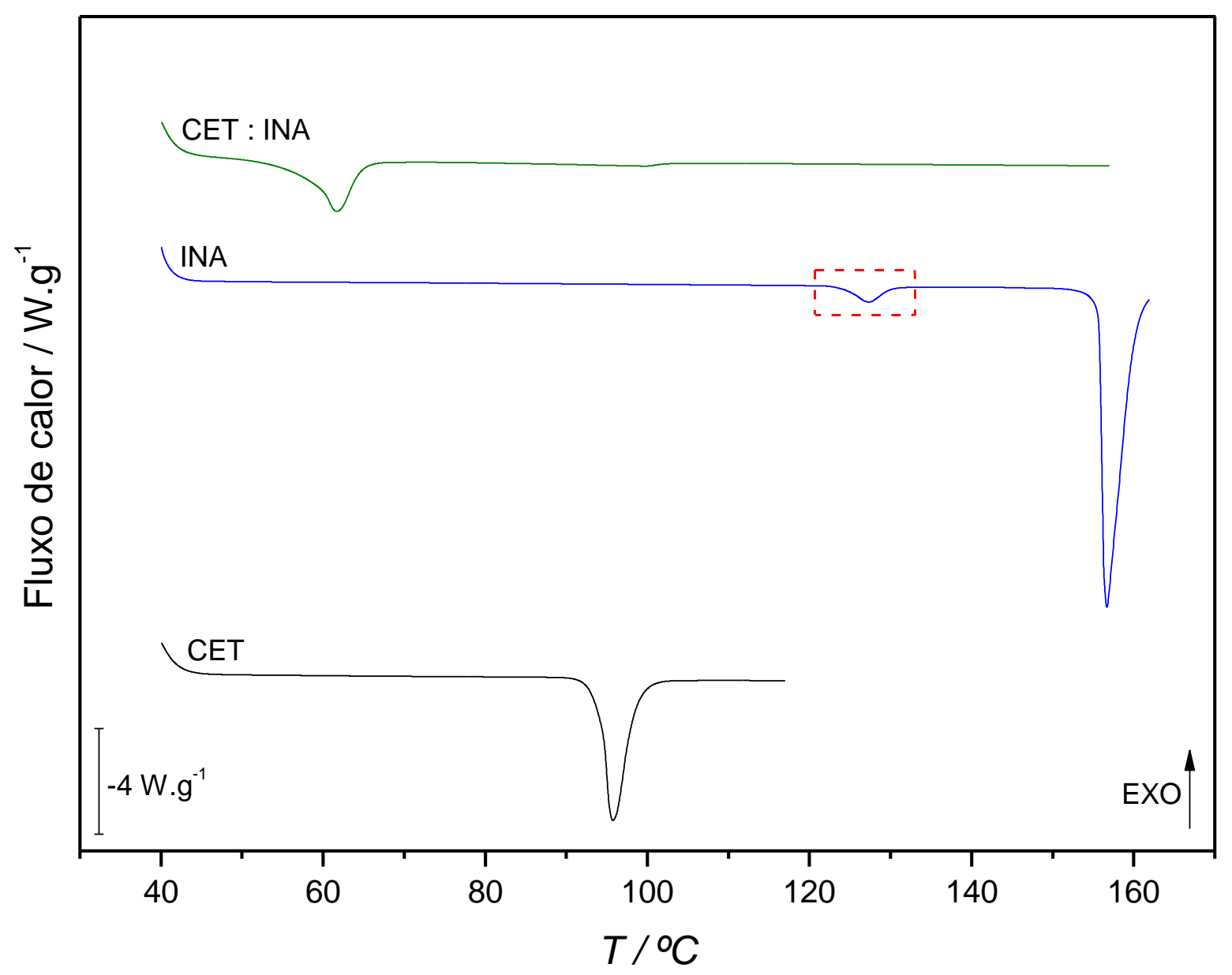

O destaque pontilhado na Figura 36 mostra que a INA sofre uma transição polimórfica a $127,29{ }^{\circ} \mathrm{C}$, aproximadamente, com um $\Delta_{t r s} H=1,63 \mathrm{~kJ} \cdot \mathrm{mol}^{-1}$, fundindo $61,48{ }^{\circ} \mathrm{C}$ acima do CET, com um intervalo estreito de temperatura, característico de fenômenos endotérmicos de baixa energia antes da fusão, indicados pelos valores de $\Delta_{f u s} H$ na Tabela 8 . Entretanto, embora os valores de temperatura para a transição de fase e fusão estejam próximos aos valores encontrados por Jinjing Li e Caira (JINJING LI; CAIRA, 2011), não é possível, através da técnica de DSC, definir entre quais formas polimórficas essa transição ocorre.

Já a curva DSC da mistura CET : INA, apresenta um pico de fusão com temperatura mais baixa que o CET e a INA, sugerindo a ocorrência de formação de um cocristal, ou um composto eutético.

A comparação dos difratogramas de raio X de pó mostrados na Figura 37, mostra que o difratograma da mistura CET : INA corresponde à soma dos outros dois difratogramas, sugerindo a formação de um composto eutético, ao invés de um cocristal. 
Figura 37 - Difratogramas de pó da mistura CET : INA (1:1), obtida por moagem, e do cetoprofeno e da isonicotinamida puros.

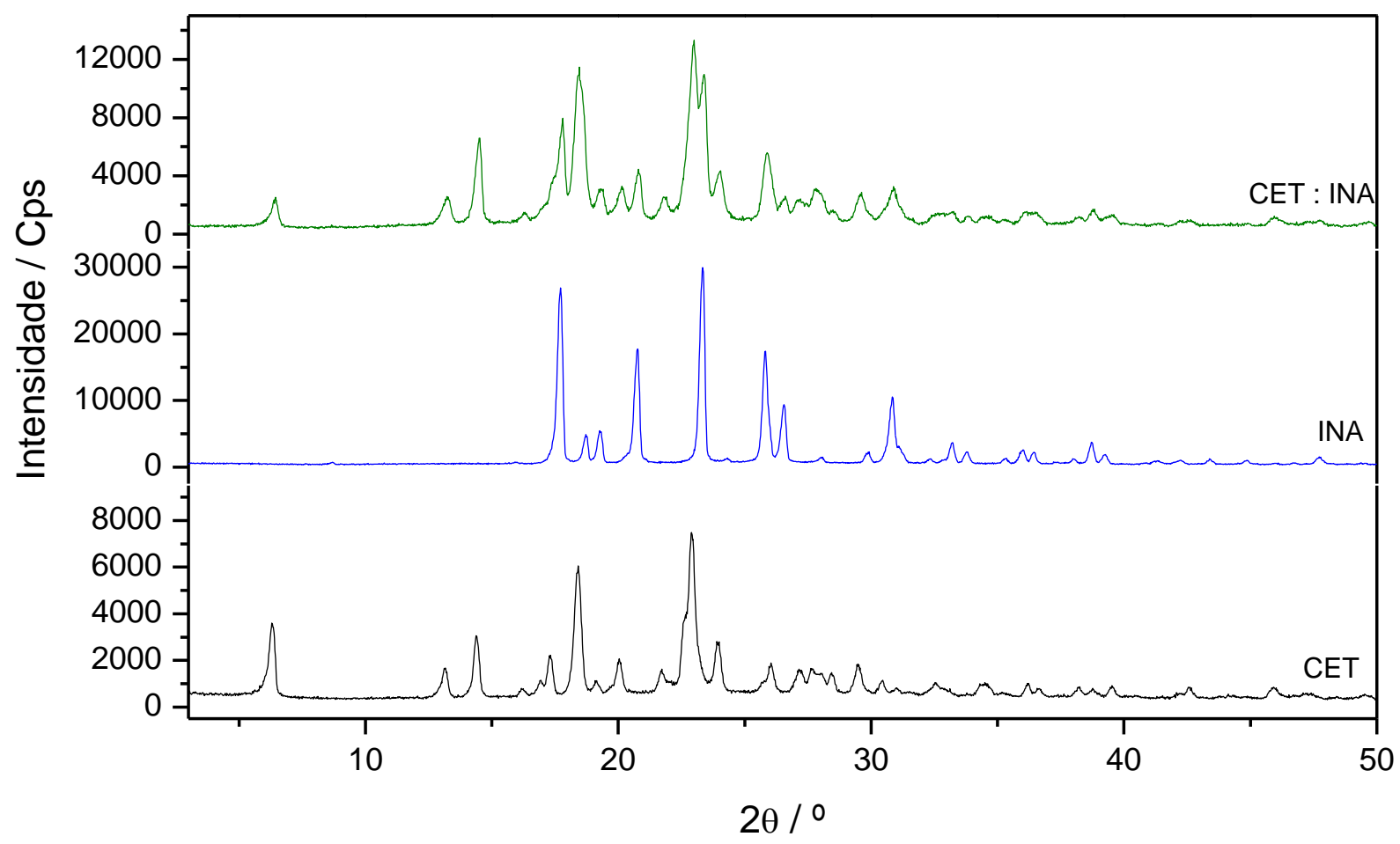

A Figura 38 mostra os espectros de FTIR do cetoprofeno, da isonicotinamida, da mistura 1:1 destes compostos e o espectro soma simulado (CET + INA), resultante da soma dos espectros experimentais do CET e da INA. A análise da Figura permite verificar que os espectros CET + INA e CET : INA são praticamente idênticos, como esperado para um composto eutético.

Dessa forma, fica comprovado que houve somente a formação do eutético, confirmando, assim, a informação obtida através das análises de raios X. 
Figura 38 - Espectros de FTIR da mistura CET : INA (1:1), obtida por moagem, do cetoprofeno e da isonicotinamida puros e o espectro soma (CET + INA) dos compostos puros.

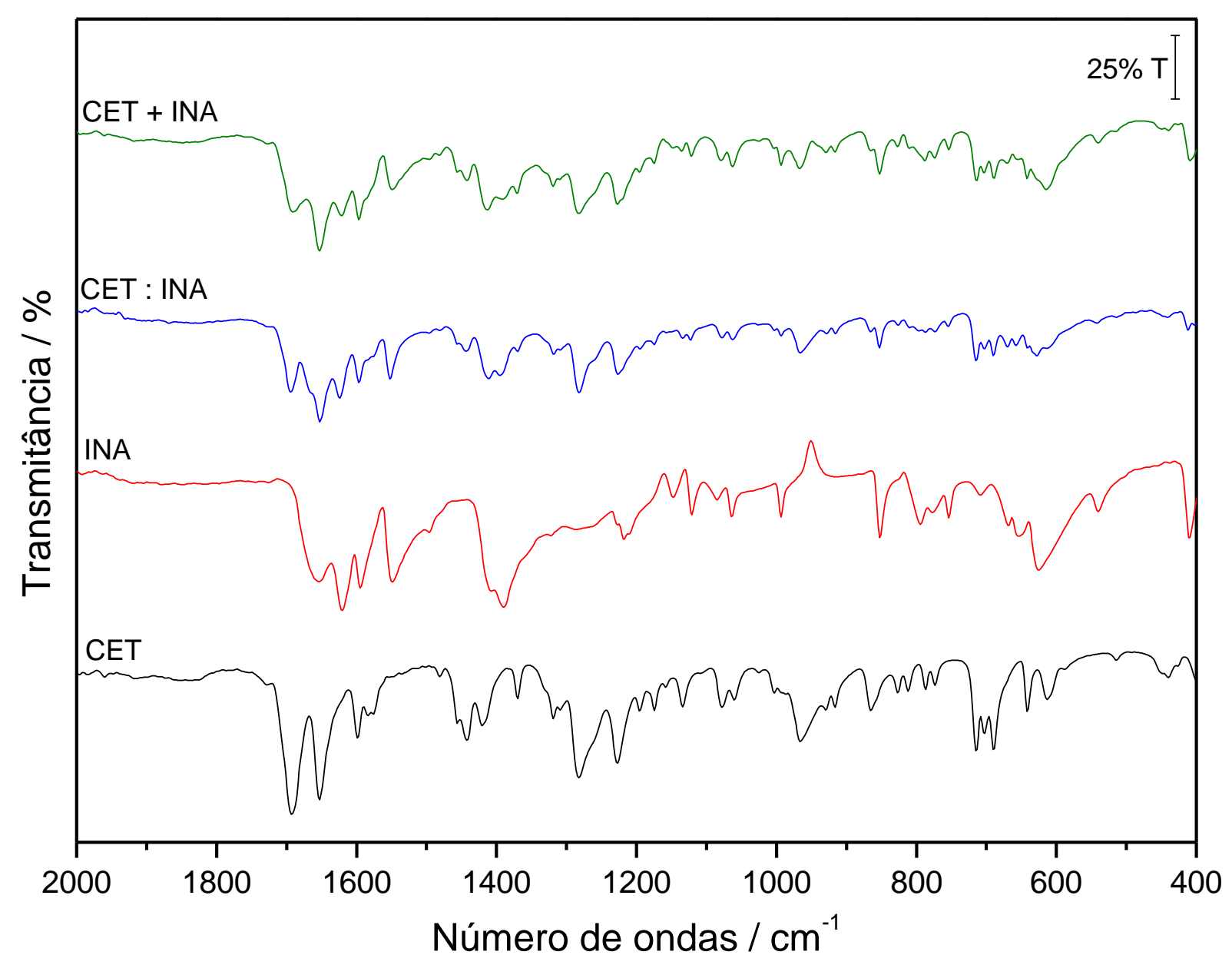

\subsubsection{Sistema cetoprofeno (CET) : pirazinamida (PZA)}

A pirazinamida pode apresentar quatro formas polimórficas $(\alpha, \beta, \gamma$ e $\delta)$ que foram amplamente estudadas por Castro et. al. e Cherukuvada et. al. (CASTRO et al., 2010; CHERUKUVADA, 2010). A Figura 39 mostra o difratograma de raios $X$ de pó da pirazinamida pura obtida após ter sido moída num moinho de bolas. 
Figura 39 - Difratogramas de pó da pirazinamida pura, pirazinamida pós-moagem (pm), e da simulações da forma polimórfica $\alpha$.

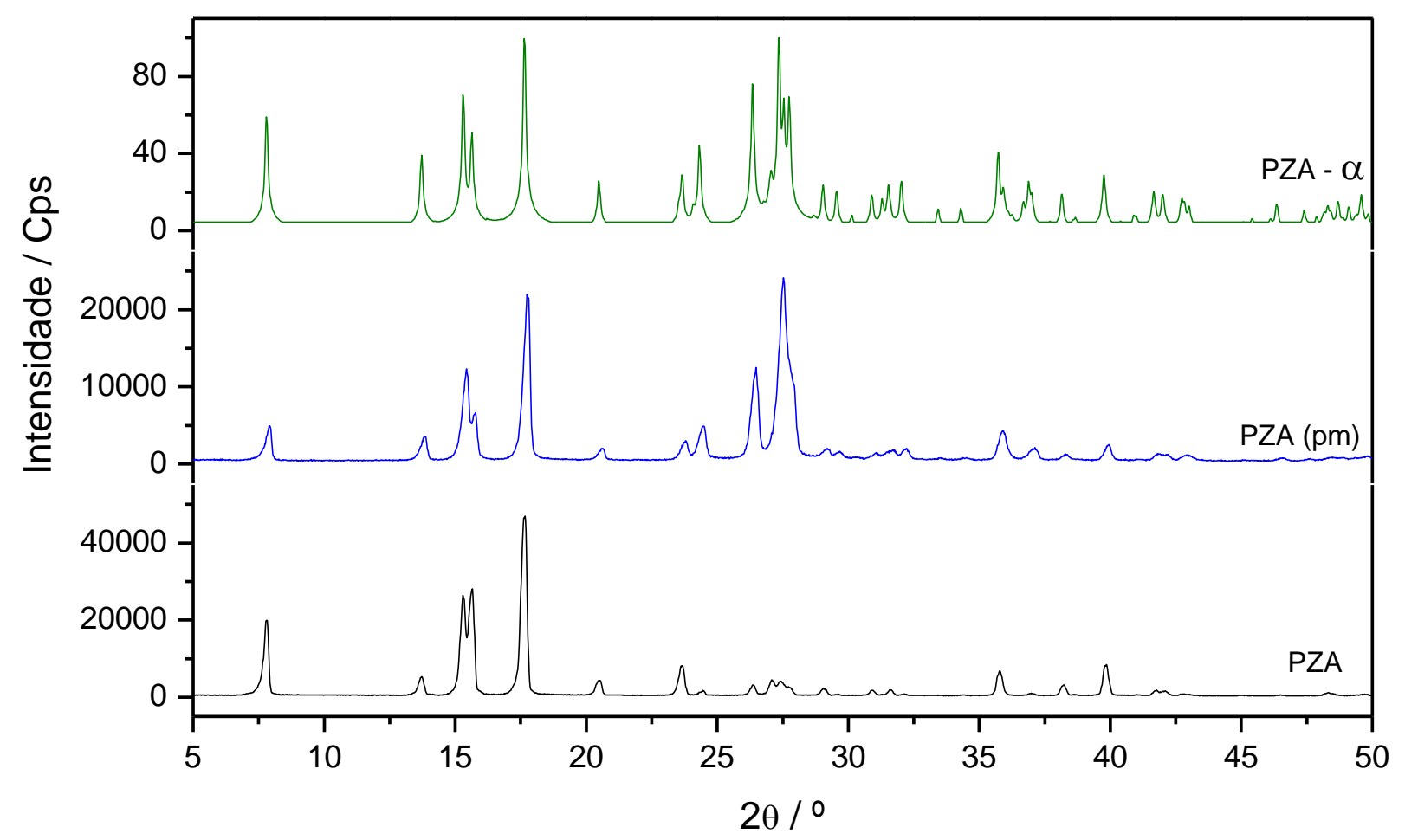

A comparação dos difratogramas da Figura 39 permite verificar que a PZA permanece na forma $\alpha$ após a moagem. Dessa forma, a condição de moagem adotada para a síntese de cocristais pode ser utilizada, com a confirmação de que durante o processo a PZA não sofrerá nenhuma transição polimórfica.

A Figura 40 mostra os resultados de DSC obtidos a partir do cetoprofeno e da pirazinamida puros (CET e PZA) e da sua mistura CET : PZA. Os parâmetros termodinâmicos referentes a essas curvas encontram-se apresentados na Tabela 9. 
Figura 40 - Curvas DSC dos componentes puros cetoprofeno, pirazinamida e da sua mistura (1:1) obtida por processo de moagem: $\mathrm{m} \sim 2 \mathrm{mg}$, atmosfera de $\mathrm{N}_{2}$, razão de aquecimento $10^{\circ} \mathrm{C} \cdot \mathrm{min}^{-1}$.

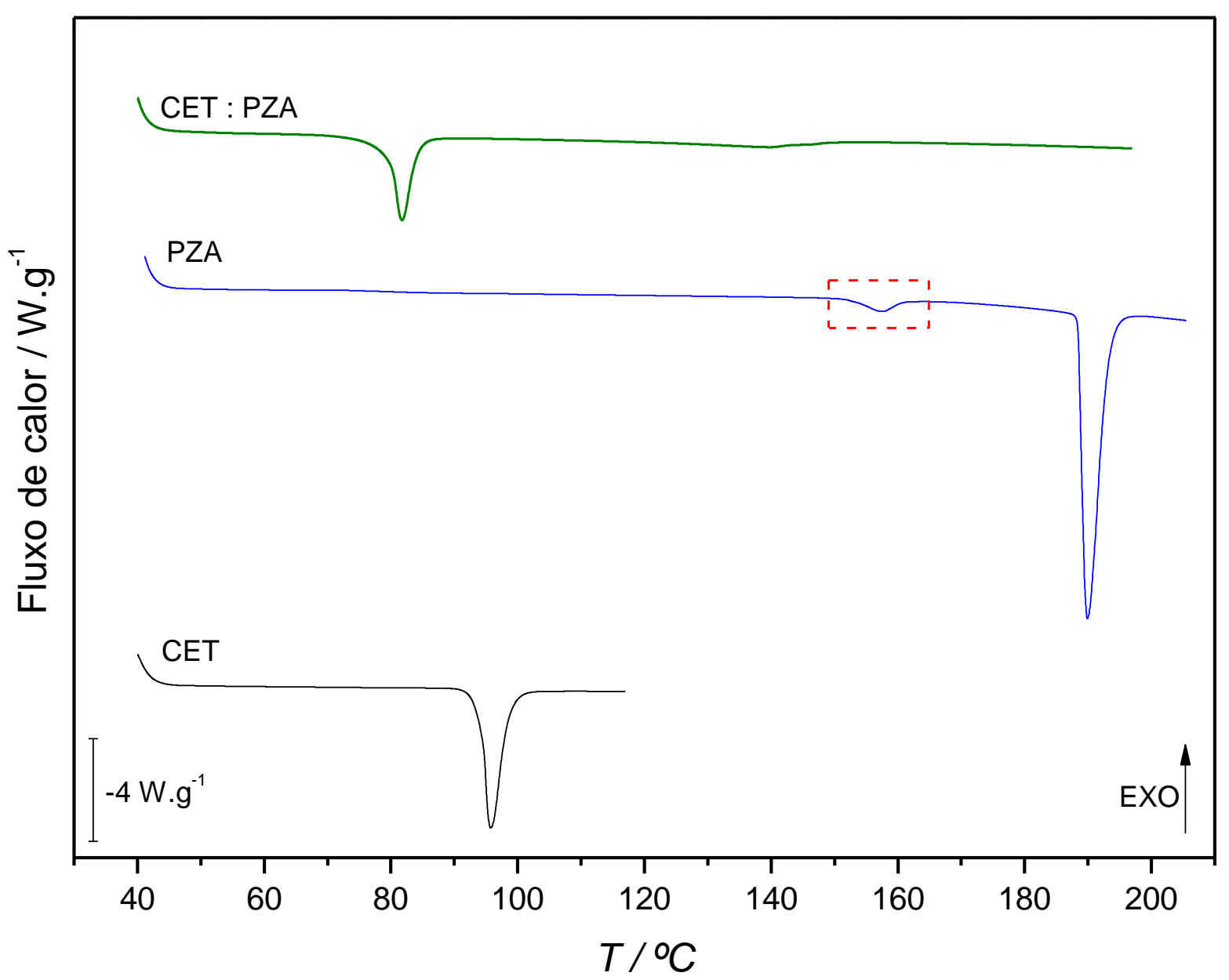

Tabela 9 - Parâmetros termodinâmicos das curvas DSC do primeiro aquecimento de CET, PZA e CET:PZA

\begin{tabular}{cccc}
\hline & $T_{\text {onset }} /{ }^{\circ} \mathrm{C}$ & $T_{\text {pico }} /{ }^{\circ} \mathrm{C}$ & $\Delta_{\text {fus }} H / \mathrm{kJ} \cdot \mathrm{mol}^{-1}$ \\
\hline CET & 94,22 & 95,73 & 30,54 \\
PZA & 188,39 & 189,88 & 32,14 \\
CET : PZA & 79,75 & 81,72 & 30,78 \\
\hline
\end{tabular}

O destaque pontilhado na Figura 40 mostra que em $156,75^{\circ} \mathrm{C}$, a PZA sofre uma transição polimórfica, com um $\Delta_{t r s} H=1,54 \mathrm{~kJ} \mathrm{~mol}^{-1}$, fundindo em $188,39^{\circ} \mathrm{C}$, com $\Delta_{f u s} H=32,14$ kJ.mol ${ }^{-1}$, conforme mostrado na Tabela 9.

Como os valores de $\Delta_{t r s} H$ e $T_{\text {onset }}$ estão de acordo com aqueles apresentados por Cherukuvada et. al. (CHERUKUVADA, 2010), pode-se concluir que a parte destacada pelo 
pontilhado refere-se à mesma transição da forma $\alpha$ para forma $\gamma$ apresentada por Cherukuvada et. al.

Já a curva DSC da mistura CET : PZA, apresenta um pico de fusão com temperatura mais baixa que o CET e a PZA, sugerindo a ocorrência de formação de um cocristal, ou um composto eutético.

A comparação dos difratogramas de raios X de pó mostrados na Figura 41, mostra que o difratograma da mistura CET : PZA corresponde à soma dos outros dois difratogramas, sugerindo a formação de um composto eutético.

Figura 41 - Difratogramas de pó da mistura CET : PZA (1:1), obtida por moagem, e do cetoprofeno e da pirazinamida puros.

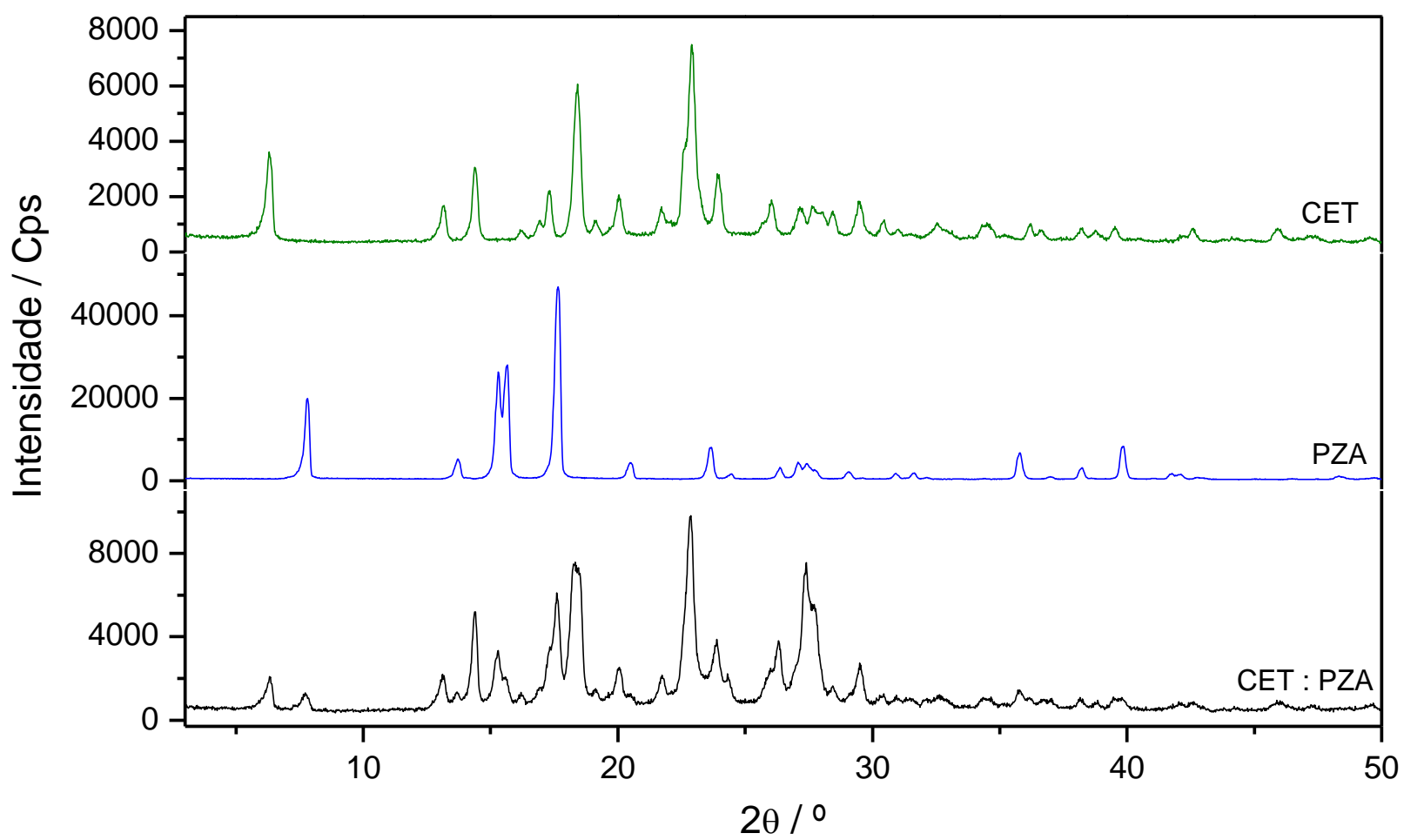

Os espectros de FTIR do cetoprofeno, da isonicotinamida, da mistura 1:1 destes compostos e o espectro soma simulado (CET + INA), resultante da soma dos espectros experimentais do CET e da INA estão mostrados na Figura 42, onde é possível verificar que os espectros CET + INA e CET : INA são praticamente idênticos, o que permite comprovar a formação do eutético e confirmar a informação obtida através das análises de raios X. 
Figura 42 - Espectros de FTIR da mistura CET : PZA (1:1), obtida por moagem, do cetoprofeno e da pirazinamida puros e o espectro soma (CET + PZA) dos compostos puros.

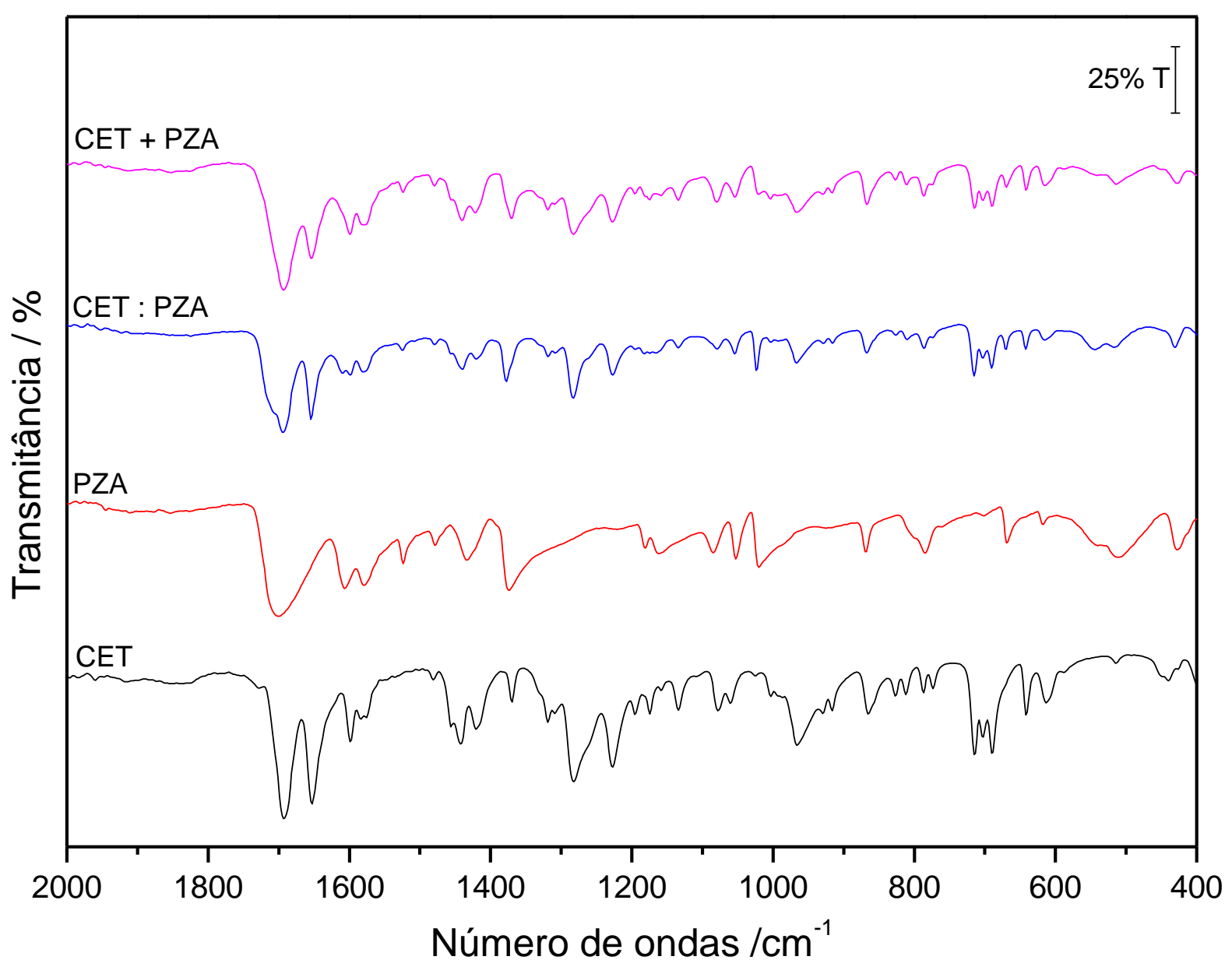

\subsubsection{Sistema cetoprofeno (CET) : nicotinamida (NA)}

A nicotinamida caracteriza-se como um pó branco, com massa molar igual a 122,13 g.mol ${ }^{-1}$ e ponto de fusão igual a $128-131^{\circ} \mathrm{C}$, podendo, também, apresentar-se sob quatro formas cristalinas distintas entre si. É altamente solúvel em água, etanol, metanol e pouco solúvel em éter etílico e clorofórmio (MOETY, 1991).

Visando a ocorrência de possíveis transições polimórficas, 0,5 g desse composto puro foram moídas num moinho de bolas e o difratograma de raios $\mathrm{X}$ obtido após a etapa de moagem encontra-se apresentado na Figura 43. 
Figura 43 - Difratogramas de pó da nicotinamida pós-moagem (pm), e da nicotinamida pura.

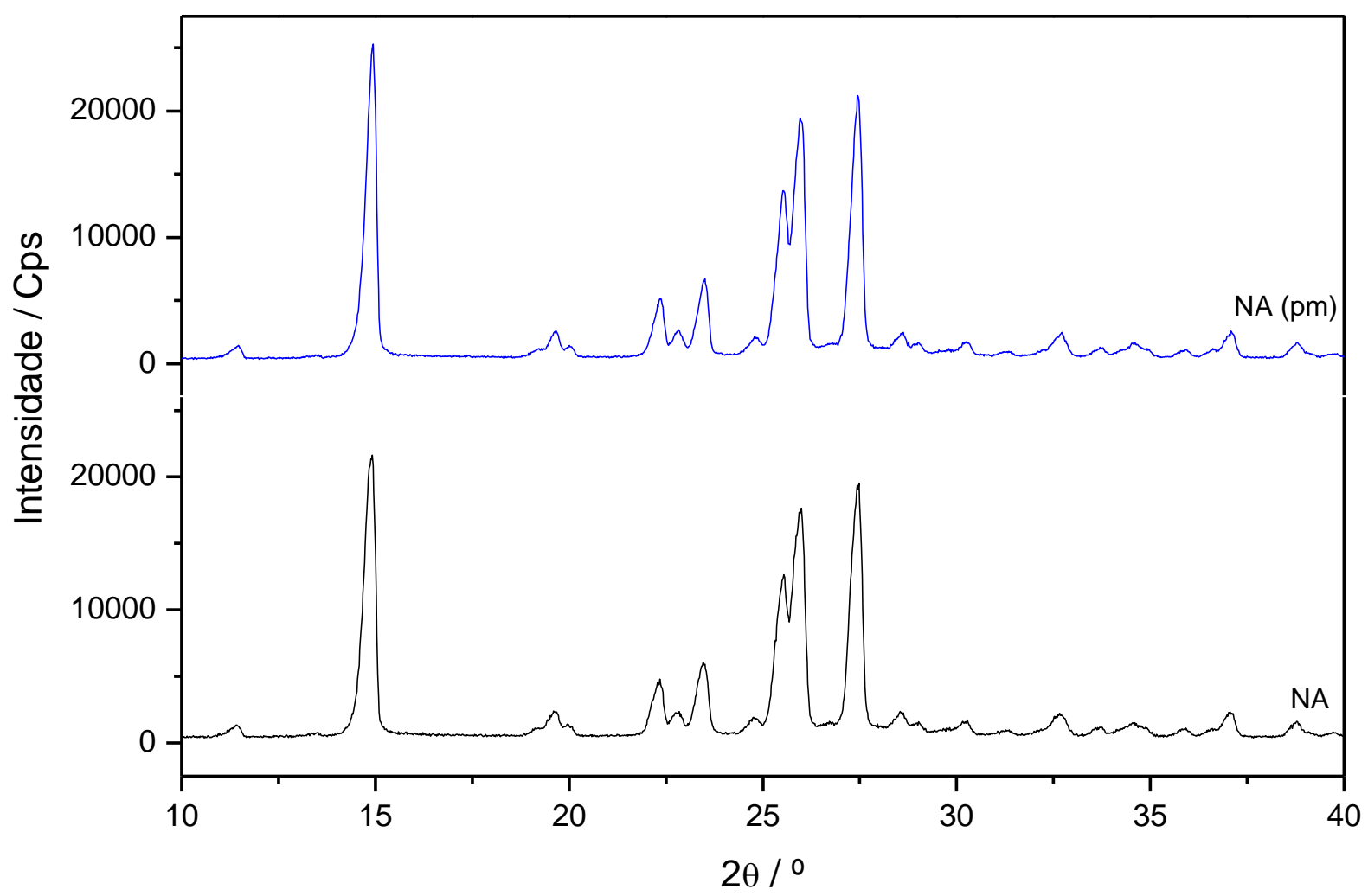

A Figura 43 mostra que a nicotinamida não sofre transição polimórfica durante o processo de moagem, indicando que a condição de moagem adotada para a síntese de cocristais por processo mecanoquímico pode ser utilizada para esse co-formador, sem que ocorra transição polimórfica durante o processo.

$\mathrm{Na}$ Figura 44, estão apresentados os resultados de DSC obtidos a partir do cetoprofeno e da nicotinamida puros (CET e NA) e da sua mistura CET : NA. Os parâmetros termodinâmicos referentes a essas curvas encontram-se apresentados na Tabela 10. 
Figura 44 - Curvas DSC dos componentes puros cetoprofeno, nicotinamida e da sua mistura (1:1) obtida por processo de moagem: $\mathrm{m} \sim 2 \mathrm{mg}$, atmosfera de $\mathrm{N}_{2}$, razão de aquecimento $10^{\circ} \mathrm{C} \cdot \mathrm{min}^{-1}$.

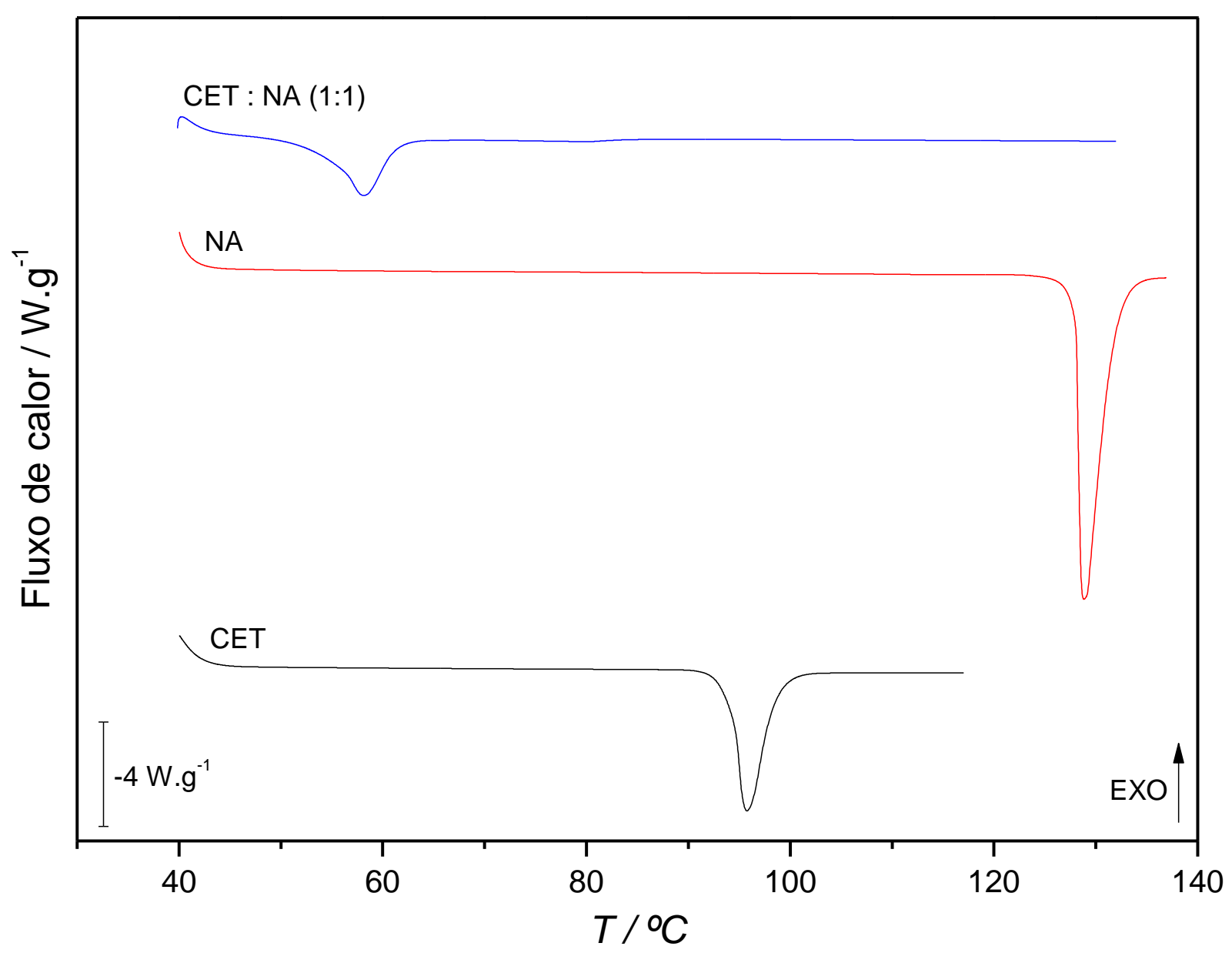

Tabela 10 - Parâmetros termodinâmicos das curvas DSC do primeiro aquecimento de CET, NA e CET:NA

\begin{tabular}{cccc}
\hline & $T_{\text {onset }} /{ }^{\circ} \mathrm{C}$ & $T_{\text {pico }} /{ }^{\circ} \mathrm{C}$ & $\Delta_{\text {fus }} H / \mathrm{kJ} \mathrm{mol}^{-1}$ \\
\hline CET & 94,22 & 95,73 & 30,54 \\
NA & 128,01 & 128,83 & 24,55 \\
CET $:$ NA & 54,55 & 58,08 & 33,17 \\
\hline
\end{tabular}

A Figura 44 mostra que a fusão da NA ocorre $33,79^{\circ} \mathrm{C}$ acima da fusão do CET, com um intervalo estreito de temperatura, com valores de $\Delta_{f u s} H$ indicados na Tabela 10. A curva DSC da mistura CET : NA, apresenta um pico de fusão com temperatura mais baixa que o CET e a NA, sugerindo a ocorrência de formação de um cocristal, ou um composto eutético. 
A comparação dos difratogramas de raio $X$ de pó mostrados na Figura 45, mostra que o difratograma da mistura CET : NA corresponde à soma dos outros dois difratogramas, visto que as posições dos picos da mistura CET : NA coincidem com as posições dos picos do CET ou da NA puros. Essas informações sugerem a formação de um composto eutético, sem formação de cocristal.

Figura 45 - Difratogramas de pó da mistura CET : NA (1:1), obtida por moagem, e do cetoprofeno e da nicotinamida puros.

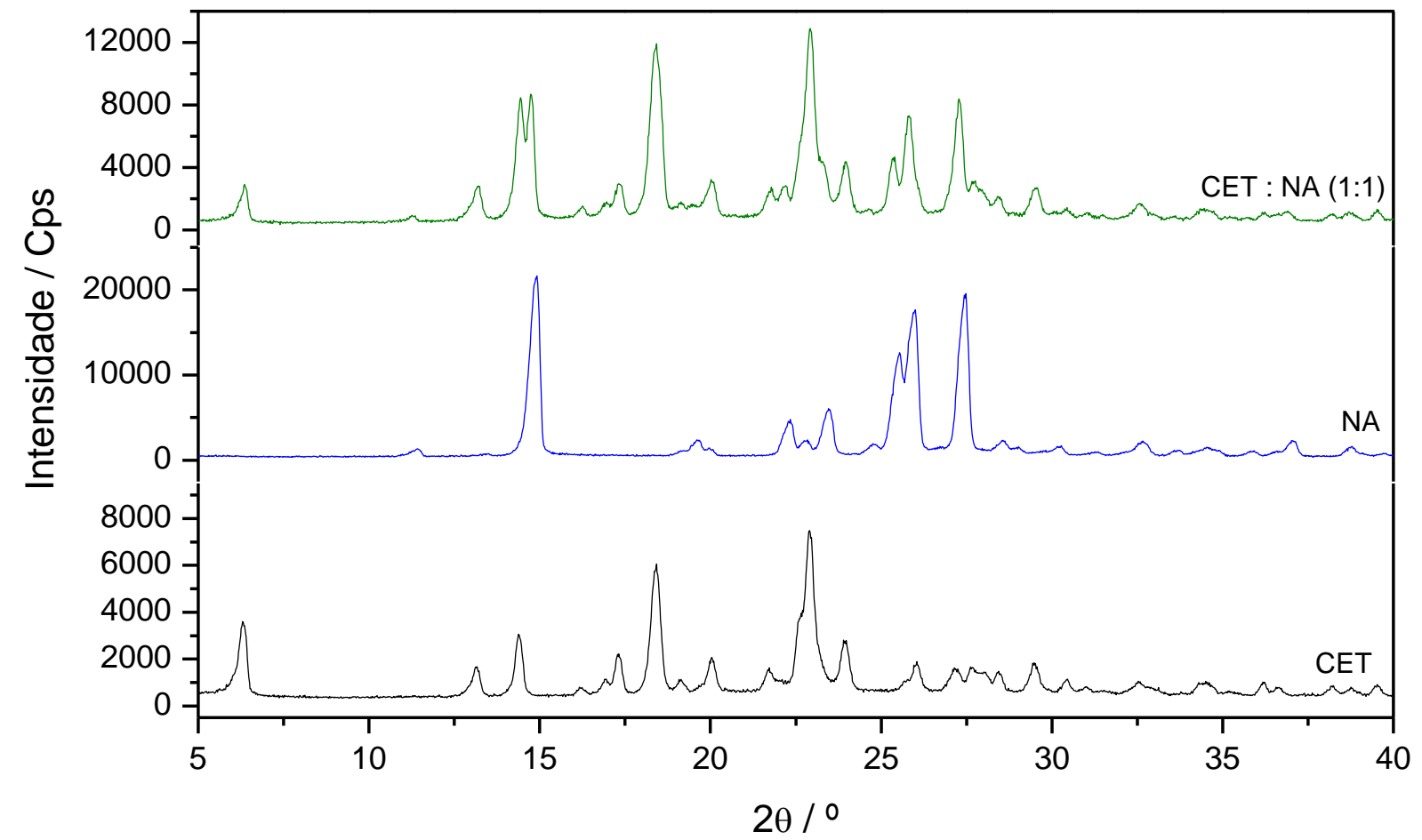

A Figura 46 mostra os espectros de FTIR do cetoprofeno, da nicotinamida, da mistura 1:1 destes compostos e o espectro soma simulado $(\mathrm{CET}+\mathrm{NA})$, resultante da soma dos espectros experimentais do CET e da NA. A análise da Figura permite verificar que os espectros CET + NA e CET : NA são praticamente idênticos, como esperado para um composto eutético.

Dessa forma, fica evidenciado que houve apenas a formação do eutético, confirmando, assim, a informação obtida através das análises de raios x. 
Figura 46 - Espectros de FTIR da mistura CET : NA (1:1), obtida por moagem, do cetoprofeno e da nicotinamida puros e o espectro soma (CET + NA) dos compostos puros.

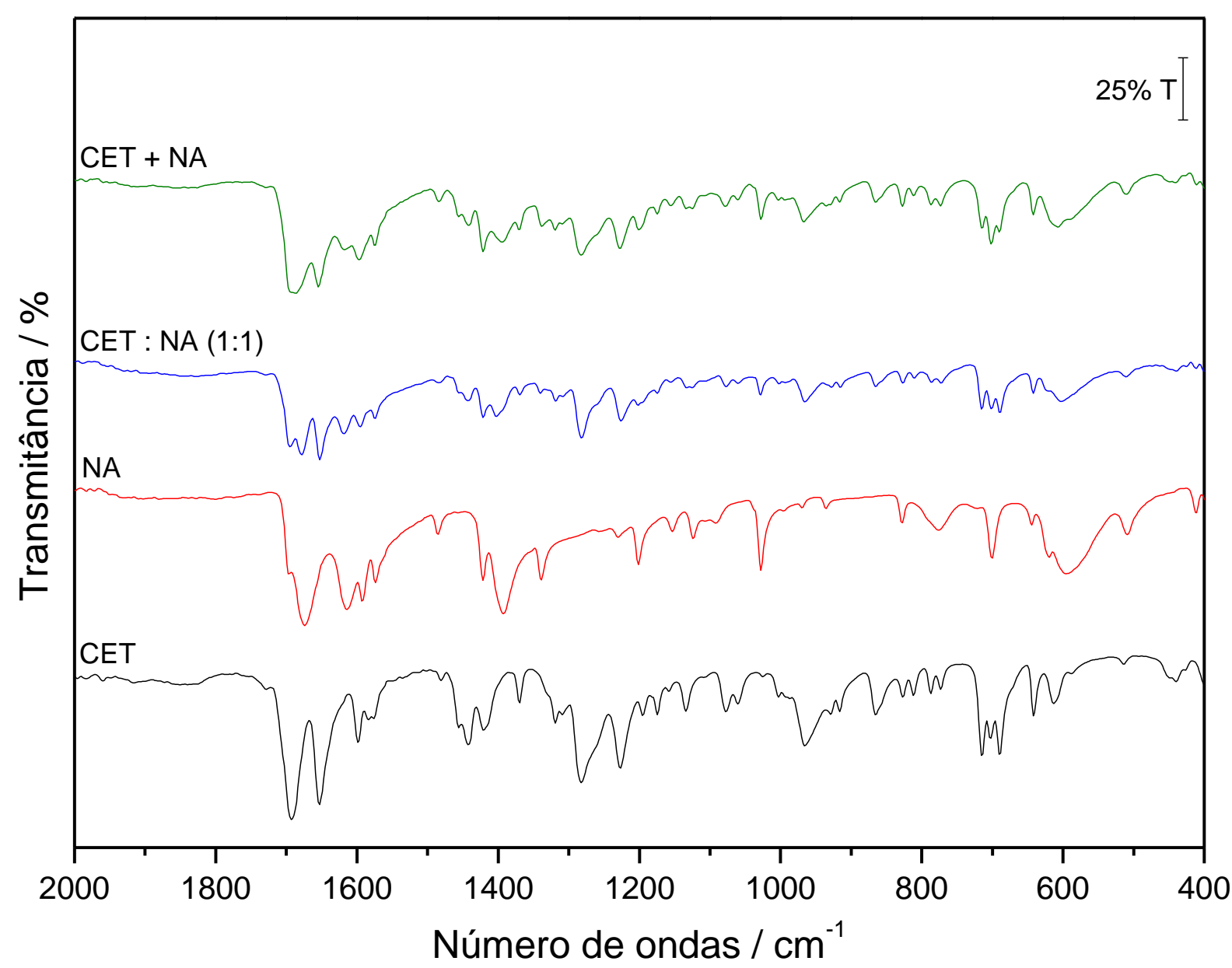

\subsection{Diagramas de fases sólido-líquido}

Uma das formas de provar se estamos na presença de um cocristal ou composto eutéctico é a construção do diagrama de fases. Assim, foram feitas moagens em diversas proporções para cada sistema estudado para a construção dos diagramas de fases teóricos e experimentais.

Para a construção do diagrama de fases experimental, as amostras obtidas através das moagens foram aquecidas, no equipamento de DSC, a uma razão de aquecimento baixa, 5 ${ }^{\circ} \mathrm{C} / \mathrm{min}$, mais próximas do equilíbrio. Na Figura 47, pode-se observar as curvas DSC obtidas para cada proporção do sistema CET-INA, sendo que a curva destacada em vermelho refere-se ao composto cujas proporções molares representa um eutético ou um cocristal. $\mathrm{O}$ valores de temperatura de fusão $T_{\text {onset }}$ e $T_{\text {peak }}$ foram determinados para o pico correspondente ao eutético e ao excesso (de CET ou INA), respectivamente, para a proporção CET:INA 4:1, conforme 
mostrado na figura 48. Essas estimativas foram feitas para todas as demais proporções, e, com base nos valores obtidos, foram construídas as três curvas de temperatura de fusão em função das frações molares de cetoprofeno ( $\mathrm{X}_{\mathrm{CET}}$ ) (curva dos líquidus, sólidus INA e sólidus CET), que juntas, compõem o diagrama de fases experimental, mostrado na Figura 50.

Figura 47 - Curvas DSC dos componentes puros CET, INA, e suas proporções $\left(2 \mathrm{mg}, 5^{\circ} \mathrm{C} / \mathrm{min}\right.$, atmosfera $\left.\mathrm{N}_{2}\right)$.

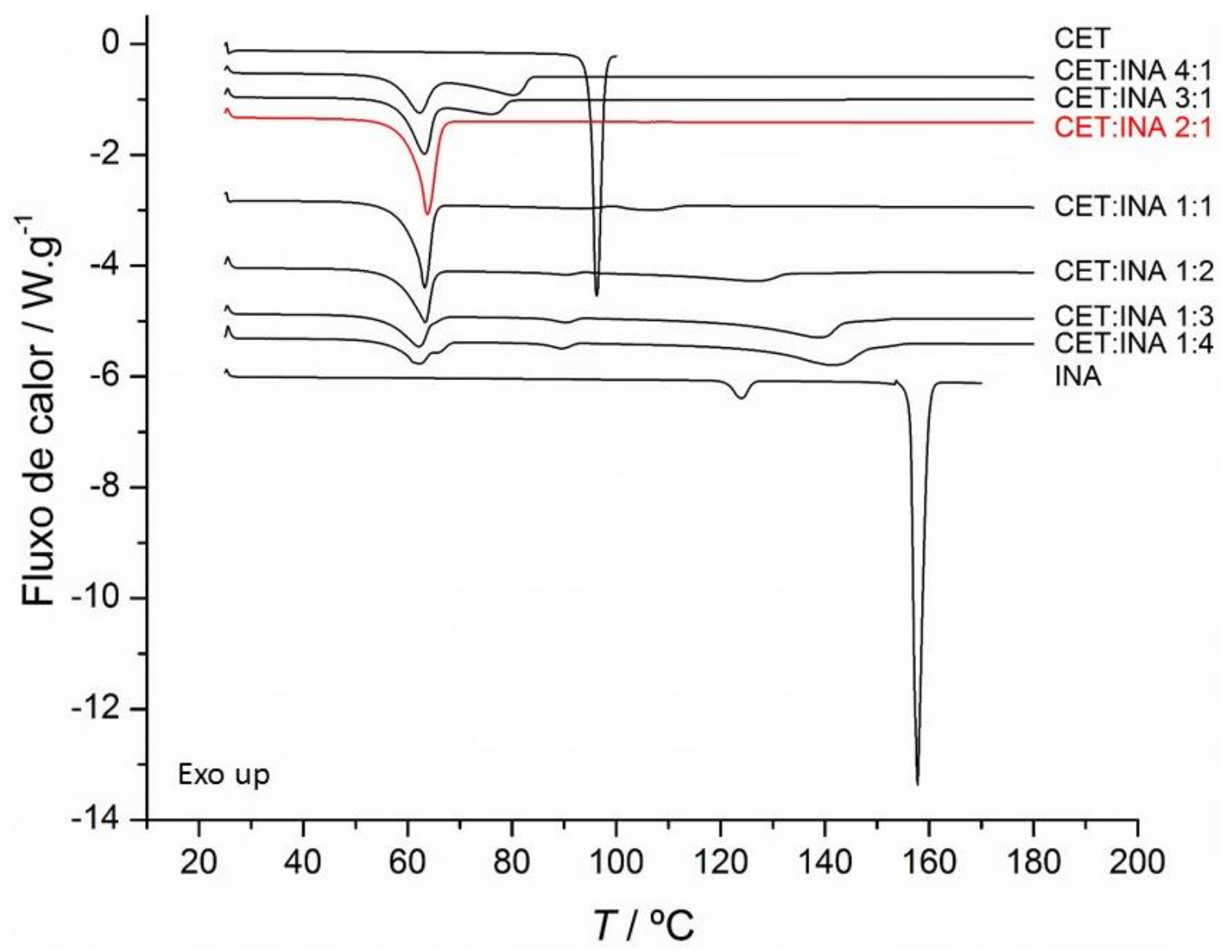


Figura 48 - Cálculos para a construção das curvas do diagrama de fases experimental

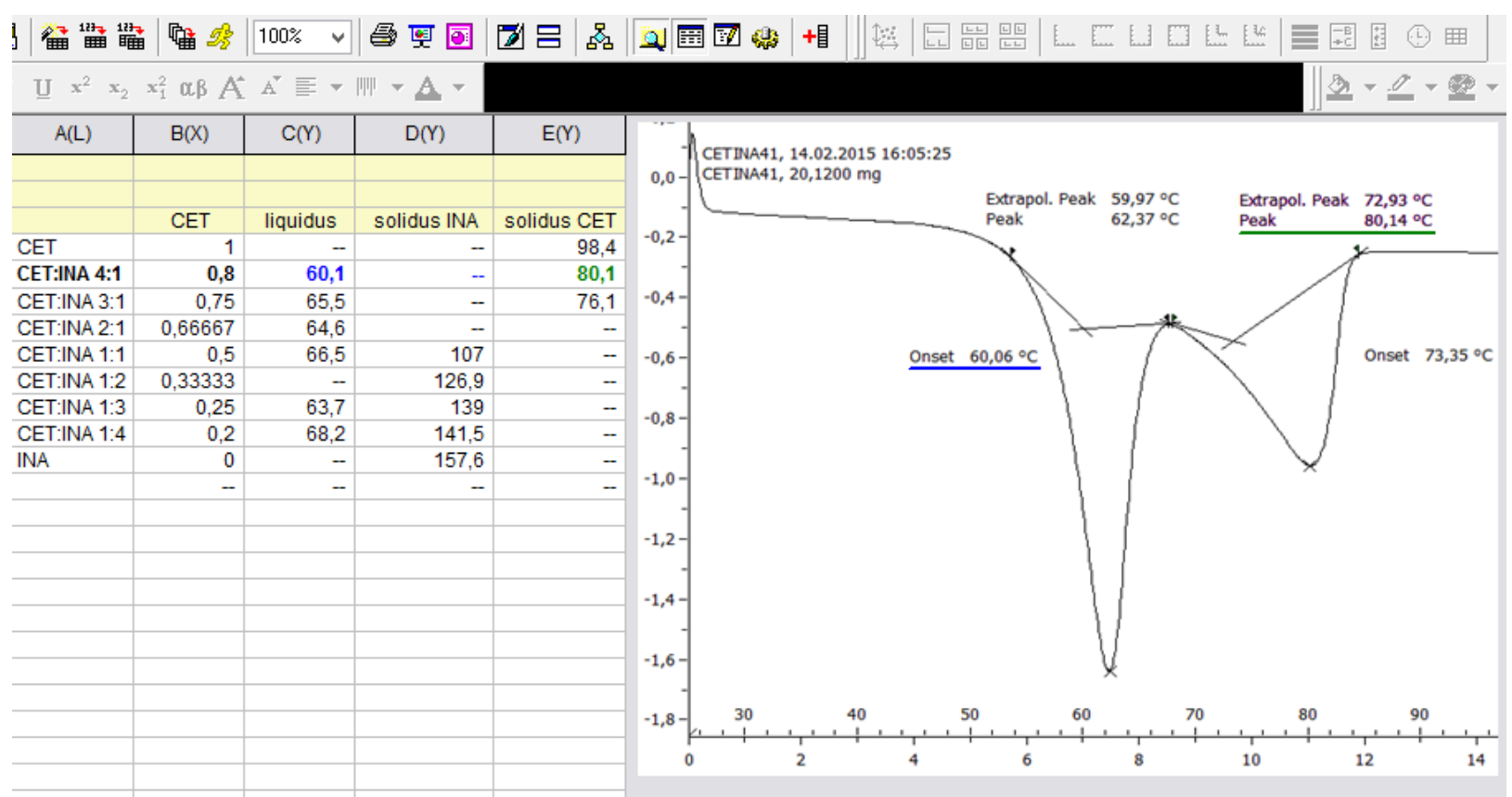

O Diagrama de fases teórico foi construído com o auxílio da equação de Schröder-Van Laar (GIRON, 2007):

$$
T_{x}=\left(\frac{1}{T_{f u s}}-\frac{R \ln x}{\Delta_{f u s} H}\right)^{-1}
$$

onde: $T_{\mathrm{x}}=$ temperatura de fusão da $x$-ésima fração molar.

$T_{\text {fus }}=$ temperatura de fusão dos compostos puros (CET ou INA).

$\Delta_{\text {fus }} H=$ entalpia de fusão dos compostos puros (CET ou INA).

A análise da Figura 47, permite verificar que a provável proporção molar do composto eutético ou cocristal é a 2:1, ou 0,66 CET para 0,33 INA, em termos de frações molares. A partir daí, foram atribuídos diversos valores arbitrários para x, tanto para cima como para baixo de 0,66 para o caso do CET e 0,33 para o caso da INA. Em seguida, com o auxílio da equação de de Schröder-Van Laar, foram calculadas as temperaturas de fusão teóricas para cada uma dessas proporções arbitrárias, conforme mostrado na Figura 49. 
Figura 49 - Cálculo das temperaturas de fusão teóricas para cada fração molar x.

\begin{tabular}{|c|c|c|c|c|c|c|c|}
\hline \multicolumn{3}{|c|}{ Equação de Schröder-van Laar } & \multirow{2}{*}{\multicolumn{2}{|c|}{$\begin{array}{l}\text { Vizinhança do CET } \\
\text { Composto Puro A }\end{array}$}} & \multicolumn{3}{|c|}{$\begin{array}{l}\text { Vizinhança da INA } \\
\text { Composto Puro B }\end{array}$} \\
\hline \multirow{3}{*}{\multicolumn{3}{|c|}{$T_{x}=\left(\frac{1}{T_{f u s}}-\frac{R \ln (x)}{\Delta_{f u s} H}\right)^{-1}$}} & & $\Delta_{\text {fus }} H=25895,88 \mathrm{Jmol}^{-1}$ & $\Delta_{\text {tus }} H=$ & \multicolumn{2}{|c|}{$21599,31 \mathrm{Jmol}^{-1}$} \\
\hline & & & \multirow[t]{2}{*}{$T_{\text {fus }}=$} & 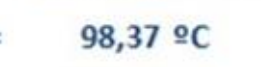 & $T_{\text {fus }}=$ & \multicolumn{2}{|c|}{157,64 ㅇ } \\
\hline & & & & $371,52 \mathrm{~K}$ & & \multicolumn{2}{|c|}{$430,79 \mathrm{~K}$} \\
\hline \multirow[t]{16}{*}{$R=$} & 8,314 & $\mathrm{Jmol}^{-1} \mathrm{~K}^{-1}$ & $x_{A}$ & $T_{\mathrm{x}} / \mathrm{oC}$ & $x_{A}$ & $x_{B}=\left(1-x_{A}\right)$ & $T_{\mathrm{x}} / \stackrel{\circ}{ } \mathrm{C}$ \\
\hline & & & 0,975 & 97,3 & 0,0250 & 0,975 & 155,8 \\
\hline & & & 0,925 & 94,9 & 0,0750 & 0,925 & 152,1 \\
\hline & & & 0,875 & 92,5 & 0,1250 & 0,875 & 148,3 \\
\hline & & & 0,825 & 90,0 & 0,1750 & 0,825 & 144,3 \\
\hline & & & 0,775 & 87,4 & 0,2250 & 0,775 & 140,2 \\
\hline & & & 0,725 & 84,6 & 0,2750 & 0,725 & 135,8 \\
\hline & & & 0,675 & 81,7 & 0,3250 & 0,675 & 131,3 \\
\hline & & & 0,625 & 78,6 & 0,3750 & 0,625 & 126,5 \\
\hline & & & 0,575 & 75,4 & 0,4250 & 0,575 & 121,4 \\
\hline & & & 0,525 & 71,9 & 0,4750 & 0,525 & 116,1 \\
\hline & & & & & 0,5250 & 0,475 & 110,3 \\
\hline & & & & & 0,5750 & 0,425 & 104,1 \\
\hline & & & & & 0,6250 & 0,375 & 97,4 \\
\hline & & & & & 0,6750 & 0,325 & 90,0 \\
\hline & & & & & 0,7250 & 0,275 & 81,7 \\
\hline
\end{tabular}

Em seguida, usando esses valores teóricos obtidos, foram construídas as duas curvas teóricas de temperatura de fusão em função das frações molares de cetoprofeno ( $\mathrm{X}_{\mathrm{CET}}$ ) (sólidus INA e sólidus CET), que juntas, compõem o diagrama de fases teórico, mostrado na Figura 50. 
Figura 50 - Diagrama de fases para o sistema CET-INA

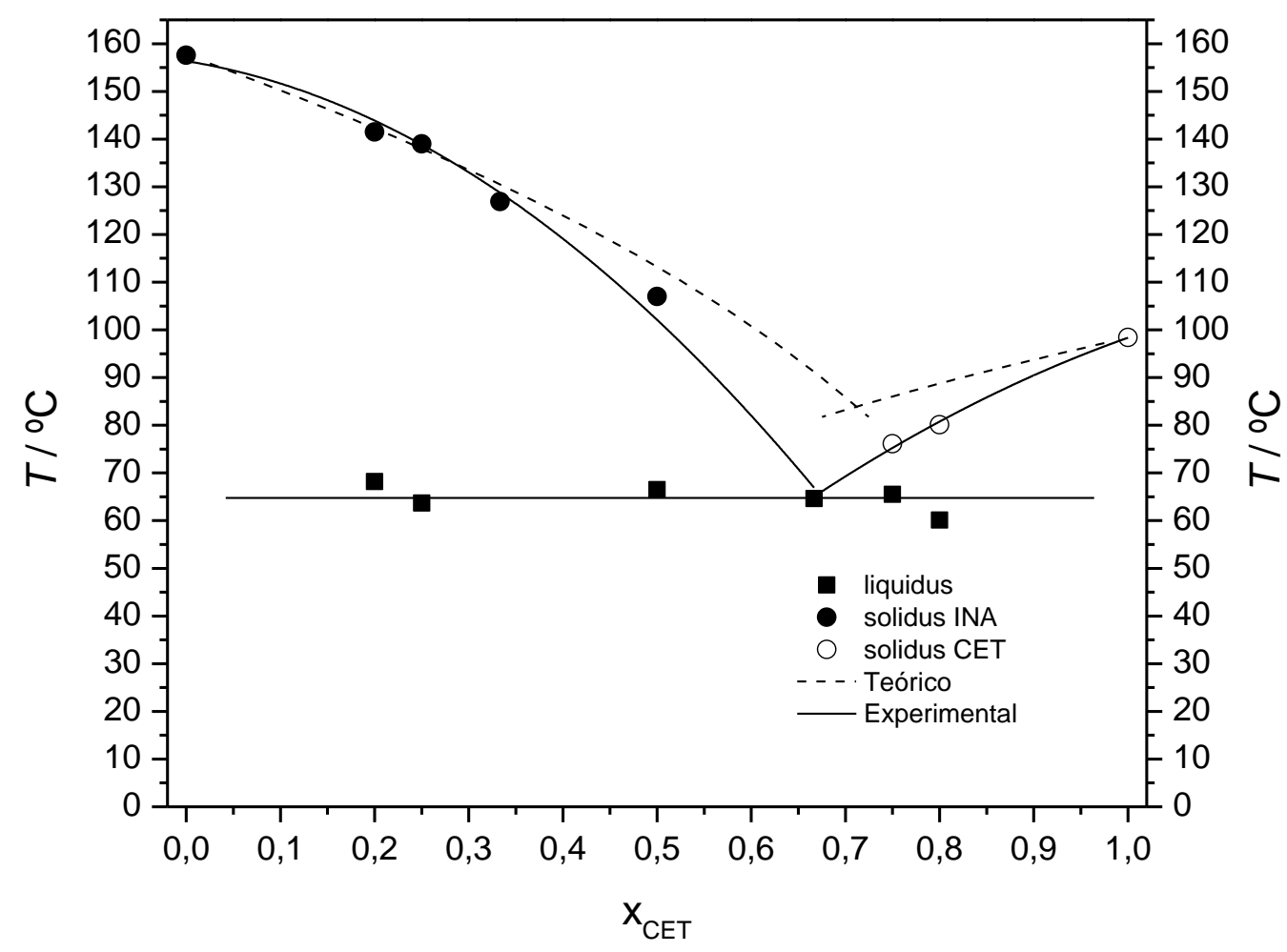

A Figura 49 mostra um diagrama típico da formação de um composto eutético, com uma composição bastante próxima daquela prevista pela equação de Schröder-Van Laar, já que a composição teórica do eutético é 0,71 mol CET, e a composição determinada experimentalmente é 0,67 mol CET. Dessa forma, a Figura 49 mostra claramente que não é possível a obtenção de um cocristal entre CET e INA através de método mecanoquímico. 
Os diagramas de fases dos demais sistemas estudados foram construídos da mesma forma descrita para o sistema CET-INA. As Figuras 51 a 56 mostram que os diagramas obtidos são típicos da formação de um composto eutético, com uma composição bastante próxima daquela prevista pela equação de Schröder-van Laar (Tabela 11). Isso significa que, de acordo com esses diagramas, a obtenção de um cocristal entre o cetoprofeno e esses co-formadores não é possível através de métodos mecanoquímicos.

Figura 51 - Diagrama de fases para o sistema CET-BA

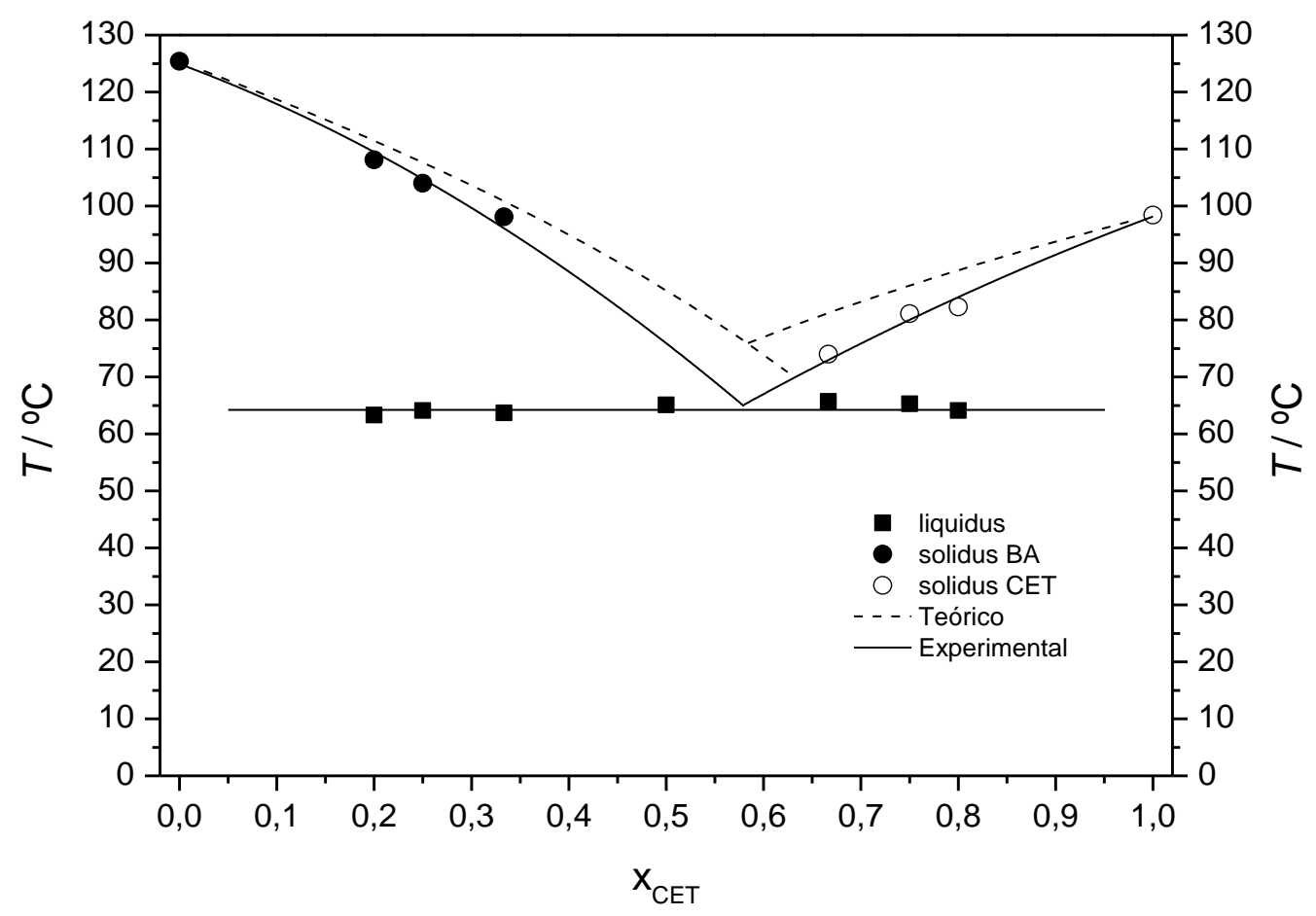


Figura 52 - Diagrama de fases para o sistema CET-BZ.

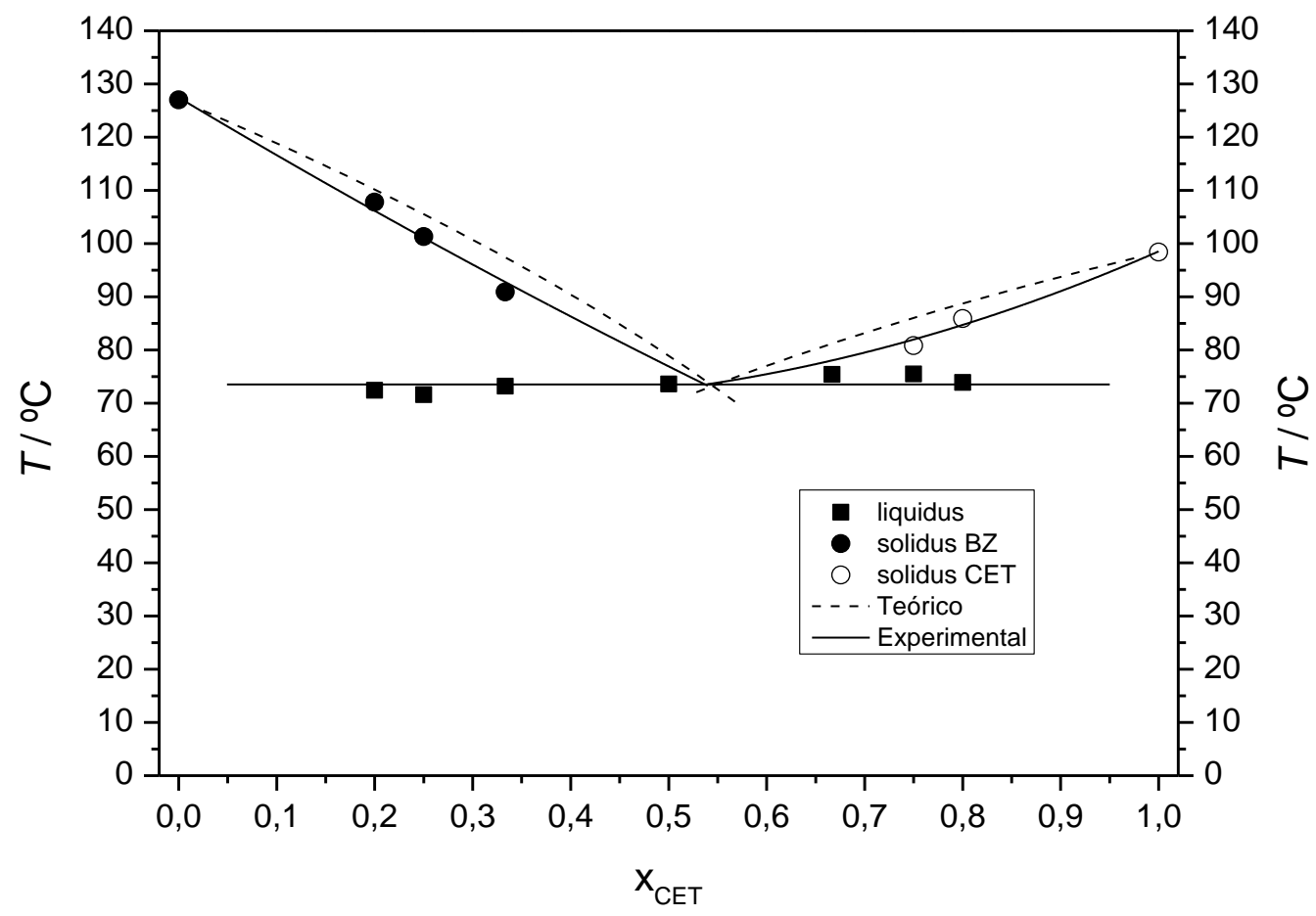

Figura 53 - Diagrama de fases para o sistema CET-NA.

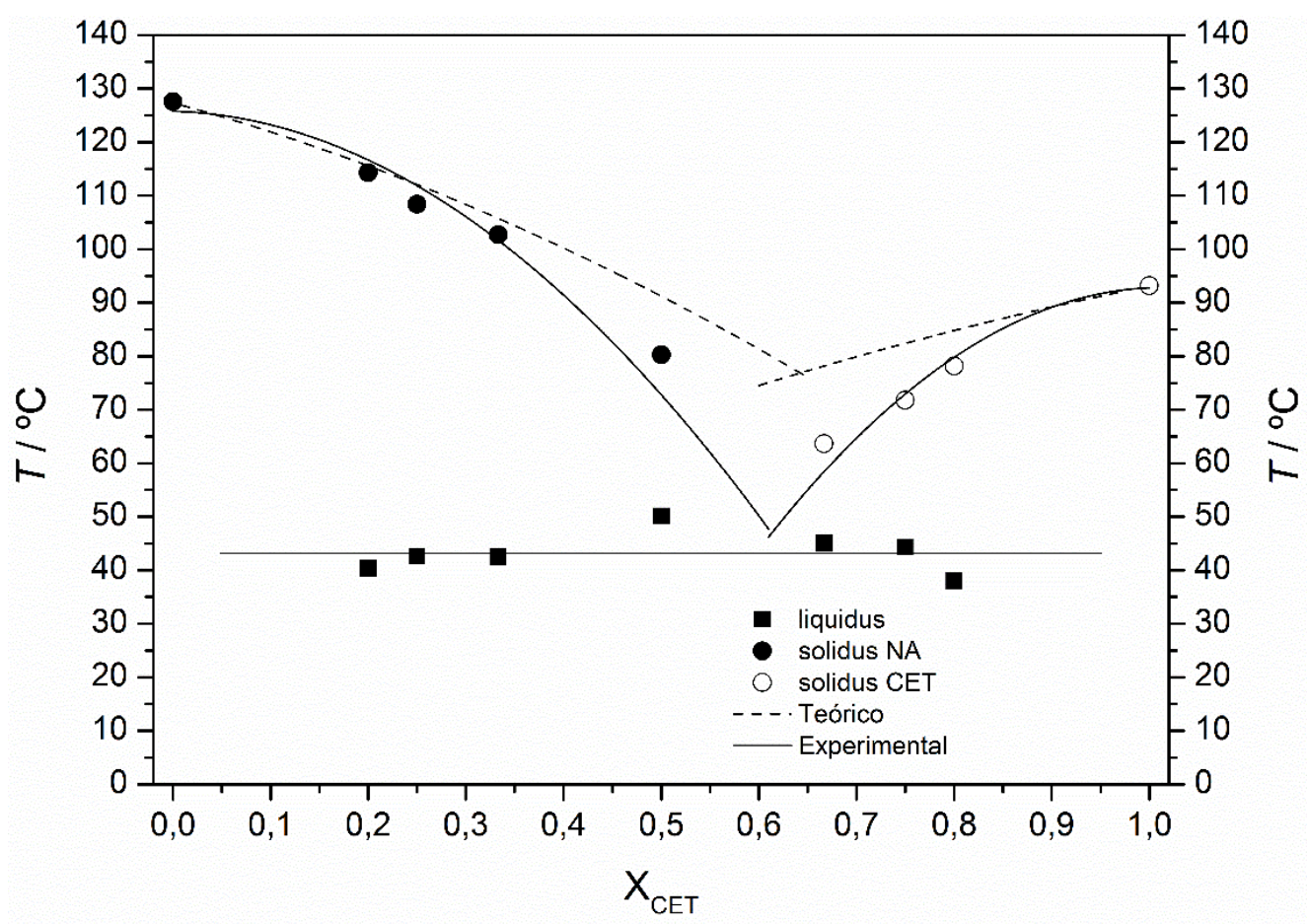


Figura 54 - Diagrama de fases para o sistema CET-PA.

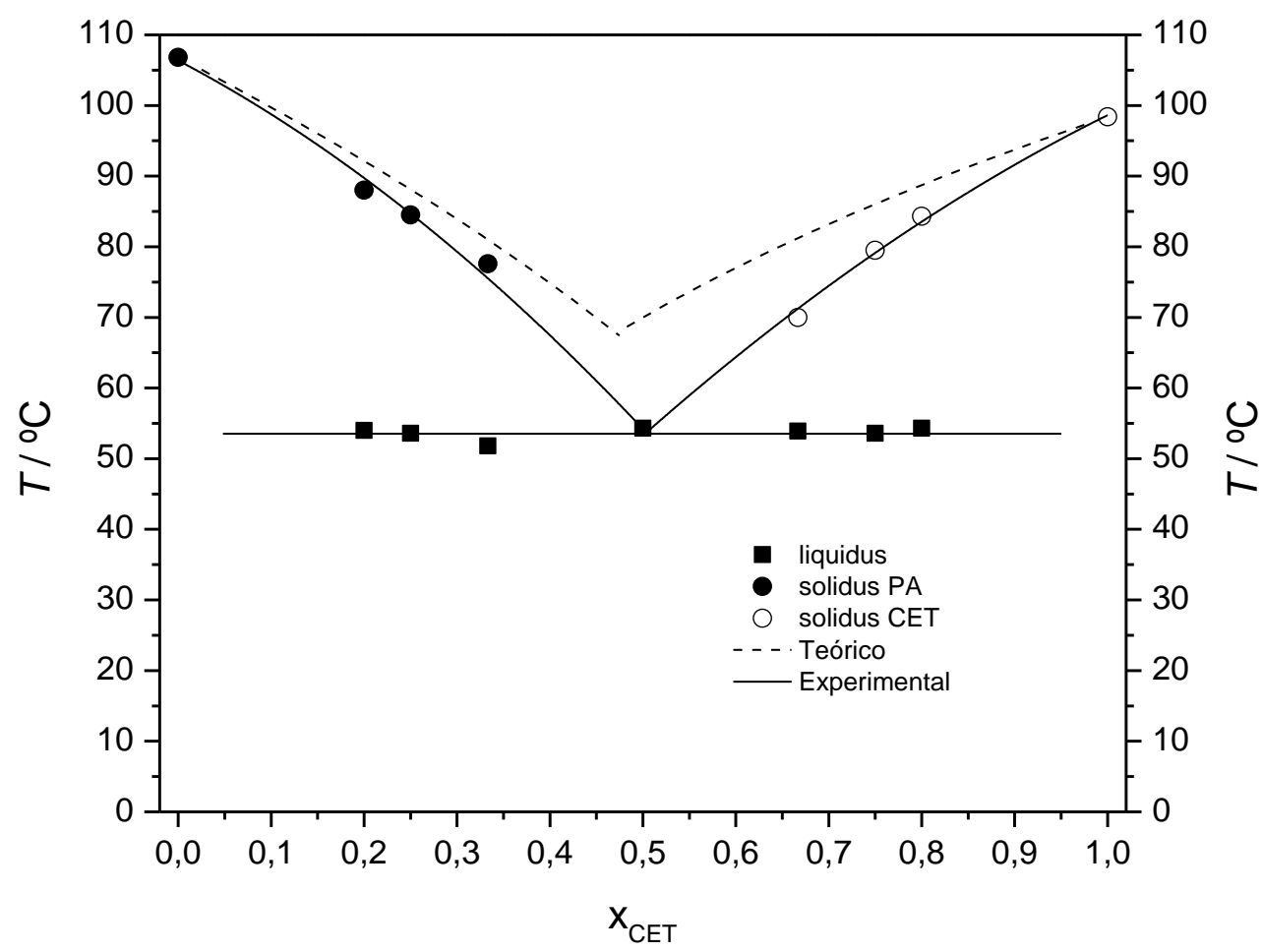

Figura 55 - Diagrama de fases para o sistema CET-PZA.

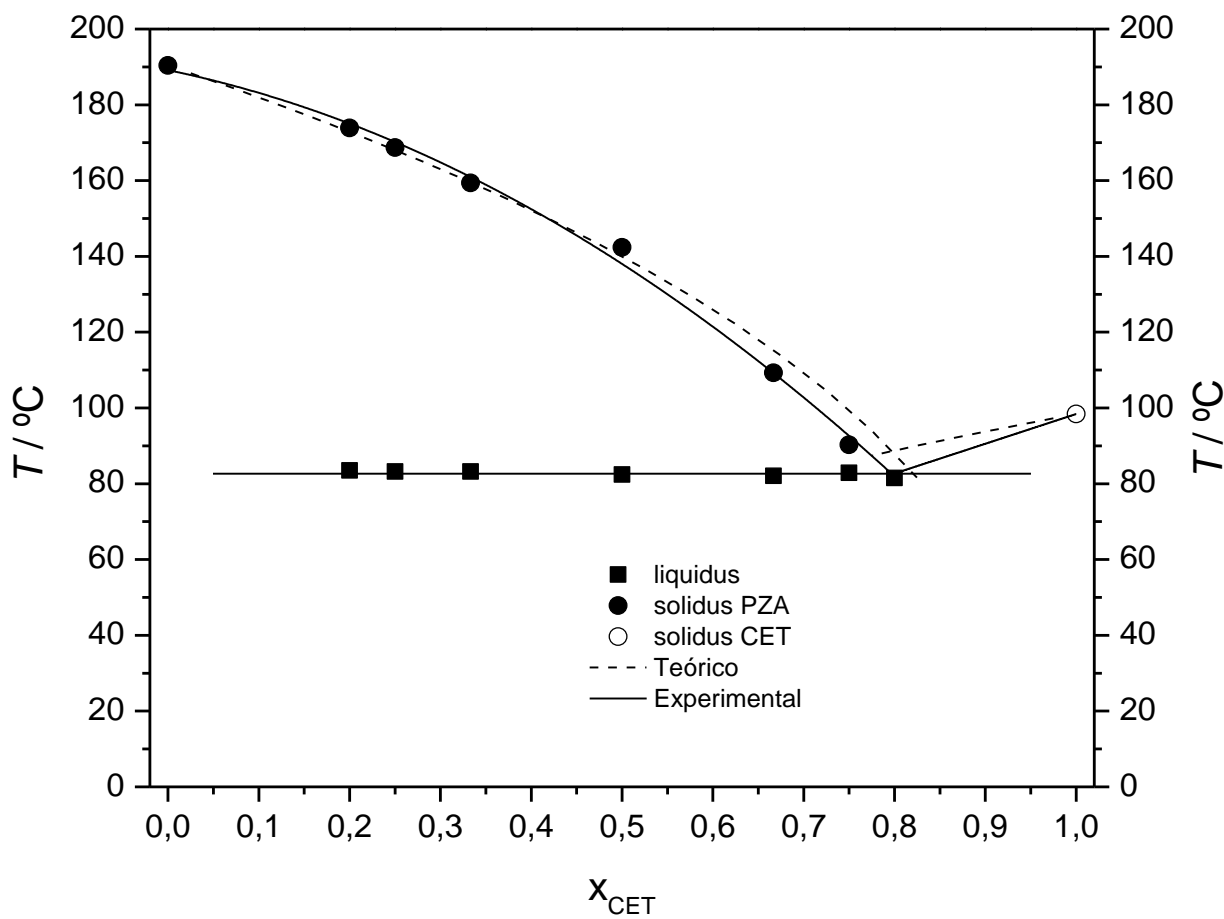


Figura 56 - Diagrama de fases para o sistema CET-SA.

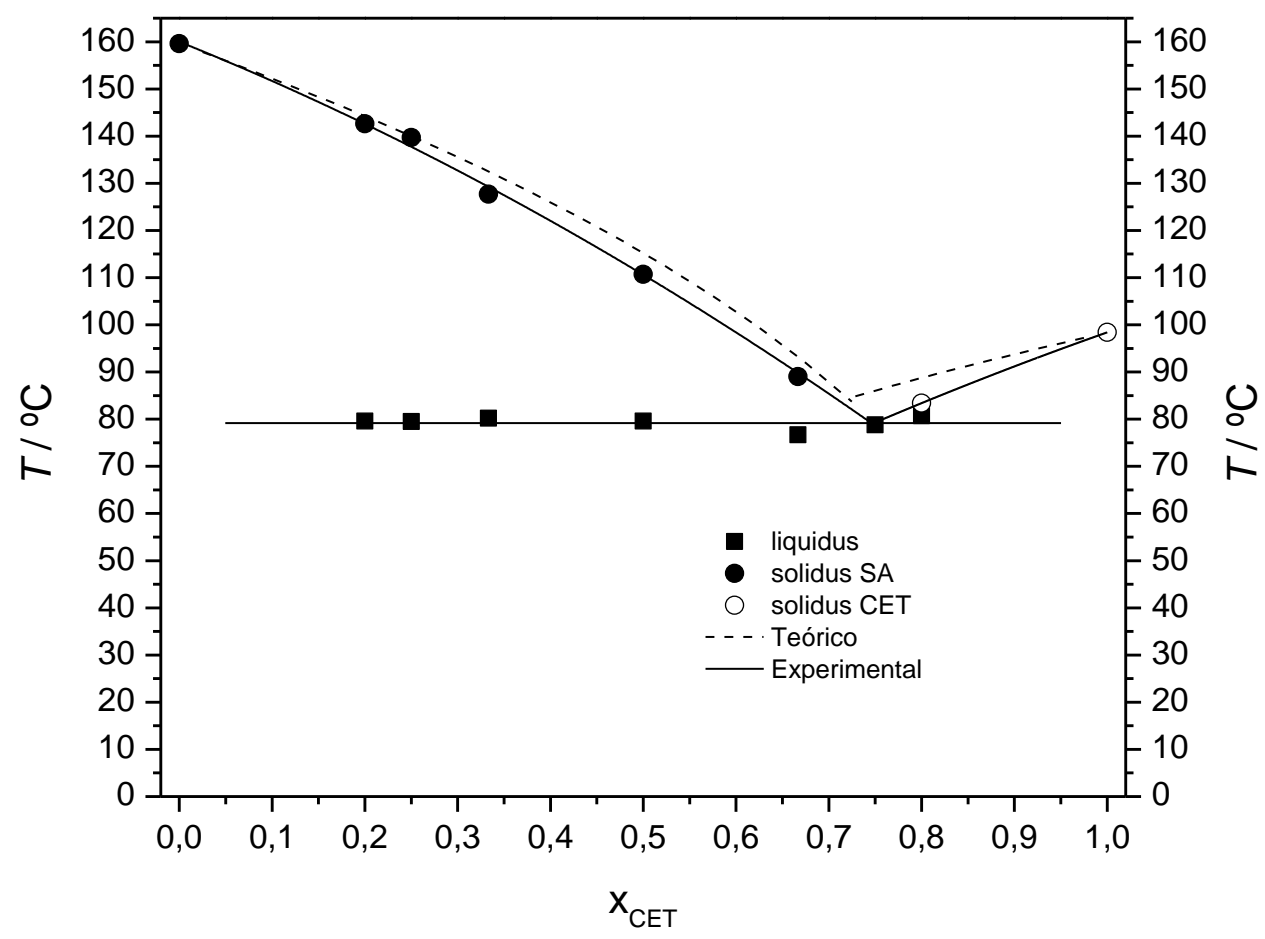

Tabela 11 - Composições teórica e experimental dos compostos eutéticos.

\begin{tabular}{ccc}
\hline & Composição teórica / $\mathrm{X}_{\mathrm{CET}}$ & $\begin{array}{c}\text { Composição experimental / } \\
\mathrm{X}_{\mathrm{CET}}\end{array}$ \\
\hline CET-BA & 0,59 & 0,58 \\
CET-BZ & 0,54 & 0,53 \\
CET-INA & 0,71 & 0,67 \\
CET-NA & 0,64 & 0,61 \\
CET-PA & 0,47 & 0,50 \\
CET-PZA & 0,80 & 0,80 \\
CET-SA & 0,72 & 0,75 \\
\hline
\end{tabular}




\subsection{Método do contato de Kofler}

A Figura 57 mostra as imagens obtidas durante o aquecimento do sistema CET-NA de 25 a $140{ }^{\circ} \mathrm{C}$, a uma razão de $2{ }^{\circ} \mathrm{C} / \mathrm{min}$, em atmosfera de nitrogênio. Nota-se que a fusão do cetoprofeno inicia-se em $80{ }^{\circ} \mathrm{C}$ e termina entre 88 e $90{ }^{\circ} \mathrm{C}$. Por volta de $120{ }^{\circ} \mathrm{C}$ deveria ser observado o início da fusão da nicotinamida. Entretanto, ao invés disso, o que se observou foi a formação de um cocristal entre CET e NA, a partir de $120^{\circ} \mathrm{C}$. Deixou-se arrefecer a amostra e num segundo aquecimento, agora até $160{ }^{\circ} \mathrm{C}$, verificou-se a fusão completa do cocristal por volta de $153{ }^{\circ} \mathrm{C}$ (Figura 58). Raspou-se um pouco desta amostra para uma cápsula de DSC e verificou-se que a mesma apresenta comportamento térmico completamente cíclico, conforme mostrado na Figura 59.

Figura 57 - Aquecimento do sistema CET-NA $\left(2{ }^{\circ} \mathrm{C} / \mathrm{min}\right.$, atmosfera $\mathrm{N}_{2}$, aumento $\left.200 \mathrm{X}\right) . \mathrm{a}=\mathrm{CET} ; \mathrm{b}=\mathrm{NA} ; \mathrm{c}=$ cocristal formado.

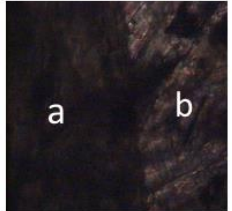

$25^{\circ} \mathrm{C}$

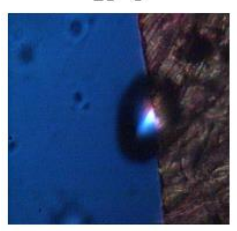

$90{ }^{\circ} \mathrm{C}$

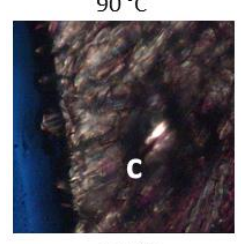

$125^{\circ} \mathrm{C}$

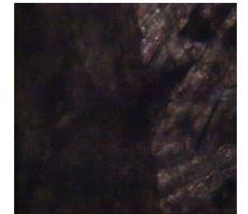

$50^{\circ} \mathrm{C}$

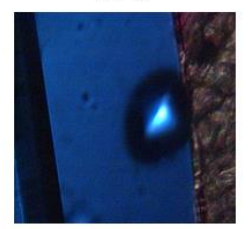

$105^{\circ} \mathrm{C}$

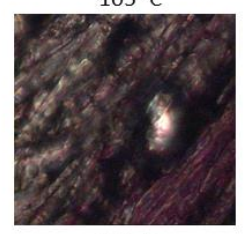

$129^{\circ} \mathrm{C}$

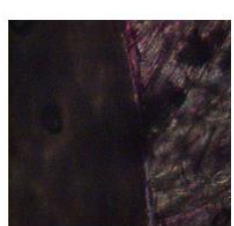

$80^{\circ} \mathrm{C}$

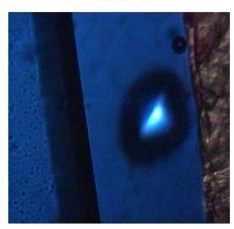

$110^{\circ} \mathrm{C}$

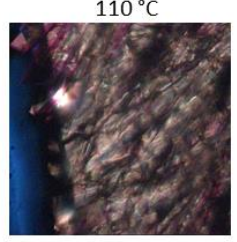

$130^{\circ} \mathrm{C}$

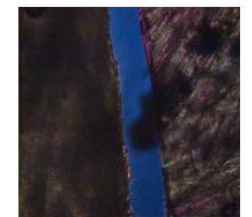

$85^{\circ} \mathrm{C}$

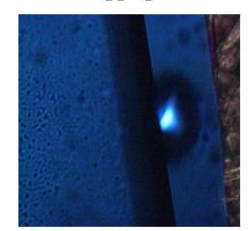

$115^{\circ} \mathrm{C}$

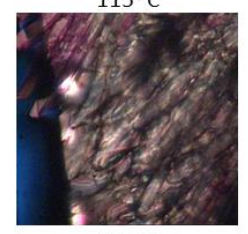

$135^{\circ} \mathrm{C}$

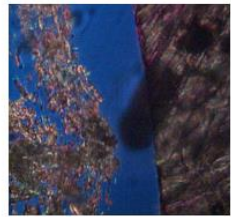

$88^{\circ} \mathrm{C}$

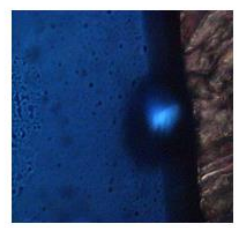

$120^{\circ} \mathrm{C}$

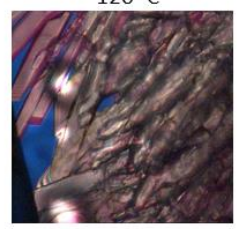

$140^{\circ} \mathrm{C}$

Os espectros de FTIR são mostrados na Figura 60, onde se nota claramente a diferença entre o composto 1:1 apresentado no item 3.2.7 e o cocristal formado. Entre estas diferenças podemos destacar a banda de elongação assimétrica do $\mathrm{NH}_{2}$ da NA que surge em $3358 \mathrm{~cm}^{-1}$ no composto 1:1 e em $3230 \mathrm{~cm}^{-1}$ no cocristal, indicando que o grupo amida se encontra envolvida numa ligação de hidrogênio mais forte no cocristal do que na rede cristalina da nicotinamida. 
Figura 58 - Aquecimento do cocristal formado $\left(5^{\circ} \mathrm{C} / \mathrm{min}\right.$, atmosfera $\mathrm{N}_{2}$, aumento $\left.50 \mathrm{X}\right)$

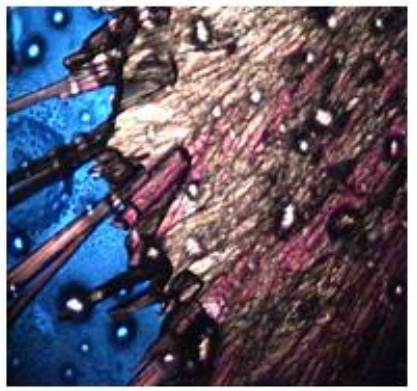

$50{ }^{\circ} \mathrm{C}$

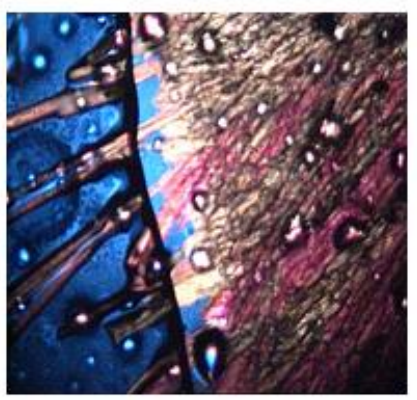

$135^{\circ} \mathrm{C}$

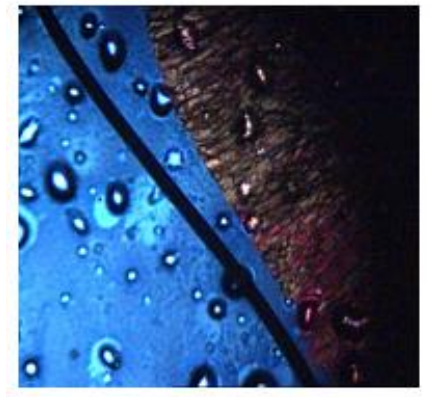

$150^{\circ} \mathrm{C}$

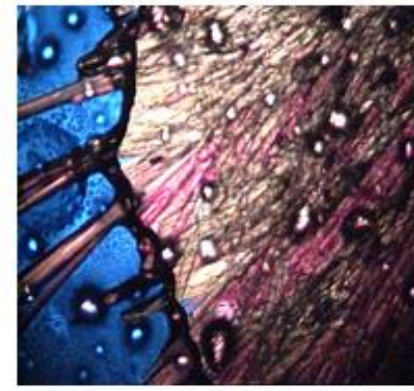

$100{ }^{\circ} \mathrm{C}$

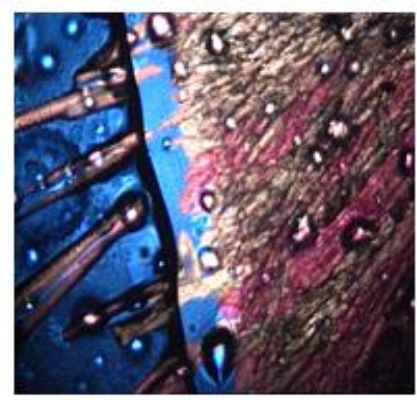

$140{ }^{\circ} \mathrm{C}$

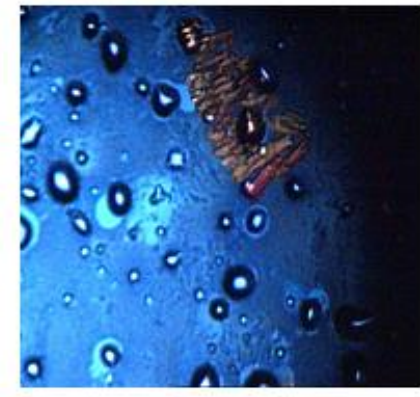

$152^{\circ} \mathrm{C}$

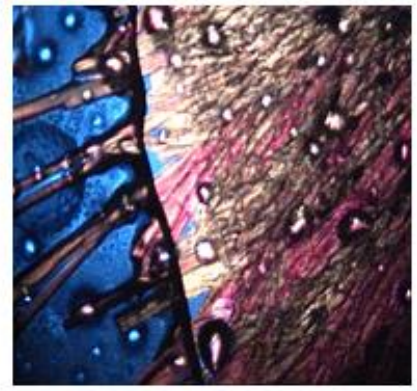

$130^{\circ} \mathrm{C}$

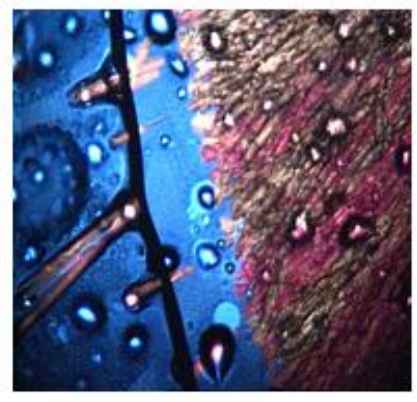

$145^{\circ} \mathrm{C}$

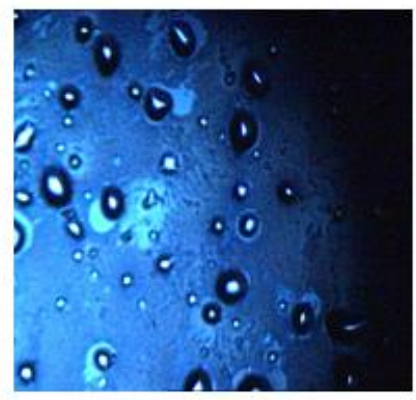

$153^{\circ} \mathrm{C}$ 
Figura 59 - DSC cíclico do cocristal CET:NA.

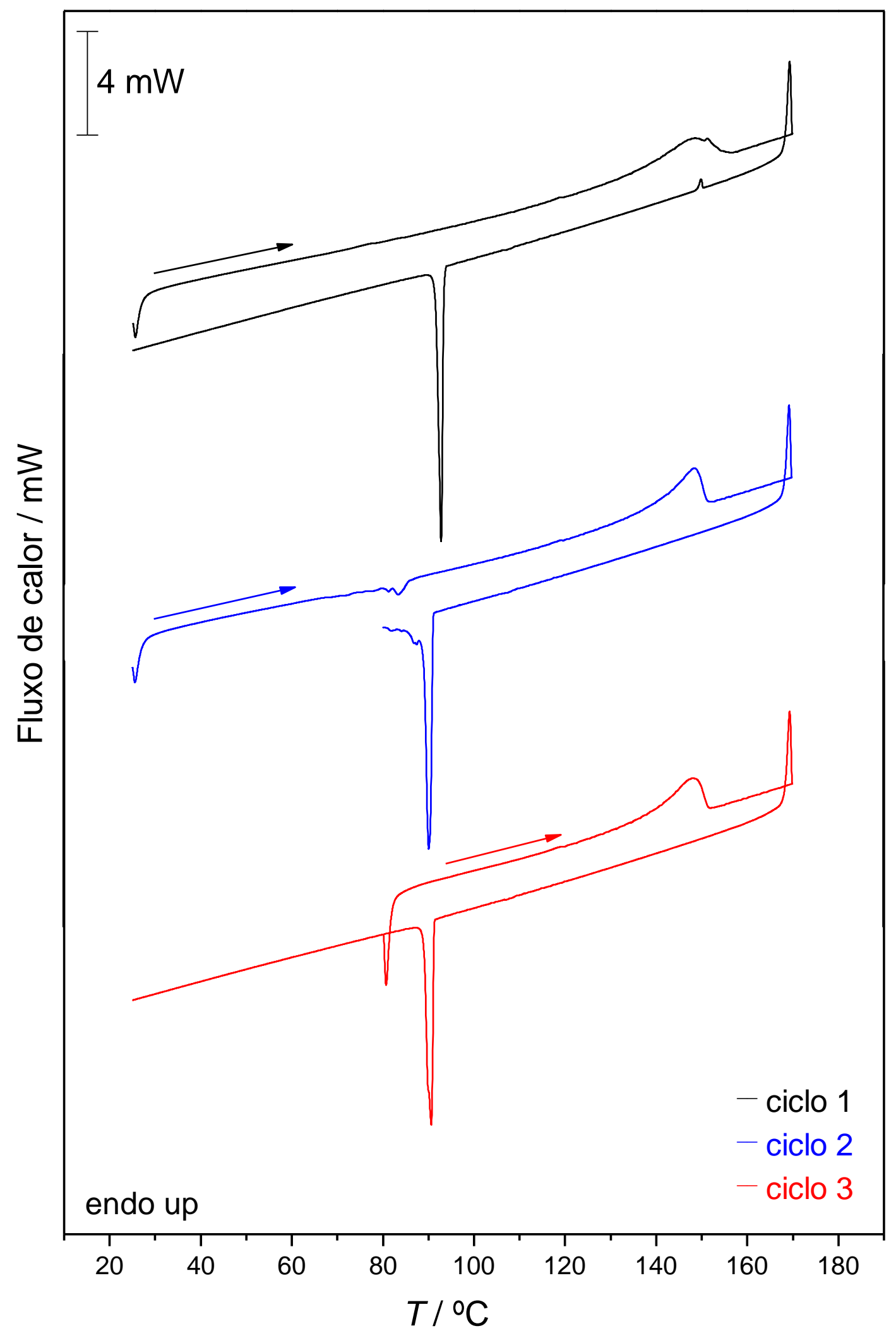


Figura 60 - FTIR do composto CET:NA (1:1) e do cocristal formado.

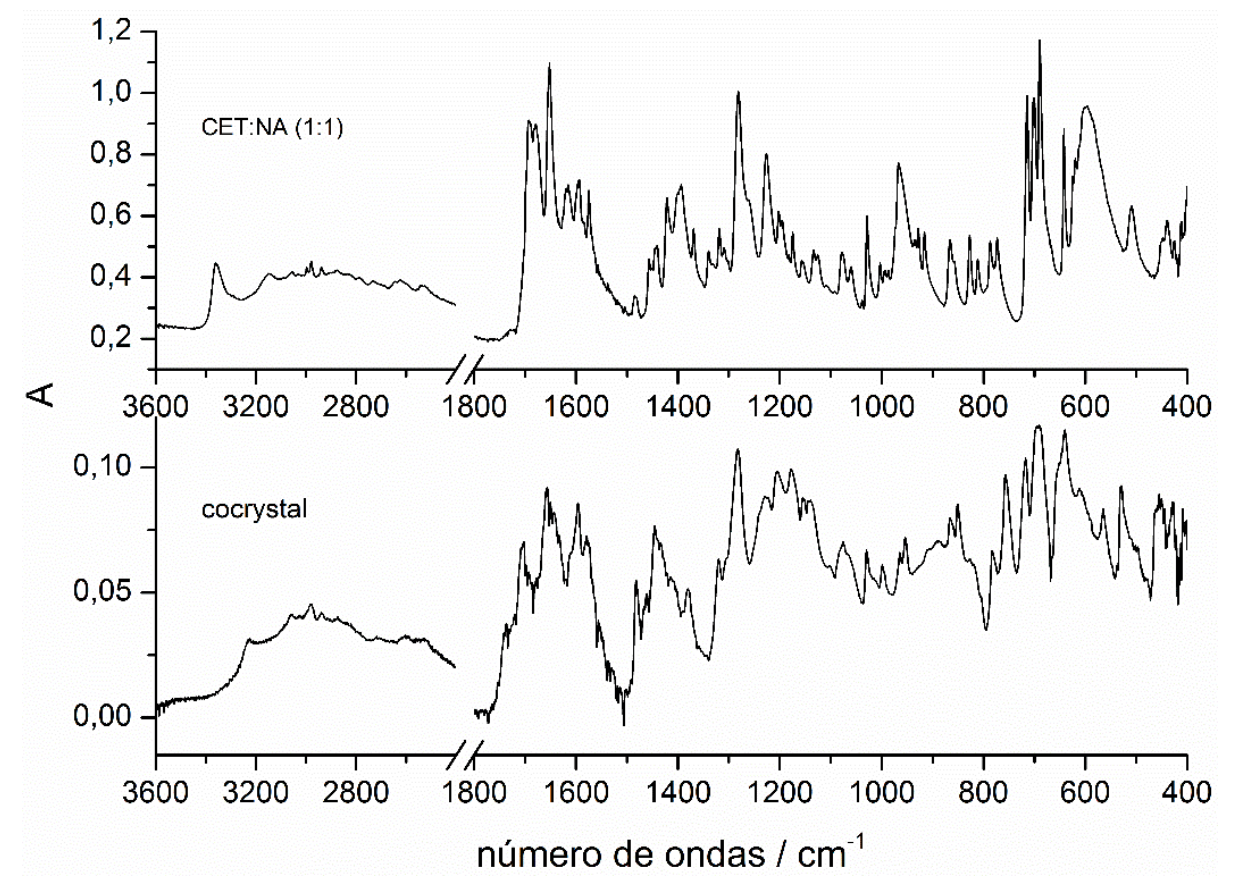

\section{CONCLUSÕES}

Devido às características físico-químicas peculiares do cetoprofeno (cristalização durante o aquecimento), não foi possível obter cocristais a partir de cristalização em solução, já que quando em contato com alguns solventes nos quais é solúvel (tais como álcool etílico e clorofórmio), ocorre dimerização do cetoprofeno, a medida que o solvente se evapora. Por essa razão, a obtenção de cocristais através da técnica de moagem com o auxílio de solventes também não foi bem-sucedida.

Embora os diagramas de fases e os experimentos de DSC, raios X e FTIR tenham confirmado apenas a obtenção de compostos eutéticos entre o cetoprofeno e os co-formadores estudados, não se pode afirmar que a obtenção de cocristais de cetoprofeno e esses coformadores não seja possível, uma vez que o método do contato de Kofler indicou a descoberta de um novo cocristal formado entre o cetoprofeno e nicotinamida.

A cristalização do CET (com a formação de cocristal) pode ocorrer durante o processo de aquecimento. No entanto, embora seja termodinamicamente favorável, verificou-se que a cinética desse processo é lenta, uma vez que a cristalização do CET levou cerca de 30 dias. 


\section{REFERÊNCIAS}

AAKERÖY, C. B.; SALMON, D. J. Building co-crystals with molecular sense and supramolecular sensibility. CrystEngComm, v. 7, n. 72, p. 439-448, 2005.

ABOUNASSIF, M. A. ET AL. Salicylic acid. In: BRITTAIN, H. G. (Ed.). . Analytical profile of drug substances and excipients. New York: Academic Press, 1994. p. 421-470.

ALMARSSON, O.; ZAWOROTKO, M. J. Crystal engineering of the composition of pharmaceutical phases. Do pharmaceutical co-crystals represent a new path to improved medicines? Chemical communications (Cambridge, England), p. 1889-1896, 2004.

ARORA, K. K.; ZAWOROTKO, M. J. Pharmaceutical Co-crystals: A New Opportunity in Pharmaceutical Science for a Long-Known but Little-Studied Class of Compounds. In: BRITTAIN, H. G. (Ed.). . Polimorphism in pharmaceutical solids. 2. ed. New York: Informa Healthcare USA, Inc., 1999. p. 282-317.

BERRY, D. J. ET AL. Applying Hot-Stage Microscopy to Co-Crystal Screening : A Study of Nicotinamide with Seven Active Pharmaceutical Ingredients Applying Hot-Stage Microscopy to Co-Crystal Screening: A Study of Nicotinamide with Seven Active Pharmaceutical Ingredients. Crystal Growth \& Design, v. 8, n. Figure 1, p. 1697-1712, 2008.

BHOGALA, B. R.; NANGIA, A. Ternary and quaternary co-crystals of 1,3-cis,5-ciscyclohexanetricarboxylic acid and 4,4'-bipyridines. New Journal of Chemistry, v. 32, p. 800-807, 2008.

BLAGDEN, N. et al. Woehler and Liebig revisited: A small molecule reveals its secrets - The crystal structure of the unstable polymorph of benzamide solved after 173 years. Crystal Growth and Design, v. 5, n. 6, p. 2218-2224, 2005.

BOND, A. D. What is a co-crystal? CrystEngComm, v. 9, p. 833, 2007.

BRITTAIN, H. G. Vibrational Spectroscopic Studies of Cocrystals and Salts. 1. The Benzamide- Benzoic Acid System. Crystal Growth and Design, v. 9, n. 5, p. 2492-2499, 2009.

CAIRA, M. R. Polymorphism. In: BROWN, M. E.; GALLAGHER, P. K. (Ed.). . Handbook of thermal analysis and calorimetry. 1. ed. Amsterdam: Elsevier, 2008. p. 597-621.

CASTRO, R. A E. et al. A new insight into pyrazinamide polymorphic forms and their thermodynamic relationships. Crystal Growth and Design, v. 10, n. 1, p. 274-282, 2010.

CASTRO, R. A. E. ET AL. Naproxen cocrystals with pyridinecarboxamide isomers. Crystal Growth and Design, v. 11, p. 5396-5404, 2011.

CHERUKUVADA, S. ET AL. Pyrazinamide polymorphs: Relative stability and vibrational spectroscopy. Crystal Growth and Design, v. 10, n. 9, p. 3931-3941, 2010. 
CHIARELLA, R. A.; DAVEY, R. J.; PETERSON, M. L. Making co-crystals - The utility of ternary phase diagrams. Crystal Growth and Design, v. 7, n. 7, p. 1223-1226, 2007.

CHIENG, N. et al. Physical characterization and stability of amorphous indomethacin and ranitidine hydrochloride binary systems prepared by mechanical activation. European Journal of Pharmaceutics and Biopharmaceutics, v. 71, n. 1, p. 47-54, 2009.

CHILDS, S. L.; HARDCASTLE, K. I. Cocrystals of piroxicam with carboxylic acids. Crystal Growth and Design, v. 7, n. 7, p. 1291-1304, 2007.

DAVID, W. I. F. et al. Polymorphism in benzamide. Angewandte Chemie - International Edition, v. 44, p. 7032-7035, 2005.

ECTORS, P.; ZAHN, D. Analysis of the molecular interactions governing the polymorphism of benzamide--a guide to syntheses? Physical chemistry chemical physics : PCCP, v. 15, p. 9219-22, 2013.

ELBAGERMA, M. A. et al. Identification of a new co-crystal of salicylic acid and benzamide of pharmaceutical relevance. Analytical and Bioanalytical Chemistry, v. 397, p. 137-146, 2010.

ÉVORA, A. O. L. et al. Pyrazinamide-diflunisal: A new dual-drug Co-crystal. Crystal Growth and Design, v. 11, n. 11, p. 4780-4788, 2011.

ÉVORA, A. O. L. ET AL. Resolved structures of two picolinamide polymorphs. Investigation of the dimorphic system behaviour under conditions relevant to co-crystal synthesis.

CrystEngComm, v. 14, p. 8649-8657, 2012.

FERREIRA, F. G. ET AL. Fármacos: do desenvolvimento à retirada do mercado. Revista Eletrônica de Farmácia, v. 6, n. 1, p. 14-24, 2009.

FRISCIC, T. ET AL. The role of solvent in mechanochemical and sonochemical cocrystal formation: a solubility-based approach for predicting cocrystallisation outcome.

CrystEngComm, v. 11, p. 418-426, 2009.

FRISCIC, T.; JONES, W. Recent Advances in Understanding the Mechanism of Cocrystal Formation via Grinding. Crystal Growth \& Design, v. 9, n. 3, p. 1621-1637, 2009.

GIRON, D. Investigations of polymorphism and pseudo-polymorphism in pharmaceuticals by combined thermoanalytical techniques. Journal of Thermal Analysis and Calorimetry., v. 64, n. 1, p. 37-60, 2001.

GIRON, D. Characterization of salts of drug substances. Journal of Thermal Analysis and Calorimetry., v. 73, n. 2, p. 441-457, 2003.

GIRON, D. Thermal analysis of drug and drug products. In: SWARBRICK, J. (Ed.). . Encyclopedia of pharmaceutical technology. 3. ed. Pinehurst: PharmaceuTech, Inc., 2007. p. 3739-3748. 
GIRON, D.; MUTZ, M.; GARNIER, S. Solid-state of pharmaceutical compounds. . Journal of Thermal Analysis and Calorimetry., v. 77, n. 2, p. 709-747, 2004.

GONSALVES, A. M. D’ A. R.; SERRA, M. A. S.; EUSÉBIO, M. E. S. Estereoquímica. 1. ed. Coimbra: Imprensa da Universidade de Coimbra, 2011. p. 200

GOOD, D. J.; NAÍR, R. H. Solubility advantage of pharmaceutical cocrystals. Crystal Growth and Design, v. 9, n. 5, p. 2252-2264, 2009.

INDRAYANTO, G. ET AL. Benzoic acid. In: BRITTAIN, H. G. (Ed.). . Analytical profile of drug substances and excipients. New York: Academic Press, 1999. p. 1-46.

JANGADEESH BABU, N.; NANGIA, A. Solubility advantage of amorphous drug and pharmaceutical cocrystals. Crystal Growth \& Design, v. 11, n. 7, p. 2662-2679, 2011.

JINJING LI, S. A. B.; CAIRA, M. R. New polymorphs of isonicotinamide and nicotinamide. Chemical communications (Cambridge, England), v. 47, p. 1530-1532, 2011.

JONES, W. ET AL. Pharmaceutical cocrystals: an emerging approach to physical property enhancement. MRS Bull, v. 31, p. 875-879, 2006.

JUNG, M. S. et al. Bioavailability of indomethacin-saccharin cocrystals. Journal of Pharmacy and Pharmacology, v. 62, p. 1560-1568, 2010.

LARA-OCHOA, F.; ESPINOSA-PÉREZ, G. Crystals and Patents. Crystal Growth \& Design, v. 7, n. 7, p. 37-39, 2007.

LIVERSIDGE, G. G. Ketoprofen. In: FLOREY, K. (Ed.). . Analytical profile of drug substances. New York: Academic Press, 1984. p. 443-471.

MCNAMARA, D. P. et al. Use of a glutaric acid cocrystal to improve oral bioavailability of a low solubility API. Pharmaceutical Research, v. 23, n. 8, p. 1888-1897, 2006.

MILES, S. Ketoprofen. In: ENNA, S. J.; BYLUND, D. B. (Ed.). . xPharm: The Comprehensive Pharmacology Reference. [s.1.] Elsevier, 2008. p. 1-7.

MOETY, E. M. A. ET AL. Nicotinamide. In: FLOREY, K. (Ed.). . Analytical profile of drug substances. New York: Academic Press, 1991. p. 478-555.

MOHAMAD, A. H. ET AL. Characterization of famotidine polymorphic forms. International Journal of Pharmaceutics., v. 149, p. 227-232, 1997.

NANGIA, A. Nomenclature in Crystal Engineering. In: ATWOOD, J. L.; STEED, J. W. (Ed.). . Encyclopedia of supramolecular chemistry. 1. ed. New York: Taylor and Francis, 2007. p. 37-41.

NORDSTRÖM, F. L.; RASMUSON, A. C. Solubility and melting properties of salicylamide. Journal of Chemical and Engineering Data, v. 51, p. 1775-1777, 2006. 
PERPÉTUO, G. L. ET AL. Thermal, spectroscopic and DFT studies of solid benzamide. Brazilian Journal of Thermal Analysis, v. 3, p. 5-10, 2014.

REHDER, S. ET AL. Investigation of the formation process of two piracetam cocrystals during grinding. Pharmaceutics, v. 3, p. 706-722, 2011.

RIBEIRO, J. D. B. Investigação de co-cristais de (S)-Naproxeno. [s.1.] Universidade de Coimbra, 2010.

SCHULTHEISS, N.; NEWMAN, A. Pharmaceutical cocrystals and their physicochemical properties. Crystal Growth \& Design, v. 9, n. 6, p. 2950-67, 2009.

SEATON, C. C.; PARKIN, A. Making benzamide cocrystals with benzoic acids: The influence of chemical structure. Crystal Growth and Design, v. 11, n. 5, p. 1502-1511, 2011.

SHAN, N. et al. Impact of pharmaceutical cocrystals: the effects on drug pharmacokinetics. Expert opinion on drug metabolism \& toxicology, v. 10, n. July 2015, p. 1-17, 2014.

SHATTOCK, T. R. et al. Hierarchy of supramolecular synthons: Persistent carboxylic acidpyridine hydrogen bonds in cocrystals that also contain a hydroxyl moiety. Crystal Growth and Design, v. 8, n. 12, p. 4533-4545, 2008.

SHEKUNOV, B. Y.; YORK, P. Crystallization process in pharmaceutical technology and drug delivery design. Journal of Crystal Growth, v. 211, n. 1-4, p. 122-136, 2000.

SHIRAKI, K. et al. Dissolution improvement and the mechanism of the improvement from cocrystallization of poorly water-soluble compounds. Pharmaceutical Research, v. 25, n. 11, p. 2581-2592, 2008.

SILVERSTEIN, R. M.; WEBSTER, F. X. Identificação espectrométrica de compostos orgânicos. 6. ed. Rio de Janeiro: LTC, 2000. p. 70-71

STAHLY, G. P. Diversity in single and multiple component crystals. The search for and prevalence of polymorphs and cocrystals. Crystal Growth \& Design, v. 7, n. 6, p. 10071026, 2007.

STAHLY, G. P. A survey of cocrystals reported prior to 2000. Crystal Growth and Design, v. 9, p. 4212-4229, 2009.

SUN, C. C. Cocrystallization for successful drug delivery. Expert opinion on drug delivery, v. 10, n. July, p. 201-13, 2013.

The Merck Index: an encyclopedia of chemicals, drugs, and biologicals. 30. ed. New Jersey: Whitehouse Station, 2001. p. 395-396

Therapeutic Systems Research Laboratories. Disponível em: <69.20.123.154./services/bcs/search.cfm>. Acesso em: 2 jun. 2012. 
VISHWESHWAR, P. ET AL. Pharmaceutical co-crystals. Journal of pharmaceutical sciences, v. 95, n. 3, p. 499-516, 2006.

VITEZ, I. M.; NEWMAN, A. W. Thermal microscopy. In: CRAIG, D. Q. M.; READING, M. (Ed.). . Thermal analysis of pharmaceuticals. 1. ed. Boca Raton: CRC Press, 2007. p. 225228.

WENDLANDT, W. W. Chemical Analysis. 3. ed. New York: John Wiley \& Sons, 1986. p. $213-258$

WEYNA, D. R. et al. Synthesis and Structural Characterization of Cocrystals and Pharmaceutical Cocrystals: Mechanochemistry vs Slow Evaporation from Solution. Crystal Growth \& Design, v. 9, n. 2, p. 1106-1123, 2009.

WIEDEMANN, H. G.; FELDER-CASAGRANDE, S. Thermomicroscopy. In: BROWN, M. E. (Ed.). . Handbook of thermal analysis and calorimetry. 1. ed. Amsterdam: Elsevier, 1998. p. 473-474.

YADAV, A. V. ET AL. A novel approach to modify physicochemical properties of active pharmaceutical ingredients. Indian Journal of Pharmaceutical Sciences, v. 71, n. 4, p. 359370, 2009. 